UNiVERSidAde de São PaUlo

FACUldade De Filosofia, Letras E CiÊnCias Humanas

DEPARTAMENTO DE LINGUÍSTICA

Programa de Pós-GraduaÇÃo EM SEMIÓtica E LiNGUística Geral

\title{
O sistema vocálico do saami skolt: uma perspectiva diacrônica
}

\author{
BEATRIZ DOMINGUES CORÁ FusER
}

Versão corrigida

São Paulo

2018 
Universidade de São PaUlo

FACUldade De Filosofia, Letras E CiÊnCias Humanas

DEPARTAMENTO DE LINGUÍSTICA

Programa de Pós-GraduaÇão em SEmiótica e Linguística Geral

\title{
O sistema vocálico do saami skolt: uma perspectiva diacrônica
}

\author{
BEATRIZ DOMINGUES CORÁ FUSER
}

DISSERTAÇÃO APRESENTADA AO PROGRAMA De Pós-Graduação em Semiótica e LiNGUÍSTICA GERAL DO DEPARTAMENTO DE LINGUística dA FACUldade DE FIlOSOFIA, LETRAS E CIÊNCIAS HUMANAS DA UNIVERSIDAdE DE SÃo PAUlo PARA A OBTENÇÃO DO TítUlo DE MESTRE EM LINGUísticA.

Orientador: Prof. Dr. Paulo Chagas de Souza

Versão corrigida

São Paulo

2018 
BANCA EXAMINADORA

Prof. Dr.

Julgamento:

Prof. Dr.

Julgamento:

Prof. Dr.

Julgamento:

Prof. Dr.

Julgamento:
Instituição:

Assinatura:

Instituição:

Assinatura:

Instituição:

Assinatura:

Instituição:

Assinatura: 
Às línguas indígenas, e a todos que respeitam e apoiam a diversidade linguística. 


\section{Agradecimentos}

Agradeço, primeiramente, ao meu orientador, Paulo Chagas de Souza, que possui inspirador interesse e curiosidade pelas línguas mais diversas, e que me apoiou desde meu intercâmbio para Finlândia, ainda na graduação, no qual descobri meu interesse pelas línguas saami;

À minha família, em especial à minha mãe, que acompanha meus bons e maus momentos, e compreende minhas escolhas por vezes pouco tradicionais;

Às amigas e amigos do Departamento de Linguística e membros do grupo FONEMOS, que foram um apoio essencial durante os últimos dois anos; em especial à Karina Oliveira, cuja ajuda possibilitou que esta dissertação fosse escrita em LTEX;

Aos professores Mário Viaro, Thomas Finbow e Timothy Feist pela paciência, dedicação, e pelos valiosos comentários e orientações na defesa, que foram essenciais para o resultado final desta dissertação;

Aos professores Luciana Storto e Thomas Finbow (novamente), pelos mesmos motivos, no exame de qualificação; e às professoras Olga Coelho e Margarida Petter, pelas aulas na pós-graduação que transformaram meu projeto inicial;

Aos professores e amigos que de alguma forma tiveram parte no meu (lento) aprendizado da língua finlandesa: Anne Palokangas, Emma Virkkunen, Johannes Salmi, Rikupekka Leinonen e, especialmente, Salli Nurminen, que é minha parte preferida da Finlândia;

Ao Jordi Ferré, por sua dedicação inspiradora às línguas e causas indígenas;

À Karina Merino, que bravamente encarou o desafio de traduzir páginas de descrições de vogais em alemão antigo;

E, por fim e não menos importante, às minhas amigas e amigos, que, cada um à sua maneira, participam positivamente da minha vida e tornam o mundo um lugar com alguma esperança. Não listarei seus nomes aqui, é difícil pôr em uma lista amizades tão longas que significam tanto, ou mesmo amizades distantes que, independentemente disso, são muito valiosas.

Pelo financiamento da pesquisa, agradeço à CAPES. 


\section{Resumo}

A presente pesquisa visa ao estudo do sistema vocálico do saami skolt (língua da família fino-úgrica, falada na Finlândia e na Rússia) ao longo do século XX, com base em dados bibliográficos, mais especificamente transcrições fonéticas feitas nos períodos pré- e pós-realocações do povo saami skolt dos vilarejos originais para a Finlândia. Procuro fazer um estudo dialetal, traçando as particularidades dos dialetos originais quanto ao sistema vocálico, e analisar esses dois registros da língua à luz da perspectiva variacionista de Labov (Weinreich et al., 1968) e Guy (Guy, 2003), considerando também as relações de contato.

O saami skolt é uma língua minoritária, falada por um povo indígena de mesmo nome, cujo número estimado de falantes varia entre 150 e 300 (Feist, 2015, 22). Impactos profundos na comunidade de fala ocorreram ao longo do século $X X$, em especial, a realocação do povo saami skolt de seus territórios originais na Rússia para a Finlândia, por volta da década de 40.

O corpus da pesquisa foi organizado a partir do registro em transcrição fonética dos dialetos originais, feito no período pré-realocações, por Toivo Itkonen, no formato do dicionário Koltan- ja Kuolanlapin sanakirja (Itkonen, 2011 [1958]) e as transcrições fonéticas e fonológicas da língua feitas entre as décadas de 60 e 70 por Korhonen (1971); Korhonen et al. (1973). A Grammar of Skolt Saami (Feist, 2015), que aborda também a situação do saami skolt no século XXI, é uma das bases para a pesquisa e descrição da língua.

Através da análise dos dados, foi possível observar e descrever a heterogeneidade da língua e de seus dialetos quanto ao inventário de vogais e ditongos. Um dos fatores observados foi, no dialeto de Paatsjoki, a ocorrência alofones anteriorizados, em comparação aos dialetos de Suonikylä e Nuortijärvi.

Palavras-chave: línguas saami, saami skolt, sociolinguística, contato de línguas. 


\section{Abstract}

This research aims at the study of the vowel system of Skolt Saami (a Finnougric language spoken in Finland and Russia) over the 20th century, based on bibliographic data, more specifically phonetic transcriptions previous to and after the relocation of the Skolt people from their original villages to Finland. I intend to do a dialect study, describing the features of the original dialects regarding the vowel system and analyse these two records of the language guided by the variacionist approach of Labov (Weinreich et al., 1968) and Guy (Guy, 2003), also taking into account the language's contact relations.

The Skolt Saami is a minority language spoken by a homonymous indigenous people, with an estimated number of speakers that varies between 150 and 300 (Feist, 2015, 22). The speech community went through deep impacts over the 20th century, in particular the relocation of the Skolt Saami people from their original territories in Russia to Finland, around the 1940s.

The corpus was compiled using the records in phonetic transcriptions of the original dialects made by Toivo Itkonen, prior to the relocations, in the dictionary Koltan- ja Kuolanlapin sanakirja (Itkonen, 2011 [1958]), as well as the phonetic and phonemic transcriptions of the language made between the 1960s and 1970s by Korhonen (1971); Korhonen et al. (1973). A Grammar of Skolt Saami (Feist, 2015), which approaches the Skolt Saami situation also in the 21st century, is one of the basis for this project and description of the language.

Through the analysis of data, it was possible to observe and describe the heterogeneity of the language regarding the vowel and diphthong inventory. One of the features found was, in the dialect of Paatsjoki, the occurrence of more fronted allophones, in comparison to the inventory of the dialects of Suonikylä and Nuortijärvi.

Keywords: saami languages, skolt saami, sociolinguistics, language contact. 


\section{Sumário}

$\begin{array}{ll}\text { Agradecimentos } & \text { v }\end{array}$

Resumo vi

Abstract vii

Lista de Tabelas $\quad$ x

Lista de Figuras $\quad$ xi

1 Introdução 1

1.1 Povos e línguas saami . . . . . . . . . . . . . . . 1

1.2 Percurso do povo saami skolt no século XX . . . . . . . . . . . . 6

1.3 A língua e seus dialetos . . . . . . . . . . . . . . . . . 10

1.4 Relações de contato . . . . . . . . . . . . . . . . . . 16

1.4 .1 Imitação e adaptação . . . . . . . . . . . . . . . . . . . . . . . 20

1.4.2 As relações de contato no estudo da proto-língua . . . . . . 21

1.5 A língua atualmente ... . . . . . . . . . . . 26

2 Aspectos da língua $\quad 28$

2.1 Estrutura silábica e acentuação . . . . . . . . . . . . . . . . . . . . 29

2.2 Duração . . . . . . . . . . . . . . . . . . 30

2.3 Consoantes . . . . . . . . . . . . . . . . . . . . 31

2.4 Vogais . . . . . . . . . . . . . . . . . . . 32

2.4.1 Vogais palatalizadas ................ 34

2.4 .2 Ditongos . . . . . . . . . . . . . . . 37

2.5 Vogais reduzidas . . . . . . . . . . . . . . . . . . 40

3 Registros e estudos acerca do sistema vocálico 41

3.1 T. Itkonen . . . . . . . . . . . . . . . . . . . . . . . . . 43

3.2 M. Korhonen . . . . . . . . . . . . . . . . . . . . . . . . . 49 
4 A mudança sonora sob a perspectiva variacionista 52

4.1 A teoria neogramática e a difusão lexical . . . . . . . . . . . . . . . . . 52

4.2 A abordagem sociolinguística . . . . . . . . . . . . . . . 55

4.2.1 A determinação de isoglossas . . . . . . . . . . . . . . . 58

4.2.2 Transferência de elementos estruturais . . . . . . . . . . . . 60

4.2.3 Mudança fonética e fonológica . . . . . . . . . . . 63

4.2.4 A difusão lexical sob a perspectiva variacionista . . . . . . . 65

5 Dados e análise $\quad 67$

5.1 Materiais e métodos . . . . . . . . . . . . . . . . . . . 67

5.2 Análise dos dados . . . . . . . . . . . . . . . . . . 70

5.2.1 Particularidades - aproximantes laterais . . . . . . . . . 70

5.2 .2 O dialeto de Paatsjoki . . . . . . . . . . . . 75

5.2.3 Os dialetos do Sul - Nuortijärvi e Suonikylä . . . . . . . . . 79

5.2.4 O dialeto de Sevettijärvi (originalmente, de Suonikylä) . . . 82

5.2 .5 Os ditongos [ie ] e [ie] / [uo] e [uo] . . . . . . . . . . . . . . 84

6 Considerações finais

Referências bibliográficas $\quad 92$

$\begin{array}{ll}\text { Corpus } & 97\end{array}$ 


\section{Lista de Tabelas}

1.1 Mutação vocálica do saami. Adaptado de Aikio 2007, 25-6. . . . . . 25

3.1 Equivalências UPA-IPA dos sons vocálicos descritos por Itkonen (2011 [1958]) . . . . . . . . . . . . . . . . . . . . 4 44

3.2 Inventário de vogais reduzido . . . . . . . . . . . . . . . 51

5.1 Aproximantes laterais em Itkonen 2011 [1958]. . . . . . . . . . . . . 71

5.2 Particularidades atribuídas ao dialeto de Paatsjoki . . . . . . . . . 76

5.3 Fonemas x Realização fonética, em Korhonen (1971) . . . . . . . . . 86 


\section{Lista de Figuras}

1.1 Árvore da família urálica por Anttila $(1989,301) \ldots \ldots$. . . . . . 2

1.2 Áreas originais das línguas saami no norte da Europa. Adaptado de Seurujärvi-Kari 2011, $38 \ldots \ldots \ldots \ldots \ldots$

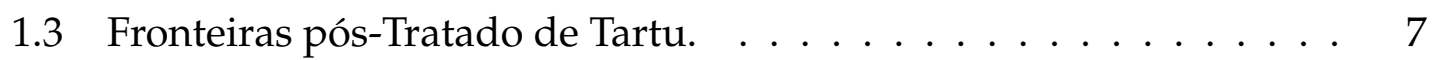

1.4 Vilarejos (siidas) saami skolt divididos pelo tratado. . . . . . . . 8

1.5 Rota das realocações. . . . . . . . . . . . . . . . . . . . 9

2.1 Inventário de consoantes - IPA (Feist, 2015, 45). . . . . . . . . . 31

2.2 Inventário de consoantes - grafemas da língua (Feist, 2015, 45). . . 32

2.3 Quadro de vogais do saami skolt (utilizando os grafemas da língua). Retirado de Feist 2015, 64 . . . . . . . . . . . . . . . . 33

2.4 Valores de F1 e F2 para os nove fonemas e suas versões palatalizadas, produzidos por uma falante adulta (Feist, 2015, 68). . . . . . 35 


\title{
1 Introdução
}

\subsection{Povos e línguas saami}

A família urálica, à qual as línguas saami pertencem, emprestou seu nome dos montes Urais, a cordilheira de montanhas entre a Europa e a Ásia. As línguas urálicas, porém, estão presentes num território além da região das cordilheiras, e especulações acerca da terra natal desta família variam desde localizações mais ao oriente, como o lado siberiano dos Urais, até a região báltica, a oeste (Janhunen, 2009:71). O número estimado de línguas urálicas varia entre 20 e 40, e, com exceção do húngaro, do finlandês e do estoniano, que possuem o status de línguas nacionais, todas são faladas por minorias étnicas (Laakso, $2011: 13$ ). ${ }^{1}$ Na página seguinte, apresentamos uma árvore proposta por Anttila (1989) para a família urálica, na qual as línguas saami estão em um dos dois núcleos do balto-fínico. A convergência de ramos indica a sobreposição de isoglossas. Segundo o autor,

\begin{abstract}
"A tree like this shows many facts at a glance. Each node defines itself by the lower nodes. Thus Uralic is a cover term for the whole family since it is the highest node, but more immediately it is defined as the sum of Finno-Ugric and Samoyed (divided into a northern and a southern group). For many practical considerations, Samoyed is still often ignored and the family is just called Finno-Ugric, it, in its turn, being defined by Finnic and Ugric, and so on. 'Finno-Ugric' is typical of the compound names used when no geographical or other term has become current." (Anttila, 1989:300)
\end{abstract}

" [...] Note that the Baltic Finnic node has two nuclei. The problem is the exact position of Lapp, but since it is so closely related to Baltic Finnic, it seems plausible that it branched off from the upper nucleus, called Early Baltic Finnic." (Anttila, 1989:302)

\footnotetext{
${ }^{1} \mathrm{O}$ termo fino-úgrico é, por vezes, utilizado como sinônimo para urálico, tal qual em Laakso (2011).
} 


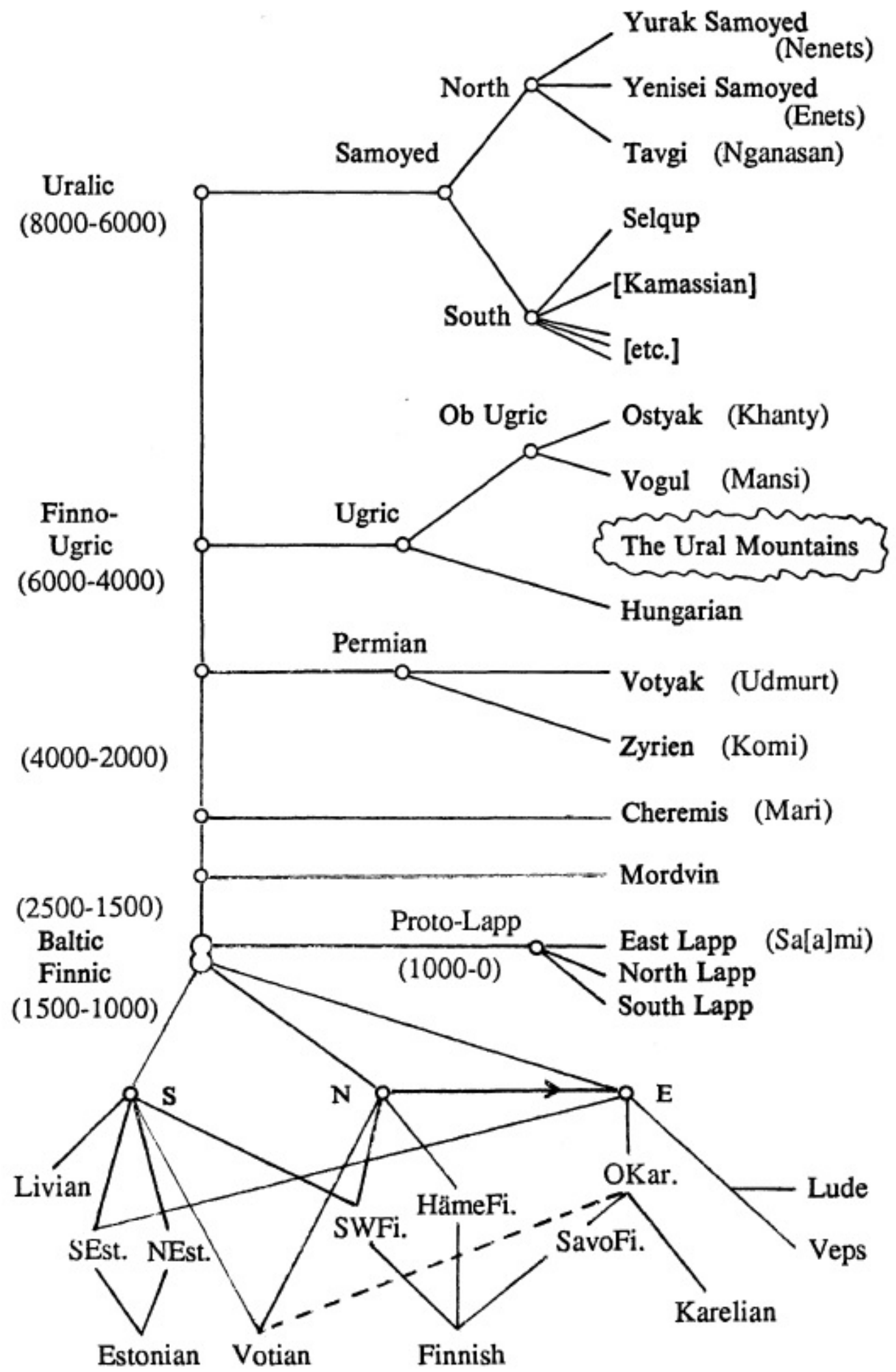

Figura 1.1: Árvore da família urálica por Anttila (1989: 301). 
Os povos saami, ${ }^{2}$ mais especificamente, são povos indígenas que tradicionalmente vivem na região da Lapônia; compreendendo partes da Rússia, Finlândia, Suécia e Noruega, num continuum dialetal (Wilbur, 2014). Ainda que haja heterogeneidade quanto à língua, religião e costumes, a palavra saami é usada como endônimo geral, com adição de um complemento quando uma etnia refere-se a si mesma em oposição às outras - os saami skolt, saami inari, saami norte etc. A nomenclatura utilizada para tais subdivisões é, no entanto, arbitrária, e varia ao longo dos anos de acordo com o ponto de vista do observador: o povo que neste trabalho será chamado de saami skolt refere-se a si mesmo como sää'mm ("saami") e à sua língua como sää mǩiõll ("língua saami"), e quando em oposição aos outros povos e línguas saami, usaria-se o termo nuõrttsää'mm e nuõrttsää'mǩiõll ("saami do Leste", "língua saami do Leste") (Feist, 2015:29). O termo skolt é de etimologia incerta, e supõe-se que veio da palavra crânio (sueco e norueguês skalle), ${ }^{3}$ sendo as razões para esse termo ter surgido ainda mais obscuras, tal como para ser adotado em pesquisas sobre a língua no início do século $X X$ e se popularizado até os dias de hoje. Historicamente, foi largamente utilizado o termo "lapão" para designar tanto os povos quanto as línguas saami, mas este termo caiu em desuso, por ser atribuída a ele uma conotação ofensiva.

Atualmente, são faladas nove línguas saami (após o desaparecimento do saami akkala), pouco compreensíveis mutuamente, com exceção de regiões em que se encontram (ou áreas de fronteira). Como forma de exemplificação do grau de compreensibilidade entre elas, a distância entre as línguas românicas é eventualmente citada como uma boa correspondência (Sammallahti, 1998 : 1). Contam, no total, com por volta de 20 mil falantes. ${ }^{4}$ Oficialmente, as línguas ou variantes

\footnotetext{
${ }^{2}$ Tal grafia corresponde à usada pela língua finlandesa, que e é notadamente mais comum nas pesquisas sobre o tema atualmente. O duplo $a$ indicador de uma vogal longa. É também possível encontrar a grafia sámi ou sami (Nelson \& Toivonen, $2007: 1$ ).

${ }^{3}$ Saa'mi Nue'tt ry. Kolttasaamelaiset. Disponível em:

http:/ /www.saaminuett.fi/kolttasaamelaiset.html [Último acesso:01/08/2017]. Trata-se de um exônimo, que possivelmente surgiu com uma conotação pejorativa.

${ }^{4}$ Baseado na soma das estimativas feitas para cada língua em Nelson \& Toivonen (2007:2).
} 


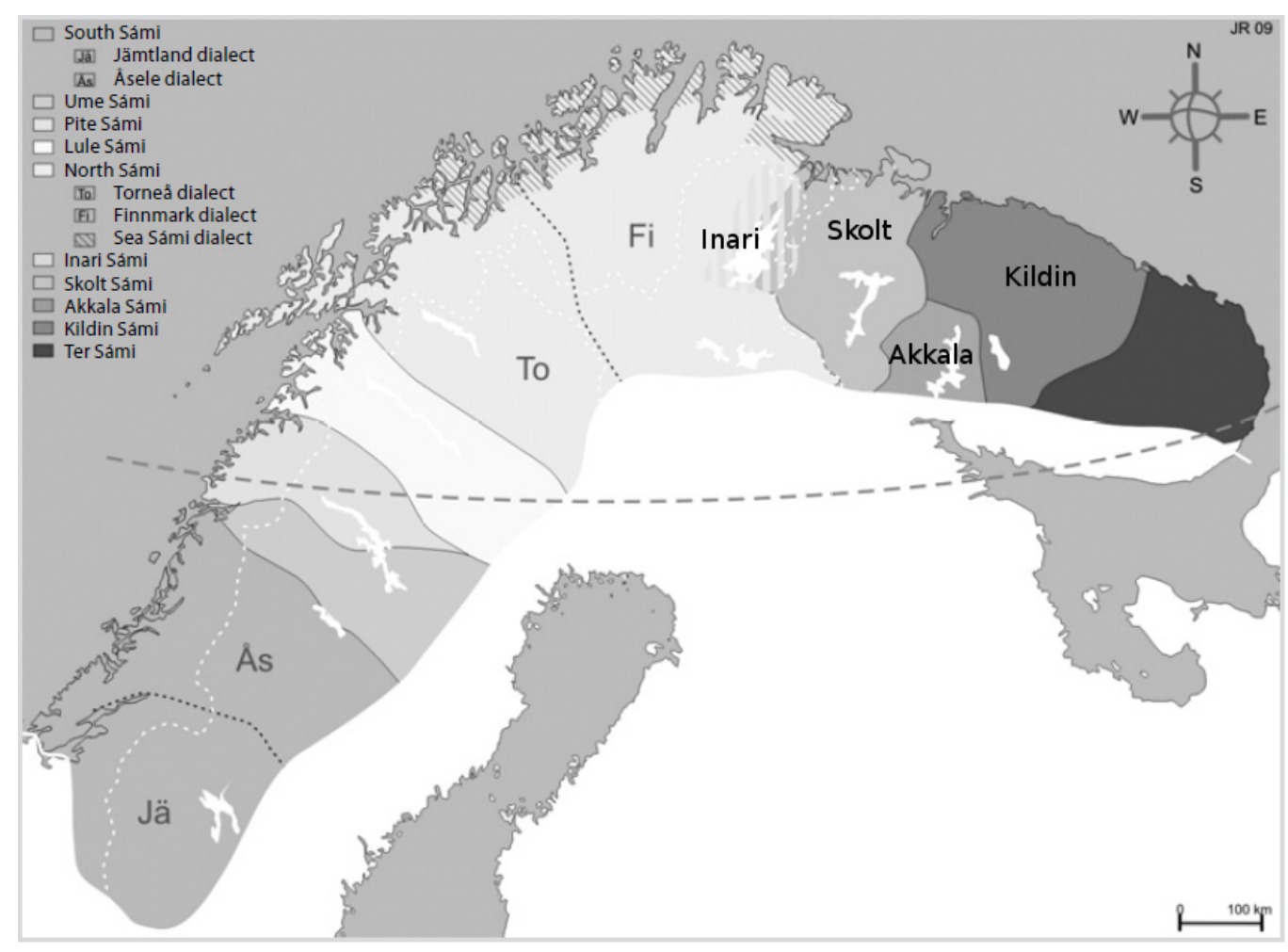

Figura 1.2: Áreas originais das línguas saami no norte da Europa. Adaptado de Seurujärvi-Kari 2011:38.

do ramo saami têm o status de dialetos; porém, será adotado o termo língua e não dialeto no presente trabalho. Anttila (1989), ao propor a árvore para a família urálica reproduzida em 1.1, levanta que, apesar da diversidade entre as línguas saami ser muito maior do que entre as balto-fínicas, as primeiras muitas vezes são tratadas apenas como uma única língua, ao passo que as balto-fínicas são enumeradas separadamente. Uma discussão mais detalhada a respeito da nomenclatura língua/dialeto é proposta em 1.3 - A língua e seus dialetos.

Conforme proposto por Sammallahti (1998), as línguas saami podem ser divididas entre as orientais e ocidentais, uma classificação relevante em muitas gramáticas ao exemplificar fenômenos distintos entre esses dois grupos. As línguas ocidentais são as mais numerosas em quantidade de falantes e se distribuem entre Noruega, Suécia e Finlândia, sendo chamadas: saami sul (no original, åarjelsaemiengïele, saami ume (ubmisámegiella), saami pite (bidumsámegiella), Lule (julev- 
sámegiella) e saami norte (davvisámegiella). Esta última é, com grande vantagem, a língua com maior número de falantes (por volta de 17 mil) (Nelson \& Toivonen, 2007:2), ao passo que as línguas saami ume e pite encontram-se seriamente ameaçadas. ${ }^{5}$ As línguas orientais, localizadas na Finlândia e a Rússia, são: saami inari (anarâškielâ), saami skolt (nuõrttsää'm̌̌iōll), saami kildin (sām' kīll) e saami ter (darjjesámegiella). ${ }^{6}$ Deste mesmo grupo, recentemente foi considerada extinta a língua saami akkala, com a morte de sua última falante em $2003,{ }^{7}$ e o saami ter está seriamente ameaçado. Saami inari, skolt e kildin, numa estimativa de 2007, contavam com, respectivamente, por volta de 350, 400 e 700 falantes (Nelson \& Toivonen, $2007: 2$ ). Segundo uma estimativa de 2015, porém, o saami skolt conta com entre 150 e 300 falantes, conforme será tratado em 1.5 - A língua atualmente.

A vasta maioria dos falantes de saami é bilíngue, e o uso da língua é geralmente restrito ao âmbito doméstico, com exceção de um movimento relativamente recente de preservação linguística, que promove ensino e produção cultural bilíngue ou mesmo exclusivamente em saami.

No caso específico do saami skolt, seu sistema de escrita só foi desenvolvido no início da década de 1970, ainda que os primeiros estudos a respeito da língua datem o início do século XX. A primeira gramática escolar veio em 2009 (Koltansaamen koulukielioppi, "Gramática escolar do saami skolt”, Moshnikoff et al. 2009) , e uma gramática descritiva, em 2015 (A Grammar of Skolt Saami. Feist 2015).

Conforme será explicado a seguir, os saami skolt foram realocados de suas terras originais na região de Petsamo (atualmente, parte da Rússia) para a região de Inari (Finlândia), implicando não somente na mudança da L2 de seus falantes, passando de russo para finlandês, como também inserindo os saami skolt numa

\footnotetext{
${ }^{5}$ A primeira gramática da língua pite, de 2014, que aponta aproximadamente 30 falantes restantes (Wilbur, 2014:7). A situação da língua saami ume é semelhante.

${ }^{6}$ gïele, giella, kielâ, ǩioll - língua.

${ }^{7}$ Marija Sergina ig. Osipova, do município de Kovdor na península de Kola (Kulonen et al. 2005:88-89 e Rantala \& Sergina, 2009:73 apud Seurujärvi-Kari 2011:37).
} 
situação cuja relação entre os povos da língua dominante e da língua minoritária diverge da anterior, tais como as consequências desta nova situação de contato.

\subsection{Percurso do povo saami skolt no século $X X$}

O século XX foi escolhido como ponto de referência nesse estudo por ser um período no qual houve uma intensa fragmentação do povo saami skolt e de seu território. Cabe, no entanto, menção ao percurso anterior a esse período, numa breve contextualização histórica:

É conhecido que povos de língua saami já estavam presentes no Norte europeu, mais precisamente no sul da Finlândia, no início da Idade do Ferro (Carpelan, 2003 : 22)(Aikio, 2012: 63), por volta de 1000 AC. No entanto, estudos a respeito da história da Finlândia e da Escandinávia, em geral, dão a tal fato importância secundária, preferindo mencionar a transição da Idade do Ferro para a Idade Média (800 a 1300 DC), quando, antes do Cristianismo, povos fínicos ocuparam o sul da Finlândia (Schefferus, 1673 apud Aikio 2012: 88) e os povos saami migraram para a Finlândia central e Lapônia, quando não foram assimilados. Após ser parte do reino da Suécia por sete séculos, a Finlândia, no início do século XIX, foi anexada à Rússia czarista como Grão-ducado da Finlândia, e obteve sua independência em 1917.

Estima-se que, no início do século XIX, havia por volta de 800 a 900 saami skolt estabelecidos majoritariamente em território russo. A segunda língua entre eles, para contato com os não saami, era o russo (tal qual para outros povos saami orientais); e a cristianização foi implementada pela Igreja Ortodoxa. Paralelamente, povos saami mais a oeste da Lapônia adquiriam como segunda língua os idiomas oficiais dos países nórdicos e eram convertidos para o luteranismo. O século XX, porém, traz uma intensa e quase súbita interferência cultural e linguística, que resultou em rupturas para o povo saami skolt. Significativa perda populacional 
ocorreu entre os saami skolt ao servirem o exército czarista na Primeira Guerra Mundial (1914-18). Ainda, em 1920, após a independência da Finlândia do Império Russo (1917) e a derrubada deste pela Revolução Russa, a Finlândia e a então União Soviética cessaram conflitos territoriais através do Tratado de Tartu, que redefinia as fronteiras entre os dois países e dava à Finlândia a região de Petsamo, importante acesso ao oceano Ártico. Petsamo, no entanto, era apenas uma parte da área migratória dos saami skolt, e a nova fronteira ali estabelecida a dividia quase literalmente ao meio.

Na figura 1.3, as fronteiras estabelecidas pelo Tratado de Tartu: em vermelho, a região de Petsamo, agora parte da recém-independente Finlândia; em verde, território finlandês cedido à URSS. 8

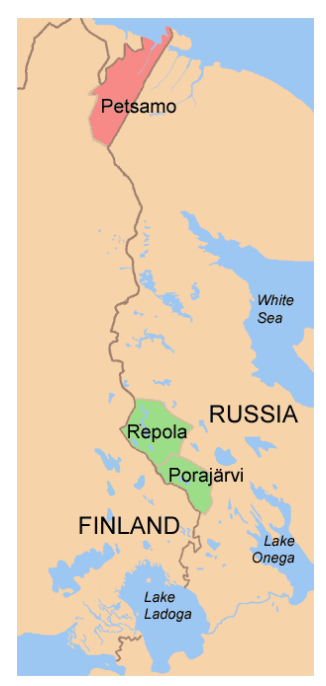

Figura 1.3: Fronteiras pós-Tratado de Tartu.

Na figura 1.4, a nova fronteira de Petsamo em pontilhado vermelho, e os círculos marcam as regiões migratórias dos saami skolt (siidas) entre a Finlândia e a URSS, a maior parte delas dividida. ${ }^{9}$ Os números referem-se às siidas: 1 )

\footnotetext{
${ }^{8}$ Fonte: Wikipedia. Disponível em:

http://en.wikipedia.org/wiki/Treaty ${ }_{\text {o }}$ artu Russian\%E2\%80\%93Finnish)[ltimoacesso : $01 / 08 / 2017$

${ }^{9}$ Fonte: Sámi Museum. Disponível em: http://www.samimuseum.fi/saamjiellem/suomi/historia.html
} 
Näätämö, 2) Paatsjoki, 3) Petsamo, 4) Muotka, 5) Suonikylä, 6) Nuortijärvi e 7) Hirvasjärvi. ${ }^{10}$

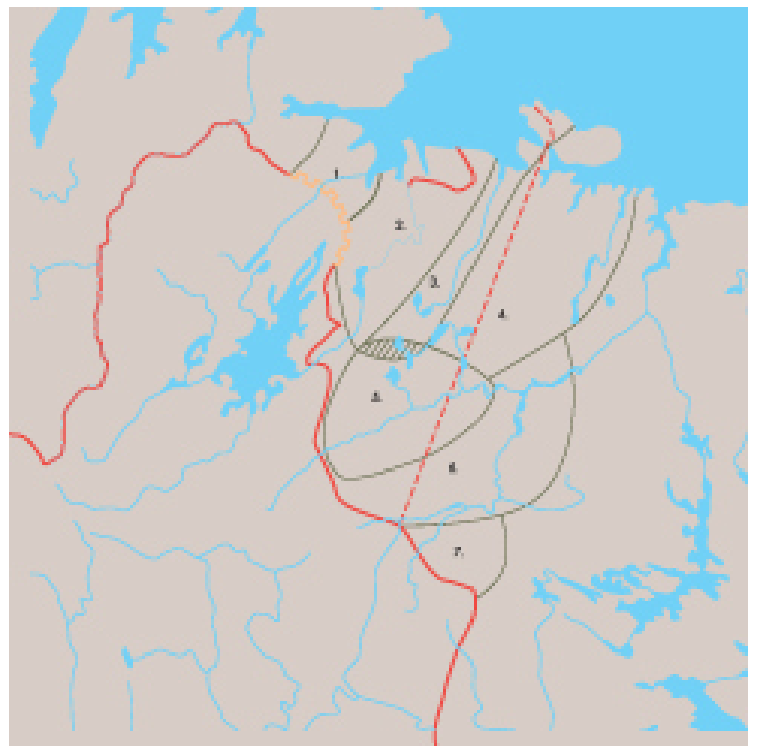

Figura 1.4: Vilarejos (siidas) saami skolt divididos pelo tratado.

Os saami skolt, tal qual os outros povos saami, viviam de maneira nômade, deslocando-se entre o que chamam de siida - palavra geralmente traduzida, de maneira bastante rasa, por vilarejo. Não pretendo aqui esgotar todos os pormenores que constroem, nas línguas saami, a ideia de siida-mas neste contexto cabe esclarecer que, como unidades territoriais, é de crucial importância para a sobrevivência e manutenção cultural. Numa mesma siida convivem várias famílias, e, no momento do tratado de Tartu, registra-se a existência de sete siidas entre os saami skolt, sendo que cinco delas foram atravessadas pela nova fronteira. Além disso, os direitos de uso da região de uma das siidas restantes foram vendidos à Noruega, causando a longo prazo a migração ou assimilação dos saami skolt ali presentes.

Como consequência imediata, o povo saami skolt dividiu-se, tornando-se cidadão de três países diferentes. Os que ficaram no lado soviético ainda foram posteriormente realocados, por consequência das políticas de coletivização. Os

\footnotetext{
${ }^{10}$ Fonte: Sámi Museum. Disponível em: http://www.samimuseum.fi/saamjiellem/suomi/historia.html
} 
saami skolt que se tornaram finlandeses, por sua vez, foram incorporados a uma nova nação da qual desconheciam a língua, além de serem ortodoxos num país luterano.

As perdas e rupturas intensificaram-se duas décadas depois, quando ocorreu entre Finlândia e União Soviética a Guerra de Inverno (1939-1940) e a Guerra de Continuação (1941-44). A primeira resultou em exílio e realocações dos saami skolt, alguns para o sul da Lapônia finlandesa, outras, para a península soviética de Kola. A segunda culminou com a devolução de Petsamo à União Soviética, e realocação de todos os saami skolt ali restantes para a região de Inari, na Lapônia finlandesa, onde foram restabelecidos completamente até a década de 50. As siidas originais do povo saami skolt foram totalmente dissolvidas, e famílias de siidas diversas, já dividas pelo exílio e realocações anteriores, agora fixavam-se num território novo. Na figura a seguir, a rota das realocações: ${ }^{11}$

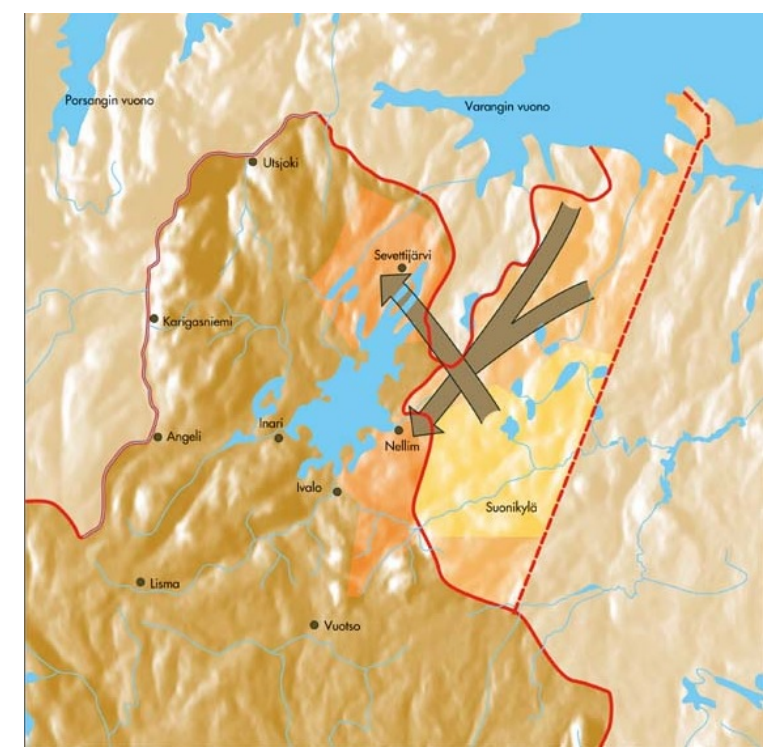

Figura 1.5: Rota das realocações.

\footnotetext{
11@SIIDA 2003. <http://www.samimuseum.fi/saamjiellem/english/kolttaalue.html >. [Último acesso: $18 / 05 / 2017]$
} 


\subsection{A língua e seus dialetos}

No presente trabalho, irei adotar as divisões dialetais do saami skolt feitas em Koltan- ja Kuolanlapin sanakirja, "Dicionário do lapão skolt e de Kola" por Itkonen (2011 [1958]), que registra quatro dialetos - Paatsjoki, Nuorttijärvi, Suonikylä e Näätämö. A divisão de variantes dentro do saami skolt não encontra muitas divergências na literatura, ao contrário da terminologia, que discorda quanto ao que chama de língua ou de dialeto.

Proponho uma breve discussão sobre o assunto, e, em seguida, irei expôr como tal divisão foi feita nos principais trabalhos sobre o saami skolt no último século.

"Uma língua é um dialeto com um exército e uma marinha", uma frase popularizada pelo sociolinguista Max Weinreich (1894-1969), ${ }^{12}$ expressa a natureza arbitrária dessas nomenclaturas, que frequentemente pouco estão ligadas a propriedades dos idiomas em si, mas sim são determinadas por fatores externos à linguística, como prestígio e/ou poder geopolítico de uma variante ou de seus falantes. O seguinte trecho de An essay on Saami ethnolinguistic prehistory (Aikio, 2012) corrobora o que foi proposto pela frase de Weinreich, e o pesquisador saami Ante Aikio exemplifica outra situação possivelmente arbitrária - o uso de uma língua como critério de definição de um povo ou etnia.
"Language does not need to determine the boundaries of an ethnic group even if it determines its prototype. By the linguistic criteria of shared innovations or mutual intelligibility one cannot find anything that would delimit all dialects of 'Swedish' as a coherent whole distinct from 'Norwegian' and 'Danish'. On the other hand, there are Scandinavian language varieties spoken within Sweden such ar Övdalian, which by the criterion of lack of mutual intelligibility as well as by their speakers' own opinion are clearly distinct languages (although refused to be officially recognized as such by the state

\footnotetext{
${ }^{12}$ originalmente em iídiche, (romanizado): a shprakh iz a dialekt mit an armey un flot. Weinreich encontrou nela uma boa expressão da situação do iídiche, que, sendo uma língua minoritária falada por judeus asquenazes - e, em si mesma, passível de divisão entre variantes - tem seu status simplificado como um dialeto do alemão, a despeito de suas singularidades linguísticas e étnicas. Para mais detalhes, https://en.wikipedia.org/wiki/A_language_is_a_dialect_with_an_army_and_navy
} 
of Sweden). Still, speakers of Övdalian consider themselves 'Swedes' and not a distinct ethnic group (Melerska 2010). Moreover, even groups speaking linguistically unrelated languages, such as Meänkieli or Torne Valley Finnish in northern Sweden, have become secondarily incorporated to the ethnic category of 'Swedes'." (Aikio, 2012:65)

Diante disso, voltar-se à historiografia e observar onde a linha entre língua e dialeto foi traçada ao longo do tempo é um passo relevante para a compreensão do que é a língua saami skolt e de sua heterogeneidade.

Na publicação no início do século XX, Gradação consonantal dos dialetos saami skolt, saami kildin e saami ter do lapão da Rússia (Venäjänlapin konsonanttien astevaihtelu Koltan, Kildinin ja Turjan murteiden mukaan), escrita por Itkonen (1916), nota-se que, o que nas pesquisas recentes vem sendo tratado como três línguas distintas, num primeiro momento, foi tratado como três dialetos de uma mesma, o lapão da Rússia, provavelmente por critério meramente geográfico - os povos saami skolt, kildin e ter habitavam, em 1917, o território do então Império Russo. No continuum dialetal das línguas saami, as três estão posicionadas muito próximas, um indicativo de compreensão mútua. Porém, o próprio Itkonen (2011 [1958]) ressalta, sem dar muitos detalhes, que o saami kildin e o saami skolt são bastante diferentes, ${ }^{13} \mathrm{e}$ que há compreensibilidade mútua entre saami skolt e saami inari ${ }^{14}$ ( visto que, no continuum, o saami inari está muito próximo do saami skolt, isso era esperado) mas não foram categorizadas como dois dialetos de uma mesma língua sob esse critério.

Mais tarde, em 1958, Itkonen lança o trabalho central para esta dissertação, Koltan- ja Kuolanlapin sanakirja (Dicionário do lapão skolt e de Kola), fazendo uso de material coletado em trabalho de campo entre as décadas de 10 e 20, e através de informantes entre 1930 e 1943. Conforme pode-se observar no caso descrito

\footnotetext{
13 “(...) um die Kildinlappen kennenzulernen, deren Mundart sich sehr von den koltalappischen unterscheidet." Itkonen 2011 [1958] :XII.

14 "Die ersten koltalappischen Familien, die wir antrafen, mit dem Sippennamen Fofanov, wohnten an dem See Madzazjaur, der auf meiner russichen Karte überhaupt nicht angegeben war. Inarilappisch verstanden sie ziemlich gut." Itkonen 2011 [1958] : VIII. / "Da Inari- und Koltalappisch ziemlich nahe miteinander verwandt sind" Itkonen 2011 [1958]:XII.
} 
anteriormente, nos trabalhos desse pesquisador, não se nota uma preocupação em justificar a categorização entre língua e dialeto: Itkonen refere-se a saami skolt, kildin e ter como dialetos, e, dentro desses, reconhece diversas variantes (que também chama de dialetos) nomeando-as de acordo com a região ou nome do vilarejo onde se encontravam (Paatsjoki, Suonikylä, etc.). Quanto ao nome do dicionário, Dicionário do saami skolt e de Kola, cabe ressaltar que Kola é uma região geográfica (o "saami de Kola"compreenderia às línguas saami kildin e ter), mas saami skolt não, conforme a etimologia explicada anteriormente.

Em 1971, Mikko Korhonen, pesquisador finlandês de línguas fino-úgricas, lançou a publicação Ehdotus koltanlapin Suonikylän (nyk. Sevettijärven) murteen fonemaattiseksi transkripioksi, "Proposta de transcrição fonêmica do dialeto de Suonikylä (atual Sevettijärvi) do lapão skolt". Especifica-se como língua de estudo não simplesmente saami skolt, mas, dentro dessa língua, um dialeto que será priorizado (Suonikylä, atual Sevettijärvi - ou seja, os informantes haviam sido realocados para Sevettijärvi, na Finlândia, mas eram falantes da variante da região de Suonikylä, atualmente na Rússia). 15

Os critérios de Korhonen parecem semelhantes aos de Itkonen - as variantes foram nomeadas de acordo com o nome do vilarejo em que se originam.

Por fim, na década de 90, numa icônica publicação a respeito das línguas saami, Pekka Sammallahti, em Saami Languages - an introduction (1998), toma como base as 10 línguas saami originais e estabelece critérios fonológicos e morfológicos para traçar divisões entre grupos de línguas, línguas e dialetos. No percurso que vai desde as 10 línguas saami até os dialetos do saami skolt, Sammallahti segue a seguinte sequência de divisões, progressivamente mais específicas:

\section{Linguas saami ocidentais e orientais;}

\footnotetext{
${ }^{15}$ Em 1973, Korhonen foi um dos autores da primeira proposta de gramática descritiva, a Koltansaamen Opas, "Guia do saami skolt", quando, pela primeira vez, usou-se o endônimo saami e não o exônimo lapão para referir-se à língua. O endônimo saami passou a ser utilizado em publicações desde então.
} 
II Dentro das orientais: Grupo continental: saami inari, skolt e akkala ${ }^{16}$ / Grupo peninsular: saami kildin e saami ter

III Dentro das continentais: o grupo Skolt (saami skolt e akkala) e o saami inari

IV Dentro do grupo Skolt, o saami skolt

V Dentro do saami skolt, os dialetos do Norte (Neiden e Paatsjoki) e do Sul (Suonikylä e Notozero-Girvasozero / Nuortijärvi) $^{17}$

Esquematizando:

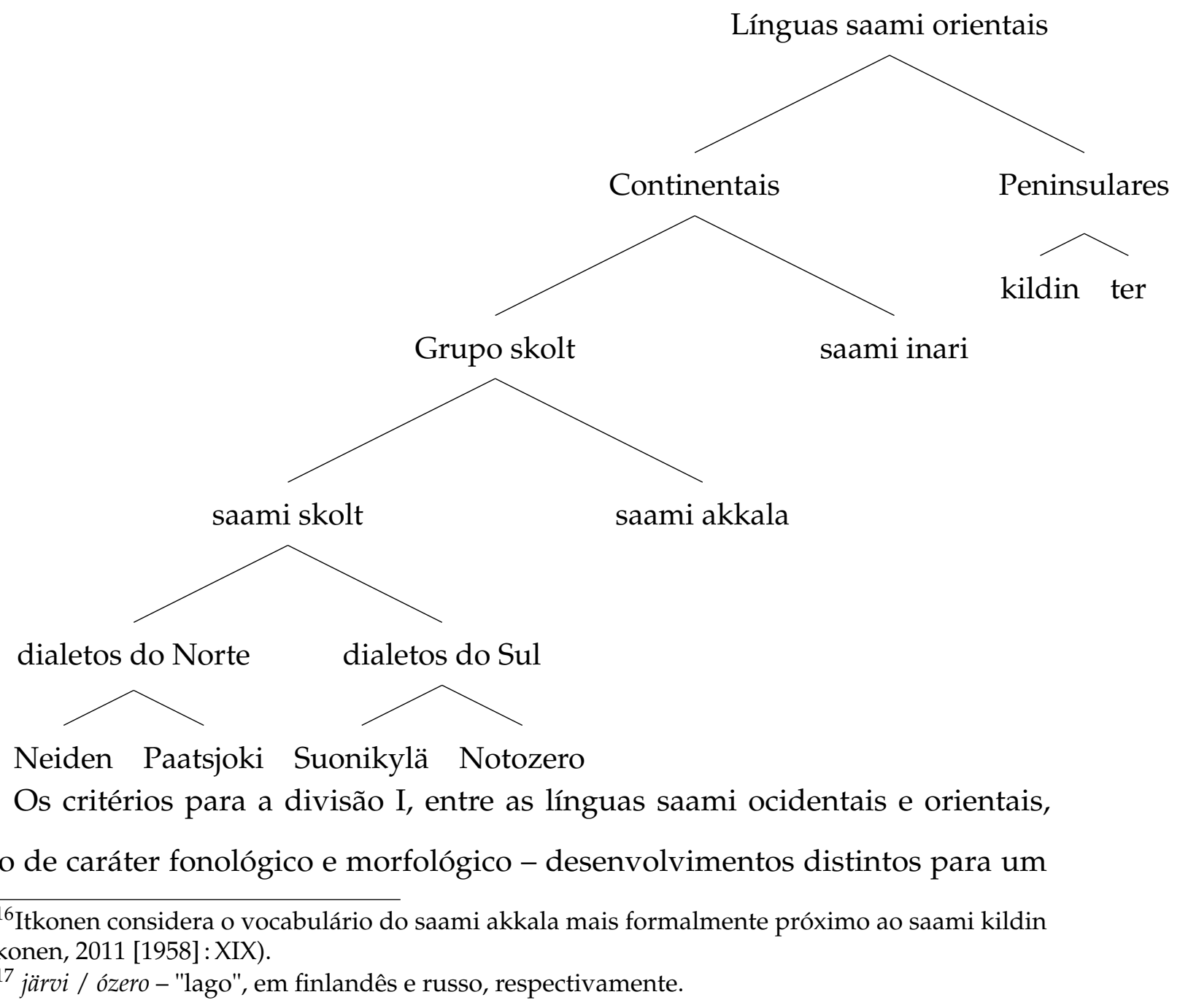


encontro consonantal do proto-saami; ${ }^{18}$ e diferenças no uso de número e caso nas construções numeral + substantivo. ${ }^{19}$

Na divisão II, entre as línguas orientais continentais e peninsulares, novamente o ponto de divisão é um desenvolvimento distinto de algumas consoantes e de uma vogal da proto-língua, além de transformações em certos encontros consonantais (Sammallahti, 1998: 26).

Quanto à divisão III, entre o grupo Skolt (saami skolt e saami akkala) e o saami inari, a base da divisão é:

- diferenças fonológicas na gradação consonantal;

- na perda das vogais finais átonas em saami skolt e saami akkala (ao passo que o Inari as preservou).

- desenvolvimento distinto de vogais da proto-língua (Sammallahti, 1998 : 2829).

Já na divisão IV, temos os seguintes argumentos:

- Akkala preservou os encontros consonantais nasal + oclusiva/africada, saami skolt os desnasalizou (concordando com as línguas saami mais a oeste).

18“These (línguas saami ocidentais e orientais) are distinguished by the treatment of PS (= Proto-Saami) preconsonantal *š́ in such clusters as *št, *šk and *šn. In the western languages *š́ has been dissolved into the consonant sequence / jh/ but not in the eastern ones." "rápido" (em um rio) - Ocidentais: saami do Sul goejhke, saami norte guoika / Orientais: saami skolt e saami akkala kuõškk (Sammallahti, 1998:6). (...) "Also the introduction of so-called prothetic stops in nasal geminates largely coincides with this border with the exception of Sea Saami (a dialect of North Saami): in the west original ${ }^{*} m m,{ }^{*} n n{ }^{*} n n,{ }^{*} \eta y$ have changed into clusters beginning wth a stop, e.g. North Saami eadni "mother : eatni GenSg vs. Inari Saami enni : eeni (= /eeńi/ with half-long /n/" (Sammallahti, 1998:6).

${ }^{19}$ As diferenças no uso do número e caso estão nas construções do nominativo e do acusativo singular. Nas línguas orientais, o substantivo fica no nominativo singular após o numeral 1, nominativo plural entre 2 e 6, e partitivo singular em maiores que 6 . Em russo, com numerais a partir de 5, usa-se o genitivo plural. Não há partitivo, mas observa-se certa semelhança. Nas línguas saami ocidentais, temos nominativo singular no numeral 1 e nominativo plural nos numerais maiores que 1. Sammallahti supõe que as línguas orientais mais provavelmente representam o sistema original, e as propriedades das construções numerais nas ocidentais podem ser atribuídas à influência do finlandês e línguas escandinavas. No finlandês, usa-se o nominativo singular nos substantivos com o numeral 1, e o partitivo singular a partir de 2 . 
- Por influência do carélio, saami akkala usa formas pessoais indefinidas de verbos como formas de terceira pessoa do plural.

Quanto ao fenômeno de desnasalização, ele teria se espalhado do oeste para o leste através da fronteira saami norte/saami inari, após a aquisição de nomes e terminologias cristãs, provavelmente no final do século 16 ou começo do 17. Exemplo: Norte ándagassii, Inari addâgâs 'desculpa' (finlandês anteeksi) (Sammallahti, 1998 : 29)).

Por fim, na divisão V, o saami skolt tem dois grupos dialetais, norte e sul. A divisão reflete diferenças na fonologia: Norte: $b>v$ nos encontros consonantais $b d$ e $b \check{z}$, mas não no sul. Neiden tovdâd 'saber', Paatsjoki tovddâd vs. Suonikylä Notozero tobddâd. Sul: $g$ mudou para uma fricativa não sibilante ${ }^{20}$ (g ou j) após sonorantes em encontros consonantais do grau fraco; norte preservou a oclusiva. 'para fora' Neiden ålggaas, Paatsjoki åålgas vs. Suonikylä - Notozero åålgas.

Os dialetos do Norte dividem-se por uma diferença morfológica:

Neiden utiliza a marcação - $k$ - no nominativo plural, ao passo que Paatsjoki tem marcação zero. Possivelmente, Neiden emprestou a marca morfológica do saami norte, que também a possui (Sammallahti, 1998:31). Exemplos: Neiden kuelek 'peixe' nom.pl., vs. Paatsjoki kue'l.

Os dialetos do Sul dividem-se entre Suonikylä (originalmente, na área ao sul de Petsamo, atualmente em Sevettijärvi, na Finlândia) e Notozero-Girvasozero (falado ao redor e ao sul do lago Notozero nas siidas originais de Nuortijärvi Notozero e Hirvasjärvi - Girvasozero) por algumas diferenças fonológicas:

Nuortijärvi possui a oclusiva $d$ no lugar da fricativa não sibilante đ: Suonikylä vue'đđed 'dormir' vs. Nuortijärvi vue'dded Hirvasjärvi vue'dde.

Nuortijärvi também possui, no lugar das sibilantes sonoras em final de palavra $z$ e $\check{z}$, as desvozeadas s e š. Suonikylä sä'mmlaž 'pessoa saami' vs. Nuortijärvi

\footnotetext{
${ }^{20} \mathrm{O}$ termo espirante é frequentemente utilizado no contexto de línguas urálicas para se referir a este tipo de consoante.
} 
sämmlaš.

\subsection{Relações de contato}

As relações de contato têm enorme relevância na formação de uma língua, sendo importante analisar não apenas as influências linguísticas externas às quais os falantes estavam expostos, mas também as situações e dinâmica do contato, como a duração e intensidade do contato entre os grupos, a proporção, prestígio e poder de cada grupo e o tipo de interação entre eles (Winford, 2003:2). As línguas saami têm pontos de divergência nesses aspectos, visto que são faladas por minorias étnicas submetidas à maioria linguística das nações que habitam.

Os estudos histórico-comparativos referentes à família fino-úgrica utiliza a análise de empréstimos e suas respectivas línguas de substrato (aqui, no sentido da linguística histórica) ${ }^{21}$ para encontrar pistas do percurso genealógico, onde e quando ocorreram cisões, quais foram e como se dividiram as proto-línguas etc. Como exemplo, podemos citar o proto-escandinavo, que, por estar parcialmente atestado nas inscrições rúnicas mais antigas, tem algumas de suas mudanças sonoras datadas com exatidão. Desse modo, empréstimos desse substrato no proto-saami podem ser datados quanto ao "terminus ante quem"22 (Aikio, 2012:76).

$\mathrm{Na}$ análise de intervalos históricos mais recentes nas línguas saami, as formas e intensidade das relações de contato são igualmente relevantes. Para aprofundar-se no tema, cabe o desenvolvimento de pesquisas específicas, que fugiriam do escopo dessa dissertação. Esse subcapítulo, portanto, tem como objetivo traçar apenas um panorama geral das relações de contato da língua, de modo a analisar os fatores que afetaram a comunidade de fala (speech community) - que, de acordo

\footnotetext{
${ }^{21} \mathrm{Ou}$ seja, substrato como uma língua de um grupo subordinado, fazendo a distinção com superestrato e adstrato. Na linguística de contato, crioulistas utilizam a palavra para se referir a uma língua de um grupo subordinado na formação de um pidgin ou crioulo (Winford, 2003 : 16).

${ }^{22}$ Do latim, lit. "o limite antes de" - a data limite antes da qual um documento foi escrito.
} 
com Winford, são:

"Speech communities can be defined at different levels of generalization, from communities of practice to the local neighborhood to the nation state. They can also be identified in terms of social criteria such as ethnicity, social class, gender, and so on. What unites each of these social constructs is the fact that its members share certain linguistic repertoires and rules for the conduct and interpretation of speech. Essentially, it is social interaction within and across speech communities that leads to diffusion of linguistic and other cultural practices." (Winford, 2003:26)

Neste caso, podemos defini-la pelo critério étnico - os falantes de saami skolt (ainda que de diferentes dialetos e vilarejos) em contraposição aos falantes de russo ou finlandês (as maiorias étnicas e linguísticas dos países habitados pelos saami skolt).

Winford descreve um espectro das relações de contato: há, em um extremo, a comunidade de fala relativamente homogênea e composta de monolíngues, com pouco ou nenhum contato direto com falantes de outras línguas (ainda assim, podendo sofrer influência linguística externa). No meio do espectro, temos situações diversas de bi- ou multilinguismo dentro da comunidade, contato entre uma minoria linguística e o grupo dominante, ou ainda, situações de alto nível de bilinguismo individual. Um desequilíbrio nesse bilinguismo pode acarretar uma mudança de língua (language shift), sendo especialmente comum em grupos minoritários sob pressão de um grupo dominante. Por fim, na outra ponta do espectro, há comunidades altamente heterogêneas, com alto grau de multilinguismo individual (Winford, $2003: 26)$.

Até o final do século XIX, quando os saami skolt estavam sujeitos à Rússia, a comunidade de fala encaixava-se numa situação correspondente ao meio desse espectro, visto que, sendo uma minoria étnica, o bilinguismo é inevitável. A população possuía o saami skolt como L1, e alguma proficiência em russo era adquirida através da educação escolar - as crianças frequentavam a escola no inverno, que geralmente era ligada ou organizada nas igrejas ortodoxas, ou ao 
servirem o exército. Havia também contato com a língua e população russa em contexto religioso, pela visita de padres ortodoxos prestando serviços ou fazendo cerimônias, ou autoridades que visitavam os vilarejos para coletar impostos e taxas ou outros tipos de serviços oficiais (Linkola, A.;Linkola, 2003 : 132-4). Não há dados que forneçam uma estimativa quanto ao percentual populacional bilíngue ou grau de proficiência média em russo. Sabe-se, porém, que a influência do russo não era homogênea entre os dialetos e vilarejos do saami skolt: Itkonen (2011 [1958] : XVIII) relata que, no vilarejo de Petsamo (falante do dialeto de Paatsjoki), encontrava-se mais palavras de origem russa que o comum na língua, por influência do mosteiro local.

O autor também relata que tanto o saami skolt quanto o saami kildin e o saami ter possuem uma grande quantidade de material do finlandês (mais precisamente, carélio do leste) de diversas épocas - os empréstimos mais antigos referentes à commonwealth e ao cristianismo vêm do carélio ${ }^{23}$ - e reconhece centenas de empréstimos do escandinavo no saami skolt, em especial nos dialetos dos vilarejos de Näätämö, Paatsjoki, Petsamo e Muotka (são encontrados em menor frequência no saami ter) (Itkonen, 2011 [1958]: XX).

Não foram encontrados registros detalhados a respeito da intensidade de contato dos saami skolt com o finlandês, uma língua tipologicamente muito mais próxima do saami do que o russo. Como padrão de comparação, vale citar que os povos saami da porção oeste da Lapônia estavam em contato com as línguas escandinavas (sueco e norueguês), diferença esta que se reflete na análise dos empréstimos lexicais nas diferentes línguas saami, ainda que, conforme citado anteriormente, também haja empréstimos das línguas escandinavas no saami skolt.

\footnotetext{
${ }^{23}$ Os carelianos, e, antes deles, os vépsios ou os vóticos, foram os principais comerciantes e intendentes dos saami na região. ("die Karelier - und vor ihnen vielleicht die Vepsen oder Woten — sind ja in dieser Gegend die ältesten Geschäftsfreunde und Besteuerer der Lappen gewesen." Itkonen 2011 [1958] : XX.
} 
Após o período de guerras e realocação, entre os saami skolt realocados na região de Sevetijärvi (parte do município de Inari, Lapônia finlandesa), relata-se que, até os anos 70, devido às residências serem espalhadas por um território amplo, não havia oferta de escolas em distância favorável, culminando com a decisão institucional de realocar as crianças em residências estudantis, longe dos vilarejos e da família, durante toda a idade escolar, para que recebessem educação formal - em finlandês. Uma vez de volta aos vilarejos, em período de férias ou após completar os estudos, as crianças recusavam-se a falar o saami skolt, e expressavam vergonha das vestimentas tradicionais de seus pais (Linkola, $2003: 204)$.

Neste ponto histórico pode-se identificar o maior golpe para a manutenção da língua ${ }^{24}$ - a estigmatização cultural da minoria saami skolt, promovida pela inserção forçada desta na sociedade finlandesa, passou a ser uma barreira para que a transmissão da língua nas gerações nascidas a partir da década de 50 fosse efetiva.

No final da década de 50, a vasta maioria dos saami skolt já havia se tornado bilíngue em finlandês. Sob as consequências sociais e linguísticas citadas anteriormente, as famílias saami skolt passaram a incentivar casamentos com finlandeses, ao mesmo tempo que os mais velhos passaram a utilizar o finlandês para dirigiremse aos filhos (Feist, 2010 :22), quando não, em casos extremos, alternaram língua doméstica para o finlandês mesmo entre si (Linkola, 2003 : 204). De modo geral, ocode switching com finlandês é comum e largamente praticado nos dias de hoje por falantes fluentes de saami skolt (Feist, 2010 :23-24), algo que não há relatos de ter acontecido com o russo.

Um estímulo à manutenção da língua foi o estabelecimento de uma ortografia oficial, idealizada em 1971 e lançada em 1973, juntamente com a primeira gramá-

\footnotetext{
${ }^{24}$ ' $T$ T] he preservation by a speech community of its native language from generation to generation", Winford 2003:1.
} 
tica descritiva da língua, Koltansaamen Opas ("Guia do saami skolt", Korhonen et al. 1973. A partir dos anos 90, programas de preservação e imersão linguística passaram a tomar forma, já que o finlandês crescia como língua majoritária, mesmo no âmbito doméstico. Os programas de imersão constituíam em isolar crianças em ambiente monolíngue saami skolt, sem que tivessem qualquer contato com o finlandês. Atualmente, é garantida pelo Estado educação bilíngue finlandês-saami skolt.

\subsubsection{Imitação e adaptação}

Retomando um conceito de Van Coetsem, temos:

"[T]here are two major processes, imitation (Haugen's "importation") and adaptation (Haugen's "substitution"). As van Coetsem (1988:7) explains, imitation produces a deviation from [innovation in-DW] the RL, yielding a borrowing that is often only an approximation to the SL item. Adaptation, on the other hand, "is an adjustment to the native rl which does not modify that language"(1988:9)." (Winford, $2005: 143$ )

Um mesmo item pode ser uma imitação quanto ao seu significado léxico, mas não quanto à fonologia (ou seja, adapta-se ao sistema fonológico da línguarecipiente), como no exemplo a seguir, ou vice-versa (Van Coetsem, 1988: 8).

Analisando a palavra spä'sseb ['spas:jep] ("obrigado", agradecimento), que Riessler (2009: 404) citou como empréstimo do russo spasíbo [spe'sibə], temos uma imitação no campo lexical, mas não no fonológico: quando absorvido pela língua saami skolt, foi adaptado à sua fonologia, ao que, por exemplo, a sílaba acentuada passou a ser a primeira (que é o padrão de acentuação da língua saami skolt) e não a segunda, como ocorre na palavra original em russo. As línguas saami kildin e ter, mais próximas ao saami skolt, fizeram esta mesma imitação lexical com adaptação fonológica.

Como exemplos de adaptação que incluem derivação, podemos citar alguns verbos em saami skolt construídos a partir de substantivos do russo e do finlandês, 
como: škoou'l'jed ("educar"), do russo škola ("escola"), ou kruu'n'jed ("coroar") do finlandês kruunu ("coroa"), que entraram no saami skolt e foram incorporados a alguma das suas classes flexionais. Alguns verbos derivados de substantivos do russo, no entanto, não se comportam de maneira regular, diferindo dos verbos nativos do saami skolt ao não serem afetados pela gradação consonantal, um dos fenômenos morfológicos mais complexos e típicos das línguas do ramo saami (Feist, $2010: 134)$.

O mesmo ocorre quanto ao empréstimo de substantivos: estes recebem sufixos flexionais de caso tal qual os substantivos nativos da língua, e estão sujeitos aos mesmos processos morfo-fonológicos (como alternância de altura das vogais e palatalização), no entanto, apresentam ausência ou irregularidades na gradação consonantal (Feist, $2010: 165)$.

Tentando analisar tais casos nos termos propostos, estes se encaixam melhor se forem considerados uma forma de adaptação e não de imitação, visto que de fato houve um ajuste em todos os níveis para a língua recipiente, ainda que não completo; e as irregularidades não causaram modificações generalizadas no comportamento da gradação consonantal da língua, e sim somente criaram exceções restritas a um grupo de palavras de substrato estrangeiro.

\subsubsection{As relações de contato no estudo da proto-língua}

A compreensão do percurso diacrônico até a formação das línguas saami modernas e a reconstrução de uma proto-língua saami esbarram em dificuldades como lacunas históricas sem achados arqueológicos, que dificultam a elaboração e confirmação de teorias. No entanto, muito pode ser deduzido a respeito do tema com base em indícios fragmentados, o método histórico-comparativo e tendo como apoio o Escandinavo Antigo, língua atestada pelas chamadas runas, que manteve contato com o ramo saami. 
Um dos primeiros questionamentos que os estudos a respeito da família urálica encontram é questão de se o saami e o fínico já foram um mesmo subgrupo, vindos de um proto-fino-saami. Em Anttila (1989), essa versão é adotada, ao que, na árvore da família urálica (figura 1.1), o balto-fínico é composto de dois núcleos, um correspondente às línguas balto-fínicas propriamente ditas, e outro, às línguas saami. O autor explica esse posicionamento argumentando que as línguas saami, por serem mais proximamente relacionadas ao balto-fínico, provavelmente se ramificaram de um núcleo acima, um “Early Baltic Finnic" (Anttila, 1989:302).

Alguns autores nomeiam essa forma de análise como hipótese de continuidade: a partir de uma unidade (podendo ser nomeada proto-fínico, proto-balto-fínico, ou proto-fino-saami, dependendo do autor), dois ramos separaram-se conforme ocorria o contato e assimilação linguística de outros povos, que teria culminado, por razões desconhecidas, numa divisão linguística e cultural: o fínico (ou baltofínico) passou a se desenvolver na região leste báltica e na costa da Finlândia, ao passo que o saami teria começado a se desenvolver no interior da Finlândia (Parpola, 2012:146-7). Ainda de acordo com a hipótese de continuidade, a separação geográfica teria contribuído para a acentuação da distância entre estes dois ramos, o fínico e o saami, visto que os contatos linguísticos com outros povos se diversificaram. Um aspecto particular do ramo saami é o suposto contato com um povo não indo-europeu sobre o qual muito pouco se conhece, os paleo-lapões, que teriam sido assimilados pelos saami, mas deixado traços de sua língua no substrato de empréstimos lexicais (Parpola, 2012:147).

A existência de um subgrupo genético a partir do qual o balto-fínico e o saami se ramificaram é questionada por analises posteriores, que demonstraram que características em comum entre os dois ramos são mais provavelmente resultado de contato linguístico do que herança genética. Aikio cita como exemplo isomorfias morfossintáticas e empréstimos do fínico para o saami em grande número 
(2012:68). Além disso, vocabulário compartilhado é um critério fraco para defender a existência de um subgrupo, já que inovações lexicais podem facilmente se disseminar entre línguas e dialetos já separados (Fox 1995: 220 apud Aikio 2012: 68). Aikio também cita uma complicação específica para este caso, a nativização etimológica - neste processo, falantes bilíngues em duas línguas relacionadas identificam correspondências de padrões sonoros e as aplicam produtivamente, ao nativizarem empréstimos em formas que estão de acordo com correspondências sonoras atestadas em vocabulário cognato (Aikio, 2012:68).

Ainda assim, mesmo que seja impossível chegar a uma resposta final sobre a existência ou não deste subgrupo, Aikio (2012:69) coloca que, de qualquer forma, é nítido que o fínico e o saami derivaram de uma mesma origem, seja ela o "fino-saami" ou uma ramificação mais abrangente a partir da qual outras línguas urálicas ocidentais também se derivaram. Além disso, é evidente que o pré-proto-saami e o pré-proto-fínico se desenvolveram em proximidade geográfica, visto que possuem pistas de consistente interação areal. Um outro ponto de vista, desenvolvido a partir da análise de empréstimos de línguas germânicas e bálticas, levanta a possibilidade de que, no lugar da unidade "fino-saami", o que havia era um continuum dialetal (Koivulehto 1999 apud Aikio 2012: 73). Aikio reitera essa teoria:

"[I]t seems likely that 'Finno-Saamic' was a dialect continuum instead of a proto-language, and that different speech communities within this continuum had different geographic patterns of interaction with outside groups. Both the speakers of Pre-Proto-Saami and Pre-Proto-Finnic have been in independent contact with Germanic speakers, even though a part of the loanwords have dif-fused between the dialects and eventually become a part of both Finnic and Saami lexicon. On the other hand, only the speakers of Pre-Proto-Finnic dialects had any signicant contacts with Baltic-speaking groups, and the Baltic loans found in Saami have secondarily diffused through the dialect continuum. Such an account explains why nearly all Baltic loans in Saami are shared with Finnic." (Aikio, 2012:74)

Através da análise do substrato do Escandinavo Antigo, nota-se uma maior 
presença de empréstimos do proto-escandinavo nas línguas saami ocidentais, geograficamente mais próximas dos povos escandinavos, e tal contato desaparece gradativamente no continuum rumo ao leste, chegando finalmente às línguas orientais, saami inari e skolt, que aparentam ter adquirido tal substrato por via do contato com o saami norte, e por fim saami kildin e ter, que apresentam pouco resquício (Aikio, 2012: 76-7).

A teoria do continuum dialetal destaca-se por ir contra a pressuposição de uma proto-língua como um objeto homogêneo, uma condição inexistente nas línguas naturais. Atualmente, a hipótese da continuidade caiu em desuso, ainda que nem tudo proposto pela teoria precise ser descartado. A possibilidade de contato do proto-saami com o paleo-lapão é bem provável, sustentada inclusive pela vasta quantidade de raízes de palavras do proto-saami de etimologia desconhecida - aproximadamente 550, mais de um terço de todo o léxico reconstruído (Sammallahti, 1998:125). Quanto à semântica dessas palavras, a vasta maioria se encaixa nos campos semânticos que tipicamente agrupam palavras de substrato estrangeiro: natureza, nomes de animais, características topográficas e aspectos climáticos (Aikio, 2012: 85). Neste caso, as referências climáticas e biológicas são de elementos típicos da Lapônia, reforçando a possibilidade do substrato ser paleolapão. A comparação entre mudanças fonológicas diacrônicas no proto-saami e em como - e se - estas se refletiam em palavras adquiridas por contato é uma forma de obter pistas para chegar em datas de quando determinada situação de contato aconteceu, e assim mapear o percurso da proto-língua.

Analisando o substrato (possivelmente) paleo-lapão no proto-saami, que passou por uma reorganização completa de seu sistema vocálico por volta de 300 AC, Aikio sustenta que o contato entre os dois ocorreu, ou ao menos manteve-se, depois desse período, visto que o léxico deste substrato apresenta combinações vocálicas não etimológicas, que teriam sido nativizadas caso estivessem presentes 
na língua anteriormente à mutação vocálica (Aikio, 2012 : 87).

Tal ponto de vista não se aprofunda na possibilidade de empréstimo estrutural ou mudança fonológica induzida por contato, priorizando haver mudanças internas na língua de forma independente, e que estas eventualmente se refletem no léxico estrangeiro absorvido. Naturalmente, seria muito difícil avaliar a possibilidade de empréstimo estrutural entre línguas reconstruídas, visto que ou a língua-recipiente, ou a língua-fonte, ou em alguns casos ambas, são línguas hipotéticas (como o paleo-lapão, extinto sem deixar registros, e o proto-saami).

Nos estudos a respeito da proto-língua saami, é recorrente se referir a uma reorganização do sistema vocálico, que foi nomeada por Aikio (2012) de Grande Mutação Vocálica do Saami:

"In contrast to Finnic, Proto-Saami completely reorganized the Uralic vowel system via a complex series of developments involving shifts, mergers, and splits. Also the vowel harmony characteristic of Finnic and many other Uralic languages was lost, and many stressed vowels were lengthened and subsequently diphthongized. The result of this 'great Saami vowel shift' was radically different from both the Uralic and the Finnish vowel paradigm" (Aikio, 2007:25)

Tabela 1.1: Mutação vocálica do saami. Adaptado de Aikio 2007 : 25-6.

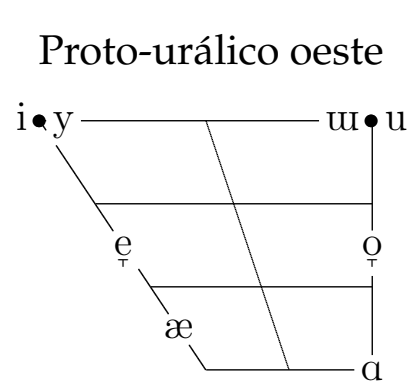

Proto-fínico e finlandês

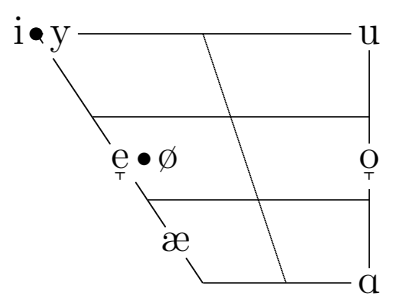

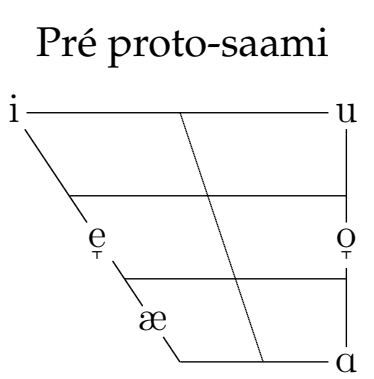

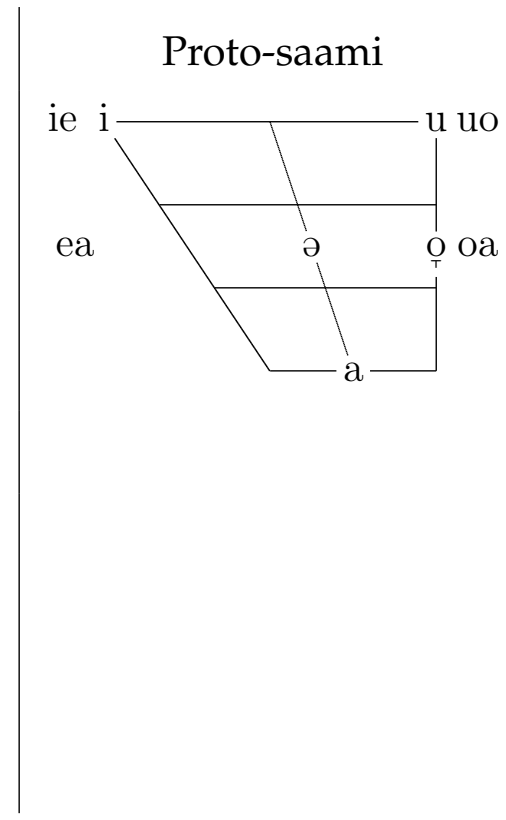


Nos quadros vocálicos propostos acima, fiz uso do IPA. Uma discussão mais detalhada a respeito do proto-saami, suas relações de contato e a formação das línguas saami modernas fogem do escopo desta pesquisa; no entanto, são campos que ajudam a compreender a complexidade e relevância do estudo do sistema vocálico das línguas saami.

\subsection{A língua atualmente}

Uma panorama detalhado a respeito da situação atual da língua, incluindo o status sociolinguístico, viabilidade, distribuição e número de falantes foi feita por Feist (2015 : 20-29), em A Grammar of Skolt Saami, a partir da qual retiramos os dados apresentados nessa seção, a menos quando indicado de outra forma.

O status sociolinguístico do saami skolt traz complexidade para uma estimativa do número de falantes, visto que a proficiência varia entre total fluência e noções muito básicas Feist (2015:22). Algumas estimativas apontavam por volta de 300 falantes na Finlândia (Kulonen et al. 2005:396 apud Feist 2015:22), mas outras fontes indicam que há somente por volta de 150 (sendo a população étnica por volta de 600 pessoas). Já no lado russo da fronteira, há dados que indicam haver menos de 20 falantes na península de Kola, dentre os 500 saami skolt que se estima haver na Rússia.

O uso do saami skolt acontece principalmente entre falantes acima dos 40 anos, com parentes ou vizinhos dentro da mesma faixa etária. Em segundo lugar, vem o uso doméstico. (Jefremoff 2005: 42 apud Feist $2010: 20$ ). Os falantes mais velhos, em especial os nascidos nas siidas originais, que têm o saami skolt como primeira língua, são também os com menor domínio do sistema de escrita oficial. Numa situação oposta, estão as novas gerações, que têm acesso ao saami skolt pela educação formal, mas, mais frequentemente, proficiência baixa, mantendo o saami skolt como L2 e o finlandês como L1. 
Tais circunstâncias se encaixam no que Winford chamou de mudança da língua (language shift), quando há um abandono total ou parcial da língua nativa de um grupo em favor de outra - às vezes, com aquisição completa da língua-alvo, com pouca ou nenhuma influência da língua nativa no grupo da mudança (Winford, 2003 : 15). Ainda não foram desenvolvidas pesquisas a respeito de se há influência do saami skolt no grupo no qual ocorreu a mudança. A morte da língua (language death) é um risco real, dada a pressão da língua nacional e o quanto a manutenção do saami skolt já está comprometida.

Nestes dois momentos da comunidade de fala de saami skolt (quando o bilinguismo era com o russo, e atualmente, que é com o finlandês), podemos analisar a diferença entre empréstimo (borrowing) e imposição (imposition), definidos quanto a dois tipos de transferência - agentividade da língua-recipiente, e agentividade da língua-fonte (Winford, 2005 : 143).

Até antes da realocação para a Finlândia, a língua saami skolt era a línguarecipiente de empréstimos do russo (língua-fonte) - e, visto que o empréstimo ocorria através de falantes nativos (L1) de saami, temos agentividade da línguarecipiente. Atualmente, através das circunstâncias expostas, podemos deduzir que o status da língua saami skolt favorece mais a ocorrência da imposição, na qual o finlandês, como língua-fonte, é a dominante para o falante, e, a partir dela, material é transferido para a língua-recipiente, na qual o falante tem menos proficiência (portanto, agentividade da língua-fonte). Este último caso trata-se de uma suposição - é algo a ser investigado, não havendo ainda pesquisas a respeito. 


\section{Aspectos da língua}

O presente capítulo descreverá alguns aspectos da língua, majoritamente referentes à fonética e fonologia, tendo como base principal o trabalho A Grammar of Skolt Saami, de Timothy Feist (2015).

O saami skolt, tal qual as outras línguas saami, é uma língua nominativoacusativa, sem flexão de gênero, que, morfologicamente, combina flexão e aglutinação. Um substantivo pode se flexionar em número (singular e plural) e em 9 casos, a saber: nominativo, acusativo, genitivo, ilativo, locativo, comitativo, abessivo, essivo e partitivo (sendo que no plural, não se flexionam no essivo e partitivo); e distribuem-se em 12 classes flexionais. Pronomes pessoais, além do previamente citado, também se flexionam no dual. Os adjetivos, quando em função predicativa, se flexionam da mesma forma que os substantivos; e não se flexionam quando na posição atributiva.

Apesar de haver o dual nos pronomes pessoais, a classe verbal flexiona-se em $1^{\mathrm{a}}, 2^{\mathrm{a}}$ e $3^{\mathrm{a}}$ pessoa somente no singular e plural (os pronomes pessoais no dual fazem uso do verbo no plural). Uma particularidade interessante da língua é a $4^{\text {a }}$ pessoa no paradigma verbal, indefinida quanto à quantidade.

Quanto aos tempos verbais, há presente e passado, e quatro modos: indicativo, potencial, condicional e imperativo. Verbos também flexionam-se em 12 formas não finitas, incluindo a participial e a conegativa (Feist, 2015 : 106). No saami skolt, tal qual no finlandês, e possivelmente na maioria das línguas fínicas, uma sentença negativa constrói-se com um verbo auxiliar de negação, que expressa pessoa e número, e o verbo principal é utilizado numa forma sem essas flexões, que é a forma aqui chamada de conegativa. No saami skolt, esta forma é utilizada em 
sentenças negativas no presente do indicativo (para todas as pessoas, sendo que a $4^{\mathrm{a}}$ possui uma forma conegativa específica). A seguir, um exemplo retirado de Feist (2015):

$$
\text { tõk a'lğğe pää'rn ooccâd, jeät kaunnu }
$$

dist.PL.NOM begin.PST.3PL boy.SG.ACC seek.INF NEG.4 find.CNG2 'they start to look for the boy, (one) does not find (him)' [MM:14]

(Feist, 2015 : 229)

No exemplo acima, notar que é o verbo de negação que se flexiona; o verbo principal não recebe marca de pessoa ou número.

\subsection{Estrutura silábica e acentuação}

Nas línguas da família fino-úgrica, vê-se como padrão o acento primário na primeira sílaba à esquerda, como em finlandês, húngaro, mansi, livônio, entre outras (Van Der Hulst, 2010 :487-493)). O saami skolt não foge à regra. A estrutura das palavras do saami skolt, conforme descrito pot Sammallahti (1998:39 apud Feist 2015 :41), é composta por pelo menos uma sílaba acentuada, que pode ser seguida por uma ou duas sílabas átonas. Esse conjunto forma um grupo acentual ("stress group"). Uma palavra com mais de três sílabas irá formar mais de um grupo acentual, com um acento secundário. Feist (2015:42) usa como exemplo a palavra ǩiiččéped (assistir.PRS.2PL para expôr a estrutura de uma palavra no saami skolt:

$\check{\mathrm{k}}-$

ii-

čč-

$e^{\prime}-$

$\mathrm{p}-$

e-

$\mathrm{d}$

initium vowel centre consonant centre latus consonant margin vowel margin finis 
O vowel centre é o núcleo da sílaba; consonant centre refere-se à consoante entre este e o núcleo da sílaba seguinte. Latus é o nome dado ao primeiro núcleo átono que o segue, e, no caso de grupos acentuais trissilábicos, a consonant margin separa o latus do próximo núcleo silábico átono (vowel margin).

\subsection{Duração}

Além do valor dos fonemas, o saami skolt constrói contrastividade também através da duração - isso se aplica tanto a vogais e consoantes, quanto a ditongos e encontros consonantais.

A ortografia oficial, tal qual o finlandês, expressa vogais longas grafando-as duplamente, como ååumaž ("ser humano", SG.NOM, em contraste a vogais simples (ånmmu, ser humano.SG.GEN), e da mesma forma que representa consoantes geminadas, como muõrr ("árvore", SG.NOM; comp. muõr, "árvore", sG.GEN).

Quanto aos encontros consonantais, quando breves, representa-se através de duas consoantes simples, dobrando a segunda consoante para expressar um encontro consonantal longo: vuõptt vuõpt ("cabelo", SG.NOM e SG.GEN, respectivamente).

Foneticamente, porém, a variedade na duração é mais complexa, havendo três quantidades distintas (que foram chamadas por Itkonen (2011 [1958]) de breve, semilonga e longa). No ortografia, tal distinção não é representada, mas, visto que há aumento compensatório entre vogais e consoantes, cabe ressaltar que uma vogal longa seguida de uma consoante breve é foneticamente mais longa que uma vogal longa seguida de uma consoante geminada breve. Assim, pode-se reconhecer uma geminada longa (ainda que grafada da mesma forma que uma geminada breve), por vir em seguida a uma vogal breve. Exemplos: 


$$
\begin{array}{ll}
\text { põol (temer.IMP.2SG) } & \text { vogal longa - consoante breve } \\
\text { põollâd (temer.INF) } & \text { vogal de duração intermediária - geminada breve } \\
\text { põlle (temer.PST.3.PL) } & \text { vogal breve - geminada longa }
\end{array}
$$

(Adaptado de Feist $2015: 76$ )

Quanto aos ditongos, pode-se deduzir que têm duração longa quando seguindos por uma consoante simples; mas sua duração não é marcada ortograficamente - assim, quando seguido por uma consoante geminada, não se pode dizer se será longa ou breve. Uma proposta é, então, usar a marca ' entre a consoante geminada para representar a duração longa, como em muõ'r're ("árvore", SG.ILL).

\subsection{Consoantes}

O saami skolt possui em seu inventário 31 consoantes. O sistema de escrita da língua é bastante detalhado, e faz uso de caracteres que coincidem com símbolos do IPA, porém, com outro valor sonoro. A seguir, uma comparação do inventário de consoantes de acordo com o IPA e de acordo com a ortografia oficial (em

\begin{tabular}{|c|c|c|c|c|c|c|c|c|c|c|c|c|}
\hline \multirow[b]{2}{*}{ Plosive } & \multicolumn{2}{|c|}{ Bilabial } & \multicolumn{2}{|c|}{$\begin{array}{l}\text { Labio- } \\
\text { dental }\end{array}$} & \multirow[t]{2}{*}{ Dental } & \multicolumn{2}{|c|}{ Alveolar } & $\begin{array}{c}\text { Post- } \\
\text { alveolar }\end{array}$ & \multicolumn{2}{|c|}{ Palatal } & \multicolumn{2}{|c|}{ Velar } \\
\hline & $\mathrm{p}$ & $\mathrm{b}$ & & & & $\mathrm{t}$ & $\mathrm{d}$ & & $\mathrm{c}$ & I & $\mathrm{k}$ & $\mathrm{g}$ \\
\hline Nasal & & $\mathrm{m}$ & & & & & $\mathrm{n}$ & & & $\mathrm{n}$ & & 1) \\
\hline Trill & & & & & & & $r$ & & & & & \\
\hline Fricative & & & $\mathrm{f}$ & $\mathrm{v}$ & ə & s & $\mathrm{z}$ & $\int$ & & $\mathrm{j}$ & $\mathrm{x}$ & $\mathrm{y}$ \\
\hline Affricate & & & & & & $\widehat{\text { ts }}$ & $\widehat{\mathrm{dz}}$ & $\widehat{\mathrm{t} \int} \widehat{\mathrm{dz}}$ & & & & \\
\hline Approximant & & & & & & & & & & $\mathrm{j}$ & & $\mathrm{w}$ \\
\hline Lateral & & & & & & & 1 & & & $\Lambda$ & & \\
\hline
\end{tabular}
destaque, os caracteres cujo grafema difere do símbolo atribuído àquele som no IPA).

Figura 2.1: Inventário de consoantes - IPA (Feist, 2015:45). 


\begin{tabular}{|c|c|c|c|c|c|c|c|c|c|c|c|c|c|}
\hline \multirow[b]{2}{*}{ Plosive } & \multicolumn{2}{|c|}{ Bilabial } & \multicolumn{2}{|c|}{$\begin{array}{l}\text { Labio- } \\
\text { dental }\end{array}$} & \multirow[t]{2}{*}{ Dental } & \multicolumn{2}{|c|}{ Alveolar } & \multicolumn{2}{|c|}{$\begin{array}{c}\text { Post- } \\
\text { alveolar }\end{array}$} & \multicolumn{2}{|c|}{ Palatal } & \multicolumn{2}{|c|}{ Velar } \\
\hline & $\mathrm{p}$ & $\mathrm{b}$ & & & & $\mathrm{t}$ & $\mathrm{d}$ & & & $\check{\mathrm{k}}$ & $\check{\mathrm{g}}$ & $\mathrm{k}$ & $\mathrm{g}$ \\
\hline Nasal & & $\mathrm{m}$ & & & & & $\mathrm{n}$ & & & & nj & & n \\
\hline Trill & & & & & & & r & & & & & & \\
\hline Fricative & & & $\mathrm{f}$ & $\mathrm{v}$ & đ & s & $\mathrm{z}$ & $\check{\mathbf{s}}$ & $\check{z}$ & & $\mathrm{j}$ & $\mathrm{h}$ & $g$ \\
\hline Affricate & & & & & & c & 3 & $\check{c}$ & $\check{3}$ & & & & \\
\hline Approximant & & & & & & & & & & & $\mathrm{j}$ & & $\mathrm{v}$ \\
\hline Lateral & & & & & & & 1 & & & & $\mathrm{lj}$ & & \\
\hline
\end{tabular}

Figura 2.2: Inventário de consoantes - grafemas da língua (Feist, 2015 : 45).

A palatalização é um traço suprassegmental e distintivo no saami skolt. Consoantes palatalizadas se opõem a consoantes palatais, conforme o exemplo a seguir:

$\begin{array}{llll}\text { Pleno } & \text { mâânn } & {[\mathrm{me}: n:]} & \text { ir.PRS.3SG } \\ \text { Palatalizado } & \text { mâấnn } & {[\text { me:n:j }]} & \text { ovo.SG.NOM } \\ \text { Palatal } & \text { mâấnnj } & {[\text { me:n: }]} & \text { nora.SG.NOM }\end{array}$

(Feist, 2015 : 78)

\subsection{Vogais}

De acordo com a gramática de Feist (2015), o saami skolt possui 9 fonemas vocálicos (conforme veremos em 3.2, há outros inventários com certas divergências). Nesse trabalho, o autor escolheu representar os segmentos vocálicos da língua usando os grafemas oficiais ao longo da gramática, fornecendo uma equivalência aproximada no IPA para cada um deles previamente. Segue um quadro vocálico que faz uso dos grafemas da língua, proposto por Feist (2015), com o intuito de ilustrar as propriedades das vogais quanto a altura e posição anterior/posterior, e 
em seguida as equivalências grafema $\mathrm{x}$ fonema propostas pelo mesmo autor: ${ }^{1}$

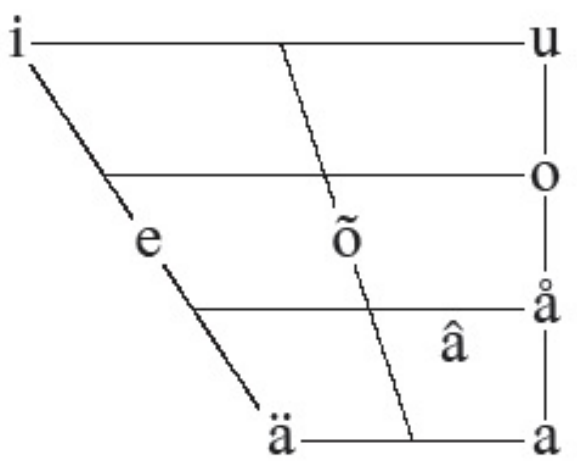

Figura 2.3: Quadro de vogais do saami skolt (utilizando os grafemas da língua). Retirado de Feist 2015 : 64 .

Aa $/$ a
Ââ $/$ e/
Ee /e/
Ii /i $/$
Oo /o/
Õõ /ə/
Uu /u/ /w /
Åå /ə/
Ää /a/

(Feist, 2015:38)

O grafema < õ > está presente também na língua estoniana; ao contrário do português, não está relacionado à nasalidade.

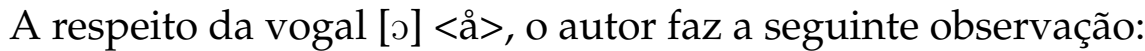

\footnotetext{
1 "The IPA vowel symbols are based on the closest cardinal vowel, and are not precise phonetic representations." (Feist, 2015:37)
} 
"The open-mid back vowel $<a ̊$ deserves a special mention. In many idiolects, this vowel undergoes a noticeable change in quality, beginning with a quality closer to the IPA vowel [o] and ending with a quality somewhere between the back, rounded IPA vowels [?] and [e]. Phonetically, then, it is more reminiscent of a diphthong. However, it is not treated as a diphthong from a phonological viewpoint for two reasons: firstly, because this does not appear to be a universal feature among all speakers; and secondly, because it alternates with a monophthong, $\langle 0\rangle$, when subject to vowel height variations [...] and for all other purposes shares the same distribution and behaviour as other monophthongs." (Feist, 2015:66)

\subsubsection{Vogais palatalizadas}

O saami skolt tem a palatalização como fenômeno suprassegmental, de forma que as vogais, quando palatalizadas, são realizadas de modo levemente mais elevado e mais anterior, podendo ser interpretadas como alofones da forma não palatalizada. Isso corresponde a uma mudança nos valores de primeiro (F1) e segundo formante (F2) dessas vogais. Ladenfoged, P.; Johnson (2011) fornecem a seguinte explicação a respeito do que são esses formantes:

\footnotetext{
"In summary, vowel sounds may be said on a variety of notes (voice pitches), but they are distinguished from one another by two characteristic vocal tract pitches associated with their overtones. One of them (actually the higher of the two) goes downward throughout most of the series heed, hid, head, had, hod, hawed, hood, who'd and corresponds roughly to the difference between front and back vowels. The other is low for vowels in which the tongue position is high and high for vowels in which the tongue position is low. It corresponds (inversely) to what we called vowel height in articulatory terms. These characteristic overtones are called the formants of the vowels, the one with the lower pitch (distinguishable in creaky voice) being called the first formant and the higher one (the one heard when whispering) the second formant." (Ladenfoged, P.; Johnson, 2011:22-23)
}

A seguir, temos a análise acústica das vogais distintivas do saami skolt quanto à posição dos formantes, realizada por Feist (2015), comparando as versões não palatalizadas e palatalizadas (representadas pelo sinal' '). A análise foi feita atrravés da mesma metodologia e usando gravações do mesmo falante. 


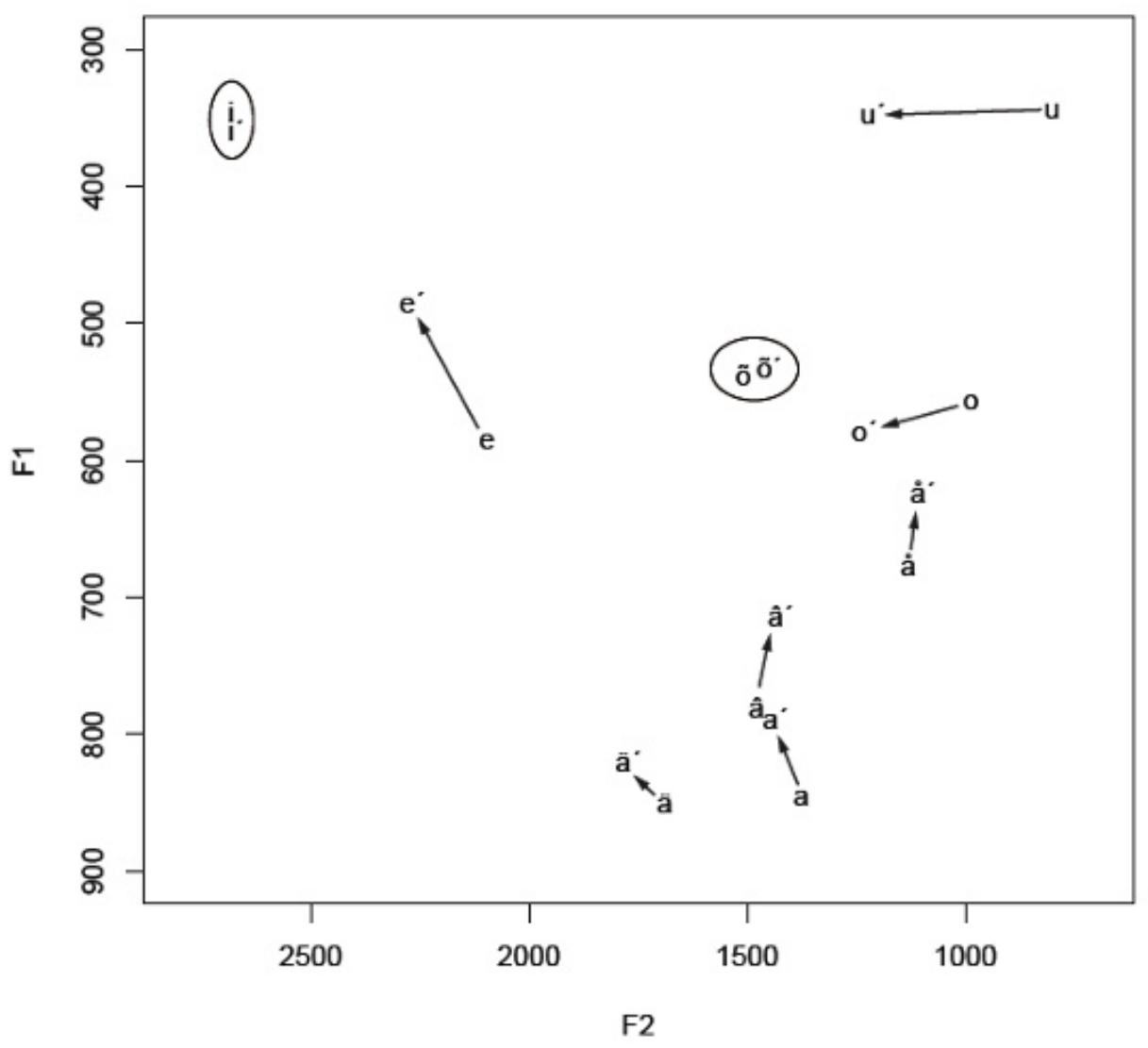

Figura 2.4: Valores de F1 e F2 para os nove fonemas e suas versões palatalizadas, produzidos por uma falante adulta (Feist, 2015:68).

Considerando, portanto, que o valor de F1 aumenta proporcionalmente à abertura da vogal, vemos que as vogais que tiveram uma redução mais significativa no valor de F1, se tornando mais agudas, foram $<\mathrm{e}>,<\mathrm{a}>,<\mathrm{a}\rangle,<\mathrm{a}>$ e $<$ ä $>$; todas dividem o traço [-alto], e, com a exceção de $<$ å $>$, [-arredondado]. A vogal posterior baixa $<$ a $>$ (correspondente a IPA $[a]$, , quando palatalizada $\left(<\mathrm{a}^{\prime}>\right)$, eleva-se e frontaliza-se ao ponto de ocupar a mesma posição acústica de <â> não palatalizada. Esta, por sua vez, eleva-se, mas não se anterioriza quando palatalizada.

Quanto à alteração nos valores de F2, que ficam mais altos conforme a vogal se frontaliza, temos uma frontalização acentuada nas vogais posteriores arredondadas $<\mathrm{u}>$ e $<0>$, que se frontalizaram mas não se elevaram $(<0>$, inclusive, indica um sutil aumento de F1), e em $<$ e $>$ e $<$ ä $>$, que passaram por ambos os processos. 
As vogais $<\mathrm{i}>$ e $<\tilde{o}>$ notadamente destacam bem menos variação no valor dos formantes frente à palatalização em comparação às outras vogais. De acordo com a Teoria da Dispersão (Flemming, 2004), na organização dos sons distintivos numa língua, procura-se: 1. maximizar a distinção dos contrastes; 2. minimizar o esforço articulatório; 3. maximizar o número de contrastes. Comparando línguas diversas, nota-se que vogais anteriores são geralmente não arredondadas, ao passo que vogais não baixas posteriores são normalmente arredondadas (Flemming, 2004:3), características que se aplicam também ao saami skolt. A variação entre posteriorização e arredondamento maximiza a diferença na frequência de F2 entre vogais anteriores e posteriores, tornando-as mais distintas. Elas diferem principalmente quanto ao F2, sendo que as anteriores possuem um valor de F2 mais alto, e as posteriores, mais baixo. $\mathrm{O}$ arredondamento reduz o valor de F2, de modo que o contraste de F2 é mais distinto quando ocorre entre vogais anteriores não arredondadas e vogais posteriores arredondadas (Flemming, 2004: 4). Observando a posição dos formantes na forma plena e palatalizada, vemos que, quando uma vogal passa a ocupar a posição de outra ao palatalizar-se $\left(<\mathrm{a}^{\prime}>\right.$ e $<\hat{\mathrm{e}}>$, esta segunda também se realoca $\left(<\hat{a}^{\prime}>\right)$, garantindo, assim, a manutenção da distinção dos contrastes.

Em Sammallahti e Mosnikoff (1991 apud Feist 2015:69, foi sugerido um quadro fonêmico de dez fonemas, sendo o fonema a mais $/ \varepsilon /$ (e tornando, dessa forma, o quadro vocálico mais simétrico) - porém, o ambiente fonológico mostra uma variação entre /e/ nas palavras palatalizadas e / $\varepsilon /$ nas não palatalizadas, de modo que, mais possivelmente, /e/ e / $/$ / sejam alofones. A possibilidade é reforçada pela ausência de pares mínimos exatos. Feist escolhe /e/ na sua lista de equivalências fonêmicas para os grafemas, e interpreta como um caso de alofones em distribuição complementar.

O fenômeno de palatalização é muito ligado à presença de uma vogal anterior 
fechada ou média $(<\mathrm{i}>$ ou $<\mathrm{e}>$ ) na sílaba seguinte. A adição de um sufixo com tais vogais pode desencadear palatalização numa raiz não palatalizada (sendo assim, pode-se classificar o fenômeno como morfofonológico). Um exemplo são os verbos com infinitivo terminado em $-\mathrm{ed}$, como $<$ kå'dded $>$ 'matar', $<$ tie'tted $>$ 'saber' e < pue'tted > 'vir'. A vogal do ilativo <e > causa o mesmo em substantivos da classe 1A:

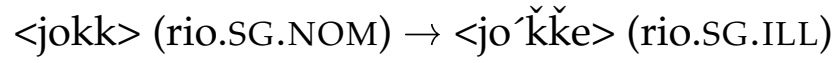

$<$ toll $>$ (fogo.SG.NOM) $\rightarrow<$ to'lle> (fogo.SG.ILL) (Feist, 2015: 82)

No caso da classe $1 \mathrm{C}$, que se adiciona a vogal do ilativo $<\mathrm{a}>$, temos o oposto: pode ocorrer a perda de palatalização de uma raiz palatalizada..

\subsubsection{Ditongos}

O saami skolt possui 8 ditongos, que são sempre abertos. Conforme tratado em 1.4.2, os ditongos nas línguas saami possivelmente se desenvolveram a partir de vogais simples, no processo chamado de Grande Mutação Vocálica do Saami. No caso de aparentes ditongos na ortogafia oficial, como $<$ ai $>$ ou $<$ au $>$, trata-se, geralmente, de uma aproximante /j/ ou /w/, no início de um encontro consonantal. Em palavras como ååumaž ("ser humano", SG.NOM), tínhamos originalmente variantes com um $l$ velarizado, como veremos em mais detalhes nas próximas seções.

A palatalização tem um efeito mais forte nos ditongos, especialmente nos que terminam com uma vogal posterior ou central, do que nestes mesmos segmentos quando aparecem como vogais simples. Os ditongos não palatalizados (à esquerda) e suas versões palatalizadas (à direita, sendo <'> a marca ortográfica para palatalização) são: 


$$
\begin{aligned}
& \text { iâ ie' } \\
& \text { eâ eä' } \\
& \text { eä eä' } \\
& \text { uõ uõ' } \\
& \text { uå ué } \\
& \text { uâ ué } \\
& \text { uä uä' }
\end{aligned}
$$

(Feist, 2015 :71)

Quando palatalizados, os que terminam em vogal posterior, $<$ uå $>$, ou na vogal central baixa â, $<$ uâ $\rangle,<$ iâ $\rangle,<$ eâ $>$, se tornam, respectivamente, $<$ ue' $\left.^{\prime}\right\rangle_{1}<$ $\mathrm{ue}^{\prime}>,<$ ie' $^{\prime}>$ e $<$ eä' $>$.

Quanto aos ditongos não palatalizados terminados na vogal média central $<$ õ $>$, o efeito da palatalização não é representado ortograficamente na língua; no entanto, a vogal final do ditongo se eleva e frontaliza, ficando próxima a /i/. Assim, se a ortografia para os ditongos (apresentada acima) fizesse jus a

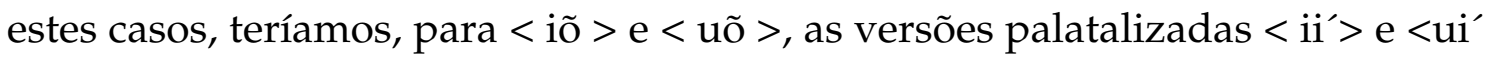
$>$, respectivamente. Mas, visto que as versões palatalizadas dos ditongos são tomadas como alofones das não palatalizadas, Feist decidiu seguir a grafia oficial da língua também nestes casos, fazendo apenas a breve observação citada.

Já quanto aos ditongos $<$ eä $>$ e $<$ uä $>$, afirma-se que, visto que são terminados em vogais anteriores, a ortografia permanece a mesma para as versões palatalizadas, com algumas exceções (como quando ocorre antes de geminada breve e encontro consonantal breve). Esta mudança nos ditongos ocorre numa palavra por efeito da palatalização na flexão verbal e nominal, como nos casos abaixo:

iõ $\rightarrow$ iõ $\tilde{o}^{\prime}$ tiõt't (mark.SG.NOM) $\rightarrow$ tiõ't'te (mark.SG.ILL)

iâ $\rightarrow$ ie' piâckk (fur.coat.SG.NOM) $\rightarrow$ pie'č̌ǩe (fur.coat.SG.ILL)

eâ $\rightarrow$ eä' teâtt (know.PRS.3PL) $\rightarrow$ teä't'te (know.PRS.3PL) 
eä $\rightarrow$ eä' seävv (wave.PRS.3PL) $\rightarrow$ seä'v've (wave.PRS.3PL)

uõ $\rightarrow$ uõ $\tilde{o}^{\prime}$ čuõškk (mosquito.SG.NOM) $\rightarrow$ čuõ $̌$ šǩke (mosquito.SG.ILL)

uå $\rightarrow$ ue' vuåš'š (horsetail.SG.NOM) $\rightarrow$ vue’ššše (horsetail.SG.ILL)

uâ $\rightarrow$ ue' kuâđđ(leave.PRS.3PL) $\rightarrow$ kue’đđe (leave.PRS.3PL)

uä $\rightarrow$ uä' vuäđđ(sleep.PRS.3PL) $\rightarrow$ vuä'đđe (sleep.PRS.3PL)

(Feist, 2015:72)

O autor ressalta que os ditongos são mais problemáticos que outros fonemas da língua por possuírem um grau considerável de variação entre os falantes. Em alguns idioletos, por exemplo, < ue' > é mais próximo em qualidade de / ui/; em outros, os ditongos iniciados em e são produzidos como iniciados em $i$.

Além disso, no caso dos ditongos $<$ uä' $>$ e $<$ eä' $>$, há uma variação alofônica

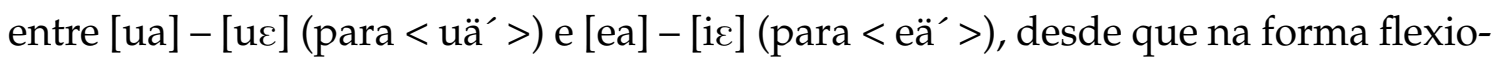
nada de palavras da chamada Classe $1 C_{1}{ }^{2}$ em determinados contextos fonológicos, conforme sumarizado abaixo:

Ocorrendo antes de: < uä'> < eä'> são reproduzidos como:

SHORT CONSONANT (x) /ua/ / ea/

LONG GEMINATE $\left(x^{\prime} x\right)$ / ua/ /ea/

LONG CLUSTER (xyy) /ua/ /ea/

SHORT GEMINATE (xx) /uc//ic/

SHORT CLUSTER (xy) /ucl/icl

(Feist, $2010: 77$ )

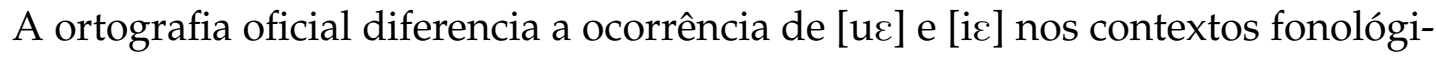
cos exemplificados acima (antes de geminada breve e encontro consonantal breve) e os representa como $<\mathrm{ue}^{\prime}>$ e $<\mathrm{ie}^{\prime}>$.

\footnotetext{
${ }^{2}$ Em saami skolt, nomes e verbos podem ser classificados em classes flexionais e subgrupos (A, B e C) de acordo com algumas características. Palavras que são palatalizadas no NOM.SG. ou infinitivo pertencem à $\mathrm{C}$.
} 
A representação ortográfica destes alofones gera uma certa confusão: passa a haver coincidência entre as palavras de classe 1C cuja vogal presente é de fato < $\mathrm{ue}^{\prime}>$, e as palavras de mesma classe cujo ditongo subjacente é / uä/ mas, sendo seguida por uma geminada ou encontro consonantal breve, é representada também como $<\mathrm{ue}^{\prime}>$.

Por fim, outro ponto relevante levantado por Feist (2015:72) relativamente aos ditongos é a variação entre os falantes, os idioletos. $\mathrm{O}$ autor conclui ressaltando que os a variação dos ditongos em idioletos carece de maior investigação.

\subsection{Vogais reduzidas}

Por fim, mais um elemento importante a respeito da fonologia do saami skolt são as vogais reduzidas ou ultrabreves, como também são chamadas. Ocorrem no final de palavras monossilábicas, podem ser desvozeadas e ser reproduzidas apenas como uma aspiração. Correspondem historicamente a uma vogal que foi perdida (Feist, $2015: 42)$. Segundo Feist (2015:42),

"McRobbie-Utasi (1999) refers to these words as disyllabics, although this grammar considers the overshort vowel as belonging to a degenerate syllable. [...] If the word is palatalised then the overshort vowel has an $e$-quality, but otherwise it has an $a$-quality.

$$
\begin{aligned}
& \text { kaupp [kawp: ă] 'shop' } \\
& \text { sue'tť̌k [suع } \left.{ }^{\mathrm{h}} \mathrm{cee}\right] \text { 'birch'." }
\end{aligned}
$$

Na ortografia, estas vogais ultrabreves são representadas por um apóstrofo < ' $>$. 


\section{Registros e estudos acerca do sistema vo- cálico}

Conforme brevemente mencionado em 1.3-A lingua e seus dialetos, em Koltan ja Kuolanlapin Sanakirja, Itkonen (2011 [1958]) registrou, fazendo uso do alfabeto fonético urálico (UPA, Uralic Phonetic Alphabet, ou SUT, do finlandês Suomalaisugrilainen tarkekirjoitus), verbetes do saami skolt separados nos seguintes dialetos: Paatsjoki, Nuorttijärvi e Suonikylä; além do dialeto de Näätämö, que foi incorporado fazendo uso do registro e transcrição feitos no final do século XIX por Genetz (1891). ${ }^{1}$ Além dos dialetos do saami skolt, os verbetes também são registrados nas línguas da península de Kola (saami ter e kildin), que não entram no escopo desta pesquisa. Será necessário excluir do escopo também o dialeto de Näätämö, cujo registro no século XIX utiliza-se de um alfabeto fonético distinto do usado por Itkonen e Korhonen (ainda que, possivelmente, seja uma forma anterior do UPA) e, não tendo acesso à obra original na íntegra, não é possível averiguar os critérios do autor para a realização da transcrição e o grau de precisão desta.

Nem todo verbete contempla todas as variantes - temos quantitativamente maior registro do dialeto de Paatsjoki, seguindo por Nuortijärvi; as variantes de Suonikylä e Näätämö são notadamente menos registradas. Ainda assim, a partir desses dados é possível analisar o perfil destas variantes quanto às vogais. Tal levantamento é especialmente relevante se considerarmos que, após as realocações, as comunidades de fala se dispersaram, percurso que certamente impactou a língua saami skolt. Considerando o lançamento, no início da década de 70,

\footnotetext{
${ }^{1}$ Kuollan lapin murteiden sanakirja ynnä kielennäytteitä - Wörterbuch der Kola-lappischen Dialekte nebst Sprachproben. Helsinki, 1891.
} 
da primeira gramática descritiva da língua (Koltansaamen Opas, "Guia do saami skolt" Korhonen et al. 1973), é relevante traçar os elementos que predominaram e desapareceram, juntamente com os fatores externos que impactaram a língua.

Descrições de características segmentais e suprassegmentais ganharam consistência a partir dos trabalhos de Korhonen (1971) e Korhonen et al. (1973). Na introdução de (Koltansaamen Opas (Korhonen et al., 1973), é especificado: “A língua deste livro são os dialetos do saami skolt falados em Sevettijärvi (Inari) e seus arredores, cujos falantes antes da $2^{\mathrm{a}}$ Guerra Mundial moravam em Suonikylä (Petsamo)" ${ }^{2}$ Nesse momento, estabeleceu-se o dialeto de Suonikylä como padrão - uma escolha que, junto às perdas na variedade dialetal, participa em moldar as próximas décadas para a língua saami skolt.

A descrição gramatical mais recente do saami skolt, lançada em 2015 (Feist, 2015), foi feita com base numa comunidade de fala já estabelecida na Finlândia há muitas décadas; portanto, um contexto inédito no percurso da língua em comparação com os materiais anteriores. Apesar de fornecer pouca informação fonética em forma de transcrições, descreve variações de idioletos e traz uma extensa descrição dos segmentos fonéticos e análise fonológica do saami skolt.

O presente trabalho se propõe a cruzar as informações fornecidas por estas fontes, possibilitando entender a situação dialetal do saami skolt entre o início do século XX até o presente momento. Sintetizando algumas informações já expostas, cabe ressaltar que, por volta da década de 40, as comunidades de fala de Suonikylä e Paatsjoki (respectivamente, dialetos do sul e do norte, conforme divisão explicada em 1.3) foram realocadas para território finlandês; e, não muito tempo depois, o dialeto de Näätämö (dialeto do norte) desapareceu. O de Nuortijärvi (sul) ainda persiste em território russo, com pouco mais de uma dezena de falantes (Feist, $2015: 23)$.

\footnotetext{
${ }^{2}$ No original: “Tämän kirjan kieli on Inarin Sevettijärvellä já sem ympäristössä puhuttavaa kulttamurretta, jonka käyttäjät ennen toista maailmansotaa asuivat Petsamon Suonikylässä." (Korhonen et al., 1973:5), minha tradução.
} 


\subsection{T. Itkonen}

Para compreender a descrição fonética das vogais descritas por Itkonen, relativas aos dialetos de Suonikylä, Nuorttijärvi e Paatsjoki (décadas de 10 a 30), e fornecer uma adaptação para o IPA, faremos uso do apêndice "The Finno-Ugric Transcription" de Saami Languages - An Introduction (Sammallahti, 1998:173-6) e das explicações do próprio autor a respeito dos símbolos utilizados para a transcrição (Itkonen, 2011 [1958] : XXXII-XXXIII).

O UPA, conforme exposto por Sammallahti, não especifica a altura quase aberta/quase fechada, sendo necessário acrescentar um diacrítico que sugira uma posição mais aberta ou mais fechada nas vogais semiabertas e semifechadas.

Outra diferença relevante é o quadro de vogais reduzidas e o de desvozeadas, que ocorrem na mesma variedade de pontos e modos de articulação que o quadro vocálico de vogais vozeadas e não reduzidas.

O símbolo > sob uma vogal indica que ela é articulada mais à frente, e < uma posteriorização.

Os símbolos ^ e indicam um modo de articulação mais alto e/ou mais pesado ("higher/heavier") e mais baixo e/ou mais relaxado ("lower/laxer"), respectivamente. Em oposição a "relaxado", interpretamos "pesado" como outro termo para referirse a "tenso".

As vogais reduzidas são expressas com o símbolo da vogal em questão invertido, e, na descrição de Itkonen, a maioria das vogais do saami skolt possui uma versão reduzida - no entanto, o valor fonético dessas vogais não é sempre definido com clareza.

A vogais desvozeadas ou semivozeadas, sempre ultrabreves, são representadas no UPA por uma vogal maiúscula sobrescrita.

A tabela foi organizada de modo a apresentar o símbolo dado por Itkonen no 
UPA, a correspondente no IPA, a posição da vogal do quadro de vogais e eventuais particularidades dialetais ou de contexto fonológico.

Em seguida, com algumas especificações do próprio autor, traduzidas do alemão (Itkonen, 2011 [1958]: XXXII-XXXIII).

Tabela 3.1: Equivalências UPA-IPA dos sons vocálicos descritos por Itkonen (2011 [1958]).

\begin{tabular}{|c|c|c|c|}
\hline UPA & IPA & Descrição & Particularidades \\
\hline a & a & aberta posterior & - \\
\hline$e$ & a & aberta posterior reduzida & - \\
\hline A & $\mathrm{a}$ & aberta posterior desvozeada [1] & - \\
\hline$\underset{\supset}{a}$ & $\underset{+}{a}$ & UPA [a] mais frontalizada & - \\
\hline$\dot{a}$ & $\ddot{a}$ & aberta central [2] & Em P. e S., também $[\underset{\lambda}{a}]$ (IPA $\left.\left[\begin{array}{c}a \\
+\end{array}\right]\right)$ \\
\hline Q⿻ & $\ddot{a}$ & aberta central reduzida & no ditongo UPA [uẹ] em S. \\
\hline$\ddot{a}$ & $æ$ & quase aberta anterior [3] & no ditongo UPA $[\ddot{\mathrm{e}}]$ \\
\hline$\stackrel{\mathrm{a}}{\mathrm{a}}$ & $\underline{\mathrm{a}}$ & UPA $[a]$ mais posterior & - \\
\hline $\mathrm{o}_{\mathrm{a}}$ & ${ }^{o} \mathrm{a}$ & alternativo a UPA [a] [4], em $1^{\mathrm{a}}$ sílaba & apenas em Paatsjoki \\
\hline a & e & quase aberta central [5] & - \\
\hline$\hat{\varphi}$ & $\mathrm{D}$ & versão reduzida de UPA [a] & - \\
\hline$\varepsilon$ & $\dddot{x} \underset{T}{\varepsilon}$ & v. anterior, UPA $[æ]$ próxima a $[\varepsilon][6]$ & - \\
\hline$\varepsilon$ & $\varepsilon$ & semiaberta anterior & - \\
\hline$\varepsilon$ & $\underline{\varepsilon}$ & UPA $[\varepsilon]$ levemente velarizada & em S., no ditongo UPA [i $[\varepsilon]]$ \\
\hline 3 & $\varepsilon$ & semiaberta anterior reduzida & em P., em UPA [шз] \\
\hline
\end{tabular}


T. Itkonen

\begin{tabular}{|c|c|c|c|}
\hline$\varepsilon$ & 3 & semiaberta central & - \\
\hline e & $\underset{\mathrm{T}}{\mathrm{e}}$ & média anterior & - \\
\hline ә & e & UPA $[\mathrm{e}]$ reduzida & ditongos não distintivos \\
\hline ə̧ & $\underline{\mathrm{e}}$ & UPA [ə] mais posterior [7] & Suonikylä e Nuortijärvi \\
\hline e & $\underline{\mathrm{e}}$ & mais posterior que UPA $[\mathrm{e}]$ & no ditongo UPA [ie] \\
\hline$\underset{>}{\mathrm{e}}$ & $\underset{+}{\mathrm{e}}$ & UPA $[\mathrm{e}]$ anterior (como finlandês terä) & - \\
\hline e & $\underset{\perp}{\mathrm{e}}$ & UPA [e] mais alto [8] & Paatsjoki \\
\hline$\dot{\mathrm{e}}$ & $\underset{\perp}{\mathrm{e}} / \mathrm{I}$ & semifechada anterior [9] & - \\
\hline$\dot{\mathrm{e}}$ & $\underset{\perp}{\mathrm{e}} / \mathrm{i}$ & mais próximo a UPA $[\mathrm{i}]$ que $[\dot{\mathrm{e}}]$ & - \\
\hline e & ә & média central & substituído por UPA $[\mathrm{a}][\dot{a}][\mathrm{g}]$ \\
\hline i & $\mathrm{i}$ & anterior fechada & - \\
\hline I & i & UPA [i] semidesvozeada & - \\
\hline $\mathrm{i}$ & $\underline{\mathrm{i}}$ & UPA [i] posterior (ex. : fin. ilma) & - \\
\hline $\mathrm{i}$ & $\underset{T}{\mathrm{i}}$ & UPA [i] mais aberta & - \\
\hline o & $\underset{\mathrm{O}}{\mathrm{O}}$ & média posterior arred. & - \\
\hline Q & $\underline{\mathrm{o}}$ & UPA $[\mathrm{o}]$ mais posterior & Paatsjoki \\
\hline Q & $\underset{+}{\mathrm{O}}$ & UPA $[\mathrm{o}]$ mais anterior & - \\
\hline O & $\mathrm{O} / \underset{+}{\mathrm{O}}$ & semifechada posterior arred. [10] & em Paatsjoki \\
\hline$\dot{\mathrm{O}}$ & $\underset{+}{\mathrm{O}}$ & semifechada posterior arred. [11] & - \\
\hline$\dot{\mathrm{O}}$ & $v$ & como UPA $[\dot{\mathrm{o}}]$, mas + anterior & 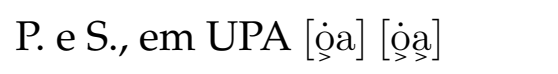 \\
\hline Q & ว & semiaberta posterior arred. & às vezes, UPA $\left[\mathrm{Q}^{\mathrm{a}}\right]$ \\
\hline $\mathrm{u}$ & $\mathrm{u}$ & alta posterior arred. & - \\
\hline $\mathrm{u}$ & $u_{+}$ & UPA $[u]$ palatalizado (frontalizado) & - \\
\hline
\end{tabular}


[1] “Em discursos comuns, ele e o ${ }^{\mathrm{A}}$ muito mais breve são substituídos frequentemente pela aspiração ', em geral, sequer é possível ouvi-los." (Itkonen, 2011 [1958]: XXXII), minha tradução.

[2] Descrição original da vogal pelo autor, minhas observações entre colchetes: " $\dot{a}$ ocorre com uma grande abertura articulatória, mais à frente que $a$ e seu valor sonoro está entre o $a$ [IPA a] e o $\ddot{a}$ [IPA æ] do finlandês. No dialeto saami skolt, falado na costa [i.e., Paatsjoki] e em Suonikylä, $\underset{x}{a}$ é produzido mais à frente que $\dot{a}$, parecido com $\ddot{a}$. [...] Especialmente no dialeto saami skolt falado na região costeira, o fonema $\dot{a}$ vem antes e é aberto, um $\dot{a}$ agudo (não reduzido)."(Itkonen, 2011 [1958]: XXXII)

[3] No guia para o UPA utilizado, o símbolo ä corresponde a uma vogal aberta anterior não arredondada; no IPA, portanto, [a]. Porém, frente à descrição de Itkonen, percebe-se como correspondência mais apropriada a vogal semiaberta anterior [æ]: "Na articulação, $\ddot{a}$ assemelha-se ao $\ddot{a}$ do finlandês (IPA [æ]) e ao $\ddot{a}$ do saami inari, e ocorre, quase sem exceções, apenas no ditongo ëä; $\ddot{a}$ é sua variante anterior ęä. (Itkonen, 2011 [1958]:XXXII)"

[4] "O o curto é ouvido com nuance ditongada mais fraca. [... ${ }^{\circ} a$ parece ter se desenvolvido a partir do $a$ do saami kildin."(Itkonen, 2011 [1958] : XXXIII). O $a$ do saami kildin é dito ser particularmente próximo ao [o], mas não arredondado.

[5] Uma vogal particularmente difícil de caracterizar a qualidade, e ausente no guia do UPA de Sammallahti. A correspondência no IPA foi proposta com base na seguinte descrição: “a é uma vogal mista, em sua pronúncia a língua levanta-se um pouco mais do que na pronúncia de $a$ e os lábios se retraem um pouco. $\mathrm{O} \dot{a}$ palatalizado corresponde a a quando nas seguintes sílabas ocorre uma vogal anterior." (Itkonen, 2011 [1958] : XXXIII) Paralelamente, na tabela descritiva do SUT de Sovijärvi \& Peltola (1970), consta o diacrítico ` embaixo da palavra como indicativo de vogal central (" “ kirjaimen alla osoittaa keski vokaalisuutta." 
Sovijärvi \& Peltola 1970:6) e a como uma vogal central baixa (não havendo distinção específica para vogais quase abertas, de modo que há espaço para que seja uma quase aberta).

[6] O UPA não especifica as quase abertas, mas indica por um diacrítico maior abertura numa semiaberta.

[7] “ə posterior, [...] seu efeito sonoro aproxima-se do o e do ö finlandês." (Itkonen, 2011 [1958]: XXXIV)

[8] Bem pouco específico quanto ao ponto de articulação, Itkonen apenas descreve: "e é um e articulado de forma mais dura [orig. fester] no dialeto saami skolt falado na costa, no ditongo ie" (Itkonen, 2011 [1958] : XXXIV). Consideramos ser uma vogal semifechada anterior, visto que UPA [e] corresponde a uma vogal média anterior. Dessa forma, $[\mathrm{e}]$ e $[\dot{\mathrm{e}}]$ tornam-se redundantes. A possibilidade mais provável é que Itkonen quis especificar com o símbolo e

[9] "é uma vogal entre $e$ e $i$, a qual, em diversos casos, nos dialetos saami skolt e saami kildin, ocorre como correspondente do $i$ original [...] e também nos ditongos ëä e èa."(Itkonen, 2011 [1958] : XXXIV)

[10] +alta/+tensa que UPA [o]. Modo e ponto de articulação não descritos por Itkonen, somente: "o articulado de forma bastante forte no dialeto saami skolt falado na costa."(Itkonen, 2011 [1958] : XXXIV)

[11] Itkonen a descreve como: "o está entre as vogais $o$ e $u$ do finlandês, em sua articulação, os lábios deslocam-se um pouco da posição do o."(Itkonen, 2011 [1958] : XXXIV) Foi considerada a possibilidade de ser uma quase fechada IPA $v$, porém, nada indica tal centralização.

Especifica-se que, entre uma vogal e uma plosiva, ocorre uma vogal desvozeada (fenômeno comum a todas as línguas saami, exceto saami inari) - transcrita como ว (em Paatsjoki, por ser mais fraco, $\left.{ }^{\circ}\right)$, com valor sonoro equivalente ao $h$ finlandês em coda silábica (IPA [h]). 
Um fenômeno característico do "lapão da Rússia" (saami skolt, kildin e ter), que, segundo Itkonen, não ocorre nas outras línguas saami (ao menos não no mesmo grau), é uma forma de palatalização no som das vogais (exceto i) e das respectivas consoantes seguintes (exceto labiais e $j$ ) em determinados contextos fonológicos. Nas palavras dele, "a vogal de uma sílaba antecedente a uma vogal anterior $(\varepsilon, \mathrm{e}, \dot{\mathrm{e}}, \mathrm{i})$ e a articulação da consoante no limite da sílaba tendem a se elevar aproximadamente à posição de $i$ (um fenômeno que também ocorre em algumas posições no finlandês, em dialetos de Savo, por exemplo, em tulit $t^{3}$ 'você veio')." (Itkonen, 2011 [1958]:XXXIV)

Genetz descreve da seguinte forma: "a vogal antecedente é um pouco aumentada, e no fim ocorre um som de $i$, onde também a próxima consoante é um pouco palatalizada, de forma que, por exemplo, $t a_{i} l l e, s o_{i} r m e[. .$.$] podem ser escri-$ tos de forma foneticamente fiel também das seguintes maneiras: tälle ou täl'l'e, sörme [...]."(Genetz 1891 apud Itkonen 2011 [1958] :XXXIV). O símbolo ' indica uma dentipalatal.

Uma palatalização significativa da consoante devido à articulação do $i$ ocorre apenas nas oclusivas palatais anteriores (surdas e sonoras) e suas dentais desenvolvidas. Para as outras consoantes (menos as labiais), Itkonen acrescenta um diacrítico semelhante a um pequeno $i$ sob elas, como em sạ̄nn $n^{\mathrm{e}}$.

Um último ponto a respeito da fonologia descrito é a redução vocálica nas línguas saami da Rússia: uma vogal sonora no final da segunda sílaba de uma palavra dissílaba (também valendo para vogal no limite entre a segunda e terceira sílaba) será omitida total ou parcialmente, ou substituída por uma aspiração. ${ }^{4}$

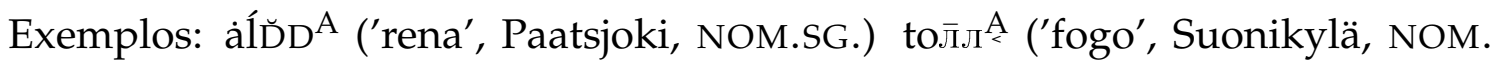
SG.) ${ }^{5}$

\footnotetext{
${ }^{3}$ IPA [tulitit]

4 Também pode ser substituída por um fonema com função vocálica semelhante à consoante sonora anterior. (Äimä apud Itkonen 2011 [1958] : XXXVI-II)

${ }^{5}$ Para valor fonético de $\pi$, vide parágrafo seguinte.
} 
Nas descrições das consoantes (que, devido ao escopo da pesquisa, não poderão ser abordadas em detalhes), a descrição da consoante л (о $l$ das línguas eslavas) é particularmente relevante para entender alguns aparentes ditongos. Itkonen descreve que л ocorre frente a vogais posteriores em todas as línguas saami da Rússia, sendo muito rara somente no dialeto de Paatsjoki. Acerca de sua articulação, ele descreve: "A parte posterior da língua se eleva em direção ao palato, e a abertura lateral é mais larga e mais posterior que nos outros sons de $l "$. Em Suonikylä e Nuortijärvi, é realizado como um $u$ antes de G, B e $m$. Exemplos:

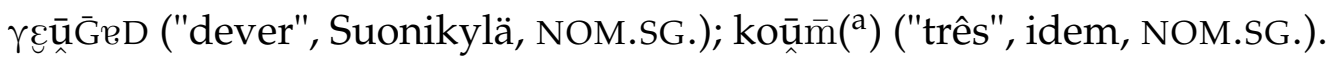

Num comentário interessante a respeito da possibilidade de mudança induzida por contato, Itkonen levanta a possibilidade de que л, tal qual como $1,{ }^{6}$, tenha emergido por influência do russo - considerando também que esse som é encontrado em outras línguas fínicas que fazem fronteira com o russo. Ele mesmo levanta, porém, que л é mais significante nos dialetos do saami skolt do interior, que estiveram menos em contato com o russo que as outras línguas da península de Kola: saami kildin e saami ter (Itkonen, 2011 [1958]: XXXI).

\author{
Paatsjoki kołm $\bar{n}^{\mathrm{a}}$ | kōłm

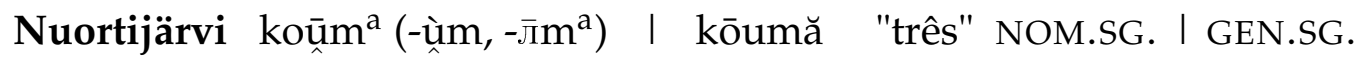

(Itkonen, 2011 [1958]: 144)

\title{
3.2 M. Korhonen
}

O trabalho Ehdotus koltanlapin Suonikylän (nyk. Sevettijärven) murteen fonemaattiseksi transkripioksi, "Proposta de transcrição fonêmica do dialeto de Suonikylä

\footnotetext{
${ }^{6}$ Conhecida como dark $l$, é uma aproximante alveolar lateral velarizada. Itkonen descreve que ela ocorre em Paatsjoki, entre vogais posteriores e quando a palavra termina em vogal posterior. Em outros contextos fonológicos, especialmente entre $\dot{a}$, èä, ë̈̈ e vogal posterior, alternativamente соm л. (Itkonen, 2011 [1958]: XXXI)
} 
(atual Sevettijärvi) do lapão skolt" (Korhonen, 1971) é pioneiro em descrever e analisar o sistema fonêmico do saami skolt, explicando como ocorre a distintividade, o padrão de acentuação e a estrutura silábica. Além disso, explica brevemente mudanças a partir da proto-língua saami até o saami skolt, e descreve o que ele acredita ser mudanças contemporâneas, em curso naquele momento, que necessitariam de futuros estudos para medir em que grau se completaram. ${ }^{7}$

Neste trabalho, são feitas cerca de uma centena de transcrições fonéticas, e um número próximo de transcrições fonológicas, exemplificando a descrição fonêmica da língua proposta pelo autor, sempre do dialeto de Suonikylä. Korhonen também utiliza o UPA - a descrição de símbolos feita por Itkonen será importante, visto que Korhonen não complementa sua transcrição com descrições adicionais dos segmentos.

Num primeiro esboço da fonologia do saami skolt, Korhonen dedica-se a descrever a língua quanto às suas características segmentais (consoantes e vogais) e suprassegmentais (acentuação, duração e palatalização).

Numa primeira seção (titulada “Quantidade e acento"), portanto, Korhonen descreve a oposição da língua entre consoantes, vogais e ditongos longos e breves, tanto no caso das vogais silábicas quanto das pós-silábicas. ${ }^{8}$ Todas as línguas saami, tal qual o finlandês (e, possivelmente, a maioria das línguas fino-úgricas), apresentam acento primário fixo na primeira sílaba; o saami skolt apresenta também acento secundário, como será explicado em mais detalhes a seguir.

Na seção "Qualidade do fonema segmentado", Korhonen fornece duas possibilidades de inventário vocálico (referente às vogais de primeira sílaba) - um

\footnotetext{
${ }^{7}$ A compreensão deste trabalho foi particularmente árdua devido à linguagem técnica do texto e à ausência de um sumário para as abreviações e símbolos. A referência à proto-língua era feita pela sigla klp., que parece se referir a kantalappi ("raíz do lapão"), uma forma de dizer proto-saami. Os proto-fonemas são marcados pelo sinal de soma sobrescrito $\left(^{+}\right)$, diferentemente do asterisco habitual $(*)$.

${ }^{8}$ A alternância de quantidade no saami skolt mostra-se um aspecto particularmente complexo da língua, objeto de estudo na tese "Quantity in the Skolt Saami Language - an Acoustic Analysis", de McRobbie-Utasi (1999).
} 
com dez fonemas, e outro com nove. Segundo ele, nas gerações mais jovens da língua, o fonema /o/ neutralizou-se com o fonema /o/, de modo que o inventário de nove fonemas representa uma versão mais recente da língua, que acabou de passar por um processo de mudança sonora. Quanto aos ditongos /ie/ / e /uo/, em alguns falantes, caíram totalmente, se neutralizando como /ie/ e /uo/.

O inventário de vogais e ditongos mais conservador é:

Após os processos de mudança, esses são os inventários:

Tabela 3.2: Inventário de vogais reduzido.

\begin{tabular}{|c|c|c|}
\hline Vogais & \multicolumn{2}{|c|}{ Ditongos } \\
\hline$/ \mathrm{u} /$ & /ie/ & $/$ uo/ \\
\hline /e/ /eg/ /o/ & $/ \mathrm{i} \varepsilon /$ & /uå/ \\
\hline /a/ / /å/ & /es/ & $/ \mathrm{u} \varepsilon /$ \\
\hline /àd /a/ & /eä/ & /oa/ \\
\hline
\end{tabular}

(Adaptado de Korhonen 1971:75)

Ao descrever as vogais e ditongos em sílaba tônica em nível fonêmico e fonético, Korhonen detalhou as variantes das vogais na pronúncia quando em ambiente fonológico palatalizado e não palatalizado. As vogais e ditongos que ocorrem num ambiente fonológico pré-palatalização são sempre mais anteriorizadas ou mais altas que as que ocorrem nos outros ambientes, como era de se esperar pela natureza do processo de palatalização. A representação que Korhonen escolheu para o fonema por vezes corresponde à versão não palatalizada, por vezes, à palatalizada, e eventualmente, é diferente de ambas. 


\section{A mudança sonora sob a perspectiva vari- acionista}

As línguas se transformam - isso pode ser tomado como fato, tal qual a inevitabilidade desse processo. Diferenças em diversos níveis da fala, desde a semântica até a fonética, podem ser notadas pelos próprios falantes em um intervalo de poucas gerações. O que desencadeia a mudança e o que determina as direções tomadas por uma língua são questões mais complexas, as quais a Linguística se propõe a debater, sob muitas perspectivas. Neste capítulo, apresentaremos algumas delas, começando com uma breve exposição do conceito de difusão lexical deKiparsky (2003) e focando na sociolinguística de Labov (Weinreich et al., 1968), também abordada por Guy (2003).

\subsection{A teoria neogramática e a difusão lexical}

A teoria neogramática, no século XIX, foi um marco no desenvolvimento dos estudos da mudança - nela, a mudança sonora é descrita como um processo condicionado foneticamente, fruto da produção da fala e sem exceções (Kiparsky, 2003 : 313). A teoria esbarra em uma série de problemas, por exemplo, em como conciliar a natureza da mudança sonora, tida como autônoma e mecânica, com a estrutura fonológica sincrônica de uma língua, que é sistemática: se a mudança sonora ocorre através de deslocamentos graduais ou mutações que operam cegamente, sem levar em consideração o sistema linguístico, o resultado mais provável seriam inventários fonéticos extensos e sem coerência. Nota-se, porém, que a mudança sonora majoritariamente não subverte princípios fonológicos, implicações 
universais e restrições (Kiparsky, 2003).

No texto "The phonological basis of sound change" (2003), Kiparsky analisa as críticas à teoria neogramática, colocando em questão se a mudança sonora sem exceções pode ser de fato o único tipo de mudança possível. O primeiro argumento contra tal afirmação é a possibilidade de difusão lexical, na qual:

"[P]honological processes sometimes spread through the lexicon of a language from a core environment by generalization along one or more phonological parameters, often lexical item by lexical item." (Kiparsky, 2003:313)

Uma vez completa, seu resultado pode ser idêntico ao da mudança sonora sem exceções descrita pelos neogramáticos, mas o processo de implementação é bastante distinto, e tal como também podem ser seus resultados, se a difusão se implementar parcialmente. Kiparsky argumenta que os casos genuínos de difusão lexical (quando garantido que não são resultado de outros mecanismos, como mistura dialetal), são, na verdade, não de um tipo de mudança à parte dos outros, mas sim de um tipo de mudança analógica - mais precisamente, da generalização analógica de regras fonológicas lexicais.

A teoria neogramática, no entanto, não se torna completamente obsoleta frente a tais questionamentos. Kiparsky propõe compreender a mudança sonora da seguinte forma: primeiramente, a variação fonética inerente à fala opera cegamente, no sentido neogramático; no entanto, essa variação é integrada ao sistema linguístico de modo seletivo, e transmitida às gerações seguintes na aquisição da linguagem. Assim, temos a mudança sonora, num primeiro nível, mecânica, no sentido neogramático; e no segundo, dependente da estrutura.

No seu conceito de difusão lexical, esse processo segue uma direção sistêmica imposta pelo próprio sistema fonológico da língua, e provoca a mudança na pronúncia de palavras já existentes, sem mudança no inventário ou sistema de 
contrastes dos fonemas. Dessa forma, trata-se de um fenômeno que preserva a estrutura da língua, ou que sempre implica em regras de neutralização, funcionando de maneira idêntica à analogia lexical.

A difusão lexical pode ser identificada ao que se observa seu processo de espalhamento estilo deriva (ing. driftlike) através do léxico: um processo fonológico estende-se de um contexto a outro, e, dentro destes, de um item a outro. Como exemplo no inglês, há o encurtamento de / $\mathrm{u} /$, que partiu de um contexto (1a) [-anterior] _ [-coronal]/[-anterior] (cook, hook, shook, rook, brook, crook, hookah, breves), no qual era categórico, e espalhou-se ao que o contexto foi flexibilizado, ou seja, perdeu a obrigatoriedade dos traços à esquerda ou à direita: (1b) _ [coronal]/[-anterior] (took, book); (1c) [-anterior]_(good, could, should) (Kiparsky, $2003: 316)$.

Para dar base a esse mecanismo de mudança, deve-se considerar a fonologia lexical juntamente com a mudança analógica, como um processo no qual há otimização, simplificação gramatical, eliminando a complexidade idiossincrática do sistema. ${ }^{1}$ Uma redistribuição de fonemas no léxico ocorre com base no sistema de regras constituintes da estrutura (structure-building rules) da fonologia lexical - a regra determina a direção da substituição fonêmica, e esta atua ao que a regra é generalizada para outros contextos, e por simplificação item por item das representações lexicais em cada contexto. Quando a idiossincrasia é eliminada, a padronização ocorre pelo sistema de regras, tal como quando a forma kine ("vacas") no inglês foi perdida e o plural de cow ("vaca") padronizou-se para cows (Kiparsky, $2003: 316)$.

Há, porém, ainda outras maneiras de olhar para a mudança sonora. Numa perspectiva variacionista, por exemplo, poderíamos considerar que houve a coexistência de kine e cows, sendo aquela uma forma que surgiu por regularidade

\footnotetext{
${ }^{1}$ Esta otimização é questionável, pois há casos nos quais a fonologia "prejudica"a morfologia, como no estoniano, que perdeu distinções de caso como em sõna.SG.NOM, sõna.SG.ACC, sõna.SG.GEN "palavra"; comparar com finlandês sana.SG.NOM, sanan.SG.GEN, sanaa.SG.PAR.
} 
(inglês médio $c \bar{u}, k \bar{u}$, pl. kyn)(Roberge, 2012:378), e esta, uma forma irregular. A padronização para cows, então, teria ocorrido pela concorrência de variantes, e não eliminando a forma kine pela idiossincrasia - inclusive, essa forma não desapareceu completamente, apesar de rara. É esta perspectiva variacionista que será adotada na presente pesquisa, e que será explicada em maiores detalhes a seguir.

\subsection{A abordagem sociolinguística}

Além de Kiparsky, no mesmo volume (Handbook of Historical Linguistics, 2003), Guy apresenta sua visão sobre a mudança sonora e críticas ao modelo neogramático no texto “Variacionist Approaches to Phonological Change" (2003). É apresentada a perspectiva variacionista, enfatizando que, antes do que é chamado de mudança, mais provavelmente houve a coexistência de formas diferentes, mais ou menos frequentes dentro de uma comunidade, e com o tempo, uma prevaleceu: "we conclude that variation in the course of change is a linguistic universal" (Guy, $2003: 372)$

A sociolinguística traz uma outra perspectiva à mudança sonora. Ao tomar os processos de mudança e variação como partes integrantes de um mesmo fenômeno, mostra-se desnecessária a dicotomia entre estudos sincrônicos e diacrônicos de uma língua. Questiona-se também a ideia de que o falante não tem consciência do percurso da própria língua: primeiramente, falantes reconhecem, dentro de uma mesma comunidade, formas mais antigas e outras mais recentes, modernas. Quando se considera a coexistência de variações, a perspectiva de uma sucessão de mudanças generalizadas torna-se obsoleta.

Na sociolinguística variacionista, como o nome sugere, procura-se descrever e explicar a variação linguística dentro e através de comunidades de fala (Gordon, 2013 : 18). Antes de maiores considerações, porém, cabe trabalhar o conceito de 
comunidade de fala, cuja definição pode variar consideravelmente entre diferentes autores. $^{2}$ Na página 16, fornecemos uma definição de Winford. Labov, por sua vez, coloca nos seguintes termos:

"The speech community is not defined by any marked agreement in the use of language elements, so much as by participation in a set of shared norms. These norms may be observed in overt types of evaluative behavior, and by the uniformity of abstract patterns of variation which are invariant in respect to particular levels of usage."(Labov 1972: 120-1 apud Patrick 2004:586)

Em “Empirical Foundations for a Theory of Language Change” (1968), ${ }^{3}$ ao especificar o sentido de "teoria da mudança linguística"expressa no título, os autores enfatizam que não há a intenção de prever, a partir de um dado momento da língua, o percurso que esta irá tomar dentro de um intervalo específico (algo possivelmente irrealizável); nem a de sublinhar que toda língua sofre alternância, formulando restrições na transição de um estado da língua para o outro - ambas estas as visões, vindas da gramática gerativa, partem de uma descrição da língua como um objeto homogêneo.

"[I]t will be necessary to learn to see language - whether from a diachronc or a synchronic vantage - as an object possessing orderly heterogeneity." (Weinreich et al., 1968:100)

Dessa forma, contrapondo-se à ideia de homogeneidade como pressuposição para que haja estrutura, necessária para o funcionamento da língua, a concepção de mudança linguística precisa comportar a descrição da diferenciação ordenada dentro de uma língua que serve a uma comunidade de fala.

"We will argue that nativelike command of heterogeneous structures is not a matter of multidialectalism or 'mere' performance, but is part of unilingual

\footnotetext{
${ }^{2}$ Uma revisão dessa definição em diferentes autores é proposta em Patrick (2004) e Vanin (2009).

${ }^{3}$ Um trabalho importante escrito por Labov juntamente com seu mentor Uriel Weinreich e Marvin Herzog, traz um detalhamento dos princípios que guiaram a perspectiva variacionista (Gordon, 2013:79).
} 
linguistic competence. One of the corollaries of our approach is that in a language serving a complex (i.e., real) community), it is absence of structured heterogeneity that would be dysfunctional." (Weinreich et al., 1968:101)

Para a compreensão do processo de mudança linguística, Weinreich et al. identificaram alguns pontos centrais a serem discutidos, que eles chamaram de: 1) problema das restrições (ing. constraints), que refere-se a questionar se há e quais são as restrições estruturais numa língua que influenciam no processo de mudança, impelindo ou influenciando-o (e para qual direção); 2) problema de transição (transition), a respeito de como são os estágios intermediários entre duas formas de uma língua em dois momentos diferentes, observando variantes estáveis e variantes nas quais uma está em vantagem sobre outra(s); 3) o problema o encaixamento (embedding), que se refere ao que está acontecendo numa comunidade de fala ou contexto social no qual se encaixem as mudanças em questão, de modo que não possam ser atribuídas ao acaso; 4) o problema da avaliação (evaluation), sobre como essas mudanças podem ser avaliadas quanto aos seus efeitos na estrutura linguística, eficiência comunicativa e em outros fatores não reproduzidos na fala. Além dessas, há uma questão mais geral: quais fatores podem explicar o acionamento das mudanças, isto é, por que uma mudança ocorre numa língua em determinado momento e não em outra, que também possui a característica em transição (sendo este o problema da implementação, ing. actuation).

Possivelmente, é impossível trazer uma resposta final a esta última pergunta. Independentemente disso, os autores entendem a teoria da mudança como uma parte de uma teoria mais ampla, referente à evolução linguística como um todo. Apesar do estudo da mudança linguística poder compreender intervalos de tempo muito extensos, como a evolução a partir de uma proto-língua, um processo de mudança de milênios, autores traçam como escopo processos em andamento que podem ser observados ao longo de uma ou duas gerações, e cortes sincrônicos nos quais podem ser feitas inferências a respeito das direções de mudança de certos 
elementos variáveis.

As evidências encontradas pela linguística apontam que a mudança é um processo contínuo e subproduto da interação linguística (Weinreich et al., 1968: 150), na contramão da visões como as de Hermann Paul (1880 apud Weinreich et al. [1968] 2006:39), que criou a dicotomia entre a fala de um indivíduo e a fala de um grupo, sustentando a ideia de idioleto homogêneo. Nesse ponto de vista, coloca-se a variabilidade e sistematicidade como conceitos excludentes, e não se procura identificar uma comunidade de fala entre diversos idioletos. No modelo proposto por Weinreich et al., porém, a mudança linguística não afeta a língua como estrutura, e sim faz parte desta, e a variação tem seu papel atenuando transições.

\subsubsection{A determinação de isoglossas}

Quanto à técnica da linguística histórica de separar línguas, dialetos e subdialetos a partir de isoglossas, Weinreich et al. sublinham: "um conjunto aleatório de isoglossas não divide um território em áreas bem delimitadas, mas, sim, num continuum de fragmentos sutilmente subdivididos" (Weinreich et al., [1968] 2006 : 89). Os autores ressaltam a relevância do exercício analítico nesse tipo de divisão dialetológica estrutural, mas é possível fazer paralelo com algumas questões a respeito da mudança mudança linguística exemplificadas anteriormente, como: a questão da transição e a do encaixamento. Quando não explicada por seu contexto linguístico ou histórico, uma isoglossa pode representar uma mudança em andamento. Os autores descrevem quatro tipos de isoglossas:

1) Isoglossa ou feixe de isoglossas coincidindo com uma fronteira política ou geográfica - esta traça os limites do padrão de comunicação responsável pela difusão do fato linguístico. Os autores exemplificam através do iídiche, como, p. ex., as grandes descontinuidades da língua no norte da Polônia (Weinreich et al., [1968] 2006:90). 
2) “A localização da isoglossa é explicada por sua relação sistemática com outras isoglossas que se enfeixam com ela" (Weinreich et al., [1968] 2006:91). Os casos de incompatibilidade linguística ilustram bem esse tipo - trata-se de quando uma mudança em progresso traz um fenômeno linguístico que não pode ser incorporado ou eliminado do dialeto vizinho para além do feixe de isoglossas, por, por exemplo, causar ambiguidade ou incompreensibilidade. O exemplo dado pelos autores é a difusão da monotongação de aj do iídiche-central para o sul da Ucrânia (hajnt ("hoje") $\rightarrow$ ha:nt). No norte da Ucrânia, perdia-se a distinção do comprimento de vogal. Se a monotongação tivesse se difundido até o norte, o monotongo teria coincidido com o $a$ breve da região e causaria homônimos, como hant (significando tanto "hoje"quanto "mão"). Assim, nota-se que a difusão parou abruptamente naquele ponto (Weinreich et al., [1968] 2006:91).

3) A direção do movimento da isoglossa é previsível em termos linguísticos, ainda que sua localização não seja compreensível por estes ou por fatores sociais. Como exemplo, o autor cita a fusão de /i - u/ e a de $i$ : e $i, u$ : e $u$ no iídiche. O fator condicionante de que as fusões se expandem em detrimento das distinções permite prever, tomando como base somente os fatos sincrônicos, a direção das mudanças (Weinreich et al., [1968] 2006: 92).

4) Além da localização da isoglossa não ser compreensível (como o caso acima), a direção do movimento também não é previsível - o caso de muitas isoglossas lexicais individuais. Nesses casos, identifica-se que o item em questão foi transportado por um falante individual que circula por linhas de comércio e trânsito, através de um padrão de comunicação bastante diferente do contato frequente entre comunidades de fala vizinhas, resultando na difusão de um traço linguístico.

Em suma, explicar a transição de dialetos tanto através de um território quanto através do tempo depara-se com a mesma questão - deve-se considerar a ocorrência de contato entre falantes dotados de sistemas diferentes. Isso nos leva a 
discutir relações de contato, e o fenômeno de que um falante pode incorporar elementos estruturais da fala de outros, ou seja, entendê-los e aceitá-los como seus. (Weinreich et al., [1968] 2006 : 92).

\title{
4.2.2 Transferência de elementos estruturais
}

O variacionismo propõe que a transferência de elementos estruturais acontece da seguinte forma: um falante A aprende uma regra ou forma usada por um falante B, não substituindo a sua, mas ganhando competência linguística nesta nova, concomitantemente com a que já possuía. Se a forma anterior for, por algum motivo, gradualmente desfavorecida posteriormente pelo falante A, pode-se falar em mudança, dentro do repertório linguístico desse falante. ${ }^{4}$ Em detalhes, os autores explicam:

\begin{abstract}
"Quando o falante A aprende pela primeira vez uma regra, $q$, de B, não é de esperar que ele a aprenda perfeitamente. Influenciado por seu próprio sistema, $\mathrm{P}$, e sem a gama total de experiência de B que suporta o sistema $\mathrm{Q}$ de $\mathrm{B}, \mathrm{A}$ adquire uma regra, $q^{\prime}$, de um tipo algo diferente - uma regra fonológica com traços alternados, uma regra lexical com diferentes privilégios de distribuição, ou uma regra gramatical com algumas condições especiais perdidas. Assim, nessa transferência inicial, um segundo tipo de mudança já aconteceu. Mas a mudança mais profunda e sistemática deve ser esperada depois que A adquiriu a regra de B. Dentro do repertório único disponível a A (contendo $p$ em P e $q^{\prime}$ ), podemos prever uma acomodação de $p$ e $q^{\prime}$ normalmente, uma assimilação de $q^{\prime}$ aos traços característicos de $p$ de modo que se torna possível a inserção final de uma $q^{\prime \prime}$ modificada dentro do sistema P." (Weinreich et al., [1968] 2006:93)
\end{abstract}

Como exemplo na fonologia, é citado o empréstimo de Trauma do alemão para o inglês: a uvular / $\mathrm{r}$ / se tornou uma apical surda e, num momento posterior, o /aw/ mudou para / / / pela restrição de /aw / frente a consoantes labiais.

O bilinguismo, tanto individual quanto social, é muito relevante para os estudos de línguas em contato. A coexistência prolongada de duas línguas não

\footnotetext{
${ }^{4}$ Em oposição à visão de idioletos individuais homogêneos, na qual existem trocas para outros idioletos e influência entre eles, mas não alternância.
} 
pode acontecer de maneira estável, havendo ajustes desde o nível semântico até o fonético, ainda que possam permanecer distintas na estrutura de superfície. ${ }^{5}$ Analisar o bilinguismo dentro do seu contexto social vai além de analisar as línguas envolvidas, analisando os sistemas coexistentes - esse mesmo contexto também condiciona o comportamento de fala do indivíduo. Dessa forma, abordase tanto o problema de transição, quanto o de encaixamento (Weinreich et al., [1968] 2006:95-96).

Nesse coexistencialismo de sistemas, cabe lembrar que a própria situação de bilinguismo é diversa, havendo possibilidades como a de um falante com domínio ativo de duas línguas ou dialetos regionais, e outras em que há domínio ativo apenas de uma. A visão da língua multicamada (ing. multilayer) enriqueceu também o conceito de empréstimo, que não é mais visto como momentâneo e eventual, mas sim parte de uma troca de estilos (ing. style switching), algo duradouro e recorrente (Weinreich et al., 1968: 164).

Outro ponto relevante na heterogeneidade é observar a coexistência de formas mais antigas e mais recentes dentro de uma mesma comunidade de fala, seja ela urbana ou rural: são formas alternativas para se referir a uma mesma coisa (sinônimos), disponíveis a todos os membros adultos da comunidade de fala, que são capazes de compreender o sentido de ambas e a significação da escolha por uma ou outra dentro do contexto (ainda que nem todos efetivamente produzam enunciados com ambas as formas igualmente, já que a escolha e a frequência de uso dependem de fatores como status social). Em suma, o modelo de heterogeneidade ordenada supõe que a escolha entre alternativas linguísticas carrega funções estilísticas e funcionais - um sistema que muda acompanhando mudanças na estrutura social. Se atitudes sociais têm um papel no curso de comunidades multilíngues, a atribuição inconsciente de características a um falante de determi-

\footnotetext{
${ }^{5}$ Exemplifica-se citando o contato entre o marati e o kannada em Kupwar (Índia) (Gumperz 1967 apud Weinreich et al. [1968] 2006: 95.
} 
nado subsistema participará do julgamento da significância social de sua variante, da relevância em alternar a fala para aquele subsistema ou não, promovendo o desenvolvimento ou a obsolência deste. ${ }^{6}$

Esses conceitos labovianos são retomados por Guy (2003): quanto à coexistência, numa mesma comunidade, de duas formas sinônimas para se referir a uma mesma coisa, sendo uma mais recente, inovadora, e outra mais antiga, Guy, em "Variationist Approaches to Phonological Change" cita o exemplo da Grande Mutação Vocálica do inglês para lembrar que tal mudança não pode ter sido abrupta, e que mais possivelmente "leading and lagging pronunciations" coexistiram como variáveis sociolinguísticas por algumas gerações nas comunidades de fala da Inglaterra, e todas essas comunidades passaram pela mudança (Guy, 2003:371). Nem toda variação resulta em mudança, havendo formas que permanecem em alternância ativa, sem que uma substitua a outra. Mas, para que haja mudança, a variação sincrônica é uma condição.

Guy também retoma a heterogeneidade do sistema linguístimo, mesmo em um único falante, reinterando que o que entendemos por mudança é, na realidade, a observação de que, com o tempo, uma das variações de articulação se tornará mais comum, geralmente no intervalo de algumas gerações - somente em casos mais extremos haverá a total substituição das variantes por uma única forma. Por razões já citadas, não é tão simples dizer que algo está em variação livre; essas variações ocorrem em padrões estatisticamente previsíveis. Os falantes, dentro de uma comunidade de fala, adotarão o que Guy chamou de frequência central (ing. central frequency), ou seja, terão uma forma predominante sendo usada, e essa frequência central pode mudar, sendo uma hora $x$, outra $y$. Para prever a probabilidade de uso de uma variante, cabe analisar o dialeto ou a comunidade

\footnotetext{
${ }^{6}$ Em um experimento de Lambert (1967:101-102 apud Weinreich et al. 1968:165), descobriuse que estudantes canadenses anglofalantes que ostentavam atitudes negativas a respeito de francofalantes mostravam uma dificuldade muito maior no aprendizado da língua francesa do que estudantes americanos.
} 
de fala na qual ela é produzida, além do momento temporal. Assim, pode-se calcular, muito além de dois extremos da mudança (a realização $x$ passando a ser $y$, categoricamente), a probabilidade de $x$ ser realizado como $y$.

Há também a questão do condicionamento fonológico. É conhecido que variantes não são uniformemente distribuídas entre os contextos fonológicos, visto que alguns ambientes favorecem certa variante e não outra. Guy cita como exemplo o /æ/ tenso e frouxo do inglês, que é encontrado com mais frequência antes de nasais tautossilábicas (p.ex. man, ham) e menos comum antes de oclusivas (cat, rag) (Guy, 2003:374). Ele conclui que condições na variação fonológica exibem os mesmos padrões encontrados nas condições para a mudança sonora: algumas são universais, outras, específicas do idioma, mas todas são consistentes com a gramática da língua. Nesse ponto, concorda-se com a dependência da estrutura citada por Kiparsky.

\subsubsection{Mudança fonética e fonológica}

Numa visão estruturalista, há uma clara distinção entre a primeira, que consistiria em meros deslocamentos fonéticos, e a segunda, que afeta a organização estrutural da fonologia, numa reanálise estrutural que mais provavelmente ocorreu no momento da aquisição da língua, dando origem a uma nova gramática mental.

Porém, em vez de interpretar fonética e fonologia como categorias opostas, na perspectiva variacionista, elas seriam polos de um contínuo. Se um dos polos representa a transição de variável para categórico, podemos colocar isso como uma mudança de 99 por cento para 100, que, em magnitude, equivale ao mesmo salto de 50 para 51 (Guy, $2003: 378)$.

Um ponto importante a respeito disso são os near mergers (Guy, 2003: 378), nos quais dois fonemas se tornam quase, porém não completamente indistinguíveis 
foneticamente, e podem, subsequentemente, se separar (Labov 1994 apud Guy 2003 : 378). Um exemplo é o das classes verbais de fool e full no inglês do sudoeste americano: os falantes nativos não conseguem os distinguir pela percepção, mas produzem sons distintos, ainda que foneticamente muito próximos. Uma aproximação quantitativa gradual e variável, portanto, aproximou duas representações subjacentes distintas, sem chegarem a se tornar um full merger (Labov et al. 1972 apud Guy 2003 :378). Quando, historicamente, dois fonemas se tornam mais distintos foneticamente, como no caso das classes de palavra meat e mate do inglês, vê-se que algumas palavras mudaram de classe gramatical, pois, dada a semelhança fonética, foram reinterpretadas fonemicamente. Se uma palavra irá cruzar ou não o limite entre near e full merger, isso também está sujeito à variabilidade (Guy, $2003: 379)$.

A própria representação subjacente de um som ou palavra não necessariamente é única e uniforme para os falantes: segundo Guy (2003), por exemplo, no caso das palavras and e just do inglês, nota-se a queda da consoante oclusiva com muito mais frequência do que o contexto ou características estruturais possam justificar, trazendo a possibilidade de que representações subjacentes com e sem a oclusiva final existam para os falantes. ${ }^{7} \mathrm{O}$ fato de serem palavras muito frequentes, porém, pode ter algum papel.

Por fim, a distribuição social de uma mudança em curso é mais um fator importante para se compreender a mudança sonora na perspectiva variacionista. Observa-se que os falantes fazem uso de formas novas em níveis diferentes - irão fazê-lo com maior ou menor rapidez ou frequência, de acordo com alguns padrões que podem ser observados. Esses padrões, porém, mudam de sociedade para sociedade, e não são totalmente independentes entre si. Uma forma básica de

\footnotetext{
${ }^{7}$ Guy não especificou se essa variação na forma subjacente foi encontrada num mesmo falante, numa comunidade de fala, ou em ambos. O autor ressalta, em outro momento do texto, evidências de que a variação na forma subjacente pode ocorrer não só no nível da comunidade de fala, mas num mesmo falante ao longo da vida (Guy, 2003:379).
} 
distinção é entre mudança inespecífica (ing. untargeted), "espontânea", que se desenvolve dentro da comunidade de fala, e mudanças que surgem a partir do contato linguístico ou dialetal (por empréstimo), o que pressupõe um input externo à comunidade de fala. Além disso, entram na equação a possível consciência social a respeito da mudança (Labov, 1966 apud Guy 2003) e a primeira língua dos falantes que são os agentes da mudança (van Coetsem 1988 apud Guy 2003).

\subsubsection{A difusão lexical sob a perspectiva variacionista}

De acordo com Guy, os estudos de variáveis linguísticas, de modo geral, apoiam que a variação e a mudança sonora são essencialmente regulares, concordando, num sentido amplo, com a teoria neogramática (Guy, 2003:391). No entanto, frente a mudanças sonoras não regulares, lexicalmente arbitrárias, e não justificáveis por mistura dialetal ou empréstimo, uma conciliação completa com essa teoria torna-se implausível.

Labov propôs tratar da questão da regularidade da seguinte forma: a regularidade é encontrada em mudanças mais concretas, como as que envolvem uma característica fonética em um espaço articulatório contínuo. A difusão lexical, por sua vez, é típica de mudanças mais abstratas, envolvendo mudanças em múltiplas características fonéticas, especialmente nas relativas (longo vs. breve, tom alto vs. baixo), mais do que nas absolutas (alveolar, oclusiva, etc.). Além disso, a regularidade predomina em fases iniciais da mudança, ao passo que a difusão lexical, nas tardias, após a mudança ter sofrido condicionamento morfossintático, e passado pela percepção consciente e avaliação social da comunidade de fala. Possivelmente, esse seria o momento no qual variantes adquirem representações subjacentes distintas (Labov 1981, 1994 apud Guy 2003 : 392).

"Labov concludes that regular sound change and lexical diffusion are not a simple dichotomy, but polar types involving a cluster of traits, rather than categories opposed in a single dimension. Other studies have found evidence 
of lexical diffusion even in concrete, single-feature changes, and have demonstrated the influence of other factors on the progress of a change, such as word frequency, saliency, and etymology (Phillips 1984; Yaeger-Dror 1996). In Labov's view, the inquiry must move beyond the question of whether the Neogrammarians were right or wrong, and turn to an investigation of "the full range of properties that determine the transition from one phonetic state to another (1994: 543)." (Guy, 2003:392)

Por fim, podemos dizer que, no estudo da mudança linguística, a perspectiva variacionista abre caminho para novas possibilidades, como: 1) um aumento da disponibilidade de evidências no estudo de uma comunidade de fala do presente (em comparação ao estudo de mudanças no passado, cuja informação é majoritariamente fragmentada); 2) com base em uma vasta quantidade de evidências, é possível dar maior atenção aos mecanismos sociais e motivações da mudança linguística, analisando-a em andamento; 3) é fornecida uma nova perspectiva quanto aos mecanismos linguísticos de mudança - considerando que falantes e comunidades de fala regularmente usam e manipulam variáveis linguísticas, pode-se entender que os processos linguísticos que produzem mudança são extensões diacrônicas de processos variáveis que são vigentes no uso e gramática sincrônicos (Guy, $2003: 370){ }^{8}$

\footnotetext{
${ }^{8}$ Para a presente pesquisa, mostra-se particularmente relevante o item 3 , conforme descrito no capítulo 5, esta pesquisa lida com dados fragmentados.
} 


\section{Dados e análise}

\subsection{Materiais e métodos}

As principais publicações utilizadas para a elaboração da pesquisa são listadas a seguir. O corpus foi compilado a partir dos primeiros três itens (Itkonen 2011 [1958]; Korhonen 1971; Korhonen et al. 1973).

- Koltan- ja Kuolanlapin sanakirja, "Dicionário do saami skolt e de Kola" (Itkonen, T. I., 1958, edição digitalizada de 2011) - Este trabalho de Itkonen é uma produção muito extensa, que, conforme o nome diz, engloba o saami skolt e as línguas da península de Kola. São registrados o que o autor chamou de dialetos de Paatsjoki, Petsamo, Suonikylä, Näätämö, Nuortijärvi, kildin, ter e akkala (ou imandra). ${ }^{1}$ Atualmente, saami kildin, saami ter (da península de Kola) e saami akkala são tratadas nas pesquisas linguísticas como línguas distintas, e os dialetos Paatsjoki, Petsamo, Suonikylä, Näätämö e Nuortijärvi, como variantes que compõem o saami skolt (para discussão mais detalhada, conferir 1.3). O dicionário foi resultado de gravações coletadas ao longo da primeira metade do século $X X$, mais especificamente entre a década de 10 e a de 30, elaborado em alfabeto fonético fino-úgrico e impresso pela primeira vez em 1958. A versão digitalizada lançada em 2011 contém pouco mais de mil páginas em entradas lexicais.

\footnotetext{
${ }^{1}$ Os dialetos grafados com maiúscula correspondem a regiões geográficas.
} 
- Ehdotus koltanlapin Suonikylän (nyk. Sevettijärven) murteen fonemaattiseksi transkripioksi, "Proposta de transcrição fonológica do dialeto de Suonikylä (atual Sevettijärvi) do lapão skolt" (Korhonen, 1971) - Este trabalho é pioneiro em descrever e analisar o sistema fonêmico do saami skolt, explicando como ocorre a distintividade, o padrão de acentuação e a estrutura silábica. Além disso, explica brevemente mudanças a partir da proto-língua saami até o saami skolt, e descreve o que ele acredita ser mudanças contemporâneas, em curso naquele momento, que necessitariam de observação futura para confirmar se iriam se completar ou não. Neste trabalho, são feitas perto de uma centena de transcrições fonéticas, e um número próximo de transcrições fonológicas, com o intuito de exemplificar a descrição dos fonemas da língua proposta pelo autor. Como indica o título, usa-se como base o dialeto de Suonikylä (que era falado naquele momento, após as realocações, em Sevettijärvi).

- Koltansaamen opas, “Guia do saami skolt” (Korhonen, M. Sammallahti, P. e Mosnikoff, J., 1973) - Trata-se da primeira gramática descritiva da língua, elaborada com base no dialeto de Suonikylä, tomado portanto como a forma "oficial" da língua. Apesar de ser nomeado como guia (no finlandês, opas) e não como gramática (fin. kielioppi), encaixa-se na definição de gramática de Auroux (1992), ao que apresenta: 1) categorização das unidades - termos teóricos, fragmentação da cadeia falada; 2) exemplos; e 3) regras para construir enunciados (no caso, os exemplos fazem esse papel). Este trabalho de Korhonen estabeleceu um sistema de escrita para o saami skolt, que passou a ser usado em todos os trabalhos a respeito da língua a partir de então. Apresenta algumas transcrições fonéticas (as fonêmicas foram substituídas pela grafia oficial), que foram utilizadas nesta dissertação. 
- Saami Languages - An introduction (Sammallahti, 1998) - Trata-se de trabalho de referência sobre as línguas saami. Sammallahti descreve diferenças dialetais entre elas e fornece listas comparativas de vocabulário e propostas de reconstrução da proto-língua.

- A Grammar of Skolt Saami (Feist, 2015) - Uma extensa e detalhada gramática descritiva do saami skolt. É escrita com base nos dialetos de Paatsjoki e Suonikylä, que são falados atualmente em Nellim e Sevettijärvi, respectivamente, vilarejos do município de Inari, na Finlândia. São os únicos dialetos falados na Finlândia. Há ainda por volta de vinte falantes na Rússia, do dialeto de Nuortijärvi, mas não estraram no escopo desta gramática. Feist utiliza para transcrições e descrição de fones da língua no Alfabeto Fonético Internacional, e fornece uma importante análise do sistema vocálico, além de discutir possíveis alofones e o papel da palatalização na distintividade. Feist opta por grafar as palavras de acordo com a ortografia oficial, que expressa de forma razoavelmente próxima à pronúncia destas (Feist, 2015:38).

Com a compilação de um corpus que fornece transcrições fonéticas de uma mesma palavra em diferentes dialetos e em dois momentos históricos (Itkonen 2011 [1958]; e, décadas depois, Korhonen 1971; Korhonen et al. 1973), a metodologia consiste em analisar as particularidades de cada dialeto em cada momento (quanto ao sistema de vogais e ditongos) e averiguar possíveis mudanças e seleção de variantes, com base no que foi descrito em 4. Serão levados em consideração os fatores externos à língua que possivelmente tinham alguma influência na comunidade de fala saami skolt em cada momento histórico. Dessa forma, será possível compreender o papel da variação e seleção entre diferentes dialetos e o contato de línguas. 


\subsection{Análise dos dados}

\subsubsection{Particularidades - aproximantes laterais}

Antes de abordarmos as vogais, alguns detalhes a respeito das aproximantes laterais são relevantes quanto a diferenças dialetais.

Itkonen oferece as seguintes descrições:

- " $l$ - um som vozeado dentialveolar. O $l$ dentro de uma palavra tem uma articulação se aproximando de dorsal antes de vogais anteriores ou na coda (auslaut) após uma vogal anterior; eu o chamo de $l,{ }^{\prime 2}$

- "í - um som dentipalatal, apenas ocorre no meio de palavra, como geminada."3

- “t, dark $l$ - aparece no dialeto da costa [Paatsjoki], entre vogais posteriores e quando a palavra termina em vogal posterior. Nas outras posições, especialmente entre à ëä èa e uma vogal posterior, alternativamente com л." ${ }^{\prime 4}$

- “л - do russo, л; comumente antes de vogais posteriores em todos os dialetos, sendo raro somente no dialeto da costa. о л, a parte posterior da língua se eleva contra o palato mole, e as aberturas laterais são mais largas e muito mais para trás do que os outros sons de $l$. A natureza dо л parece mudar de acordo com a posição posterior da articulação da língua e o tamanho das aberturas laterais. Nos dialetos de Suonikylä e Nuortijärvi, pode ocorrer em

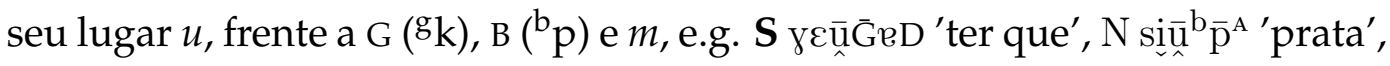

2 " $l$ ist ein stimmhafter dentialveolarer Laut. Das inlautende $l$ hat eine der dorsalen sich nähernde Artikulation vor vorderem Vokal und im Auslaut nach vorderem Vokal; ich bezeichne es mit l". Itkonen 2011 [1958] : XXX.

${ }^{3 \text { " } ~} l$ = ein dentipalataler Laut, nur als Geminate im Inlaut auftretend." Itkonen 2011 [1958]:XXX.

4 " $¥$ ist ein etwas dunklerer Laut als 1 und erscheint in der Küstenmundart des Koltalappischen zwischen hinteren Vokalen und auslautend nach Hintervokal (bei E. Itkonen auch anlautend), anderswo besonders zwischen à ëä ėá und Hintervokal, alternativ mit л." Itkonen 2011 [1958] : XXXI. 
S koū $\overline{\mathrm{m}}\left({ }^{\mathrm{a}}\right)$ 'três'. ${ }^{5}$ л, tal qual IPA/UPA[1], surgiu possivelmente pelo contato com o russo, considerando que esse som é encontrado também em algumas línguas fínicas que fazem fronteira com a língua russa. Entretanto, é curioso que о som л еstá mais presente nos dialetos do saami skolt, apesar destes terem estado menos em contato com o russo do que o saami da península de Kola [kildin e ter]." 6

A seguir, uma tabela sintetizando essas informações. O ponto de articulação de $\nmid$ е л não foi indicado no original, e foi suposto com base nas outras aproximantes em questão. O termo "dentipalatal" é original do UPA, e inespecífico quanto a se tratar de consoantes palatalizadas ou palatais. Neste caso, a consoante será interpretada como palatalizada.

Tabela 5.1: Aproximantes laterais em Itkonen 2011 [1958].

\begin{tabular}{|c|c|c|c|c|}
\hline UPA & IPA & Ponto de articulação & Ambiente fonológico & Dialeto \\
\hline 1 & 1 & Dentialveolar & Diverso & Todos \\
\hline$\frac{1}{1}$ & $\Lambda$ & Palatal & Pré/pós (coda) v. anterior & Todos \\
\hline ĺ & ]$_{n}^{\mathrm{j}}$ & Dentipalatal & Cons. geminada & Todos \\
\hline$\dashv$ & 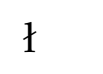 & Dentialveolar velarizada & Entre v. posteriores; + & $\mathrm{P}$ \\
\hline л & $1_{n}^{\mathrm{S}}$ & Dentialveolar faringealizada & Mesmo de 1 & Todos, raro em $\mathrm{P}$ \\
\hline
\end{tabular}

No saami skolt, temos os seguintes exemplos de transcrições comparativas

\footnotetext{
${ }^{5}$ Feist $(2015: 62,85-8)$ chamou de 'L-vocalisation. Será mencionado adiante nesta mesma seção.

6 “л = russisches л, anzutreffen vor Hintervokal in allen Mundarten, nur überaus selten im Küstendialekt des Koltalappischen. Bei dem л hebt sich der hintere Teil der Zunge gegen das Gaumensegel, und die Lateralöffnungen sind gösser und viel weiter nach hinten liegend als bei den vorhergehenden л-Lauten. Die Beschaffenheit von л scheint je nach der hinteren Lage der Zungenartikulation und nach der Grösse der Lateralöffnungen zu wechseln; zuweilen steht an seiner Stelle in den Mundarten von Suonikylä und Nuortijärvi $u$ vor G $\left({ }^{\mathrm{g}} \mathrm{k}\right)$, B $\left({ }^{\mathrm{b}} \mathrm{p}\right)$ und $m$, z.B. S

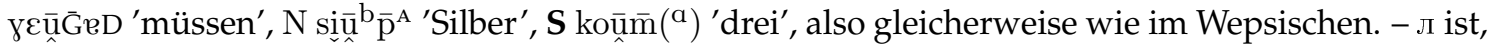
wie sein Vorgänger $t^{\prime}$, wahrscheinlich unter dem Einfluss des Russischen entstanden, denn dieser Laut ist ja auch in einigen an russisches Sprachgebiet grenzenden finnischen Sprachen anzutreffen. Nur scheint es sonderbar, dass л gerade in den Binnenlanddialekten des Koltalappischen am bedeutsamsten ist, obgleich sie mit dem Russischen weniger als das Kolalappische in Berührung gewesen sind." Itkonen 2011 [1958]: XXXI.
} 
entre os momentos linguísticos registrados por Itkonen e Korhonen, quanto aos

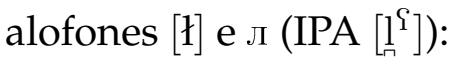

1.

\begin{tabular}{|c|c|c|}
\hline Itkonen & Korhonen & Glossa \\
\hline$P$ à্่vểłteD & 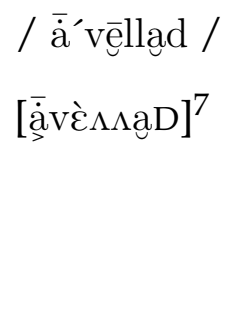 & $\begin{array}{l}\text { abrir (repetida- } \\
\text { mente ou gradual- } \\
\text { mente).INF. } \\
\text { (FIN. availla) }\end{array}$ \\
\hline
\end{tabular}

2.

\begin{tabular}{|c|c|c|}
\hline Itkonen & Korhonen & Glossa \\
\hline $\mathbf{P}$ ke $\bar{y}^{2}{ }^{\mathrm{j}} \mathrm{jeD}$ & $\begin{array}{l}\text { / kellǐjed / } \\
{\left[\underset{>}{\prime} \varepsilon \lambda \Lambda^{i}{ }^{i} j \mathrm{jeD}\right]}\end{array}$ & $\begin{array}{l}\text { aguentar, supor- } \\
\text { tar.INF } \\
\text { (fin. sietää, kestää) }\end{array}$ \\
\hline
\end{tabular}

3.

\begin{tabular}{|c|c|c|}
\hline Itkonen & Korhonen & Glossa \\
\hline 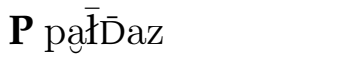 & / paldaz / & lobo.SG.GEN \\
\hline $\mathbf{N}\left(\right.$ e não S) pă $\bar{j}^{\mathrm{d}} \overline{\mathrm{t}} \mathrm{az}$ & [pằĭ̄Dą] & (fin. susi) \\
\hline
\end{tabular}

4.

\begin{tabular}{|c|c|c|}
\hline Itkonen & Korhonen & Glossa \\
\hline $\mathbf{P}$ pȩ́łteD & / pẹllagd / & temer.INF \\
\hline N реулллеD & [p $\left.\bar{\varepsilon} \breve{\Lambda} \Lambda a_{C} D\right]$ & (fin. pelätä) \\
\hline
\end{tabular}

5.

\begin{tabular}{|c|c|c|}
\hline Itkonen & Korhonen & Glossa \\
\hline $\mathbf{P}$ pợ̆ăłła & $<$ puäll > & botão.SG.NOM \\
\hline $\mathbf{N}$ рйӑліл ${ }^{a}$ & 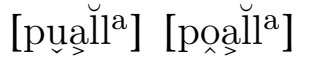 & (fin. nappi) \\
\hline
\end{tabular}

P.s.: Em 5., "botão", a forma de Korhonen é dada como nominativo, mas assemelha-se ao genitivo de Itkonen.

O que temos de Korhonen (1971) é um tanto inconclusivo: ele transcreve o som aproximante lateral nestes casos como $[\Lambda]$, que significa ou 1) uma consoante 
inespecífica (na versão do UPA apresentada em Sammallahti (1998), o símbolo $\Lambda$ é usado para designar vogais inespecíficas), ou 2) uma adaptação gráfica não especificada de $\pi$, visto que o símbolo $\Lambda$ não faz parte do quadro consonantal do UPA. No exemplo 5., o que em Itkonen era UPA [1] (em P) e [л] (em N) aparece como [1]. Tomaremos aqui o símbolo $\Lambda$ como л, visto que, em Korhonen et al. (1973), ele utiliza л em transcrições do mesmo dialeto.

Assim, pode-se dizer que a variante UPA [ł], típica de Paatsjoki, estava sendo desfavorecida (sendo a única variante que utilizava [1] preferencialmente a $[л]$ para o contexto fonológico dado). ${ }^{8}$

A respeito do contraste de aproximantes laterais no russo, temos:

"[T]hough Russian has traditionally been described as having all consonants either palatalized or velarized, recent data suggests that the velarized gesture is only used with laterals giving a phonemic contrast between $/ \mathrm{l}^{\mathrm{j}} /$ and $/ \mathrm{t} /$ as in 'coal' pronounced ['vgəlj] and 'corner/angle' (n.) pronounced ['vgəł]." (Ashby, 2011:133)

Este é exatamente o caso que encontramos como padrão no corpus do saami skolt. Alguns exemplos:

\begin{tabular}{|c|c|c|}
\hline Itkonen & Korhonen & Glossa \\
\hline $\mathbf{P}$ koḷ ${ }^{\mathrm{e}}$ & < kå'll > & ouro.SG.NOM \\
\hline $\mathbf{N}$ kọ̣l] & [koḷ, $\left.{ }^{\mathrm{e}}\right]^{\sim}$ [kå, & (fin. kulta) \\
\hline Itkonen & Korhonen & Glossa \\
\hline P kōłła & - & ouro.SG.ILL \\
\hline $\mathbf{N}$ ko ${ }^{\mathrm{a}}$ ліла & & (fin. kulta) \\
\hline
\end{tabular}

Temos kåll.sG.NOM ('ouro'), com raiz palatalizada (UPA [1], IPA $[K]$ ); na raiz não palatalizada do SG.ILL, apresenta as variantes velarizada e faringealizada. O mesmo se repete em mie'll.SG.NOM e meâlla.SG.ILL ('falésia de areia'):

\footnotetext{
${ }^{8}$ Korhonen baseou-se no dialeto de Suonikylä, que prefere л.
} 


\begin{tabular}{|c|c|c|}
\hline Itkonen & Korhonen & Glossa \\
\hline 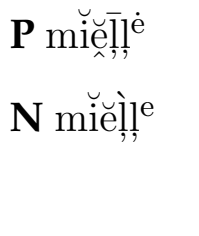 & 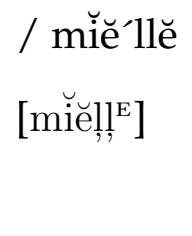 & $\begin{array}{l}\text { falésia de } \\
\text { areia.SG.NOM } \\
\text { (fin. hiekkatörmä) }\end{array}$ \\
\hline Itkonen & Korhonen & Glossa \\
\hline $\begin{array}{l}\mathbf{P} \text { mię̌̆ła } \\
\mathbf{N} \text { mіё̌лла }\end{array}$ & - & $\begin{array}{l}\text { falésia de } \\
\text { areia.SG.ILL } \\
\text { (fin. hiekkatörmä) }\end{array}$ \\
\hline
\end{tabular}

A ocorrência de UPA $[\nmid]$ e [л] num momento da língua em que os falantes tinham contato e certo grau de bilinguismo com o russo pode de fato significar, conforme o Itkonen colocou, que tais alofones sejam consequência do contato linguístico. Pode-se levantar a possibilidade de transferência de elementos estruturais (cf. 4.2.2), na qual um falante A, aprendendo uma regra $q$ de um falante B, e influenciado por seu próprio sistema (que possui uma regra $p$ ), não apenas adquira $q$ parcialmente $\left(q^{\prime}\right)$, mas também acomode $q^{\prime}$ e sua própria regra $p$, resultando em $q^{\prime \prime}$. Isso não necessariamente exclui a possibilidade de ser um processo que ocorria independentemente do russo, induzido pelo contexto fonológico. O contato com o russo teria tido seu papel, seja pelo acomodamento da regra $q^{\prime}$ (resultando em $q^{\prime \prime}$ ) mencionado anteriormente, seja ao reiforçar uma tendência comum a ambas as línguas, se este for o caso (ambos possuírem uma mesma regra $p$ ).

Estudos a respeito do saami skolt atualmente seriam necessários para analisar o presente status dessa alofonia, décadas após as realocações e após a mudança de L2 para o finlandês. Sabe-se, porém, que as gerações mais jovens têm uma preferência clara pelo que Feist $(2015: 62,85-8)$ chamou de 'L-vocalisation' $([1] \rightarrow[\mathrm{w}]$, exceto quando parte de um grupo de acento palatalizado ou precede vogais altas e anteriores [i] e [e]). A seguir, um registro de Itkonen que ilustra essa vocalização como mais um alofone de /1/ nos dialetos pré-realocações do saami skolt: 


\begin{tabular}{|c|c|c|}
\hline Itkonen & Korhonen & Glossa \\
\hline $\mathbf{P}$ òłmă & < ååumaž > & ser \\
\hline $\mathbf{S}$ о̀лmąz̆ (òumąz̆́) & [āumąž] & mano.SG.NOM \\
\hline N ò̀umes̆́ (-as̆́) & & (fin. ihminen) \\
\hline
\end{tabular}

Em outro contexto fonológico, temos, em início de palavra, uma alternância entre UPA/IPA [1] (majoritariamente Paatsjoki) e UPA Гл] (Nuortijärvi, que também apresenta [1], em início de palavra, mas com menos frequência). O registro posterior de Korhonen não fornece muitos dados: somente 4 palavras iniciadas em /l/ - em duas registra [l], e em duas, [л]. Para mais detalhes, consultar o corpus, itens 50 a 60 .

\subsubsection{O dialeto de Paatsjoki}

O dialeto de Paatsjoki, categorizado por Sammallahti (1998) (cf. 1.3) como um dialeto do Norte (tal qual Neiden/Näätämö), foi observado por Itkonen entre 1920 e 1930, através de 4 informantes: 1. 75 anos, sexo feminino; 2. 55 anos, sexo masculino; 3. 40 anos, sexo masculino; e 4. 20 anos, sexo masculino, em Kolttaköngäs (Boris-Gleb), atualmente parte da Rússia. O falante 3 viajou a Helsinki e teve sua pronúncia analisada pelo autor no instituto de fonética da Universidade de Helsinki, "através de aparatos". Mais tarde, em 1945, o mesmo foi feito com um falante do dialeto de Paatsjoki residente de Petsamo (65 anos, sexo masculino). O autor relata que, no vilarejo de Petsamo (falante do dialeto de Paatsjoki), por influência de um monastério local, podia-se notar mais palavras que origem russa do que a média (Itkonen, 2011 [1958] : XVIII).

São atribuídos especificamente ao dialeto de Paatsjoki os seguintes alofones:

Exemplos, numerados conforme a tabela (o item 4 não teve ocorrências no corpus):

\footnotetext{
${ }^{8}$ Os diacríticos na obra original não estão claros, podendo o último $a$ ser a ou à.
} 
Tabela 5.2: Particularidades atribuídas ao dialeto de Paatsjoki

\begin{tabular}{|c|c|c|c|}
\hline- & UPA & IPA & Fonema \\
\hline 1 & ${ }^{\mathrm{o}} \mathrm{a}$ & ${ }^{\mathrm{o}} \mathrm{a}$ & $/ \mathrm{a} /$ \\
\hline 2 & $3(\mathrm{em} \mathrm{u3)}$ & ${ }^{\varepsilon}\left(\mathrm{u}^{\varepsilon}\right)$ & $/ \mathrm{u} /$ \\
\hline 3 & e (em ie $)$ & $\mathrm{e}_{\perp}(\mathrm{em} \mathrm{ie})$ & $/ \mathrm{ie} /$ \\
\hline 4 & $\mathrm{o}$ & $\underline{\mathrm{o}}$ & $/ \mathrm{o} /$ \\
\hline 5 & $\mathrm{o}$ & $\mathrm{o} / \mathrm{o}$ & $/ \mathrm{o} /$ \\
\hline 6 & $\dot{\mathrm{O}}(\mathrm{em} \dot{\mathrm{o}} \mathrm{a})$ & $v(\mathrm{em} v a ̈)$ & $/ \mathrm{uä} /$ \\
\hline
\end{tabular}

\begin{tabular}{|l|l|l|}
\hline Itkonen & Korhonen & Glossa \\
\hline $\mathbf{P}$ kaĞGed (kª-) & $<$ kaggâd > & levantar.INF. \\
$\mathbf{N}$ kaĞked & [kaGGạD] & (fin. nostaa) \\
\hline
\end{tabular}

Neste exemplo, Itkonen registra alofonia entre $[\mathrm{a}]$ e $\left[{ }^{\mathrm{o}} \mathrm{a}\right]$ (IPA $[\mathrm{a}]$ e $\left[{ }^{\mathrm{o}} \mathrm{a}\right]$ ) em Paatsjoki, sendo mais comum a variante [a], e não foi especificado o perfil (sexo, idade ou vilarejo) dos falantes de cada uma dessas variantes. O autor ressalta: "[...] o parece ter se desenvolvido a partir do $a$ do saami kildin." (Itkonen 2011 [1958] : XXXIII, minha tradução). O $a$ do saami kildin é dito ser particularmente próximo ao $o$, mas não arredondado. Conforme possibilidade levantada também em 5.2.1, a transferência de elementos estruturais do kildin é plausível neste caso. Em Nuortijärvi (e, talvez, nos outros dialetos também), encontramos somente a variante [a], tal qual no que foi registrado por Korhonen, décadas mais tarde. Assim, $\left[{ }^{\circ} \mathrm{a}\right]$ pode ser uma característica dialetal que, já inicialmente menos frequente, continuou num processo de desfavorecimento na frequência de uso após as realocações, eventualmente desaparecendo.

\begin{tabular}{|l|l|l|}
\hline Itkonen & Korhonen & Glossa \\
\hline $\mathbf{P}$ vuussk $^{\mathrm{A}}$ & / vueskă / & perca.SG.NOM \\
$\mathbf{N}$ viuesk $^{\mathrm{A}}$ (vua-) & [vuäsk ${ }^{\mathrm{A}}$ ] & (fin. ahven) \\
\hline
\end{tabular}




\begin{tabular}{|c|c|c|}
\hline Itkonen & Korhonen & Glossa \\
\hline P kŭǔšssa & - & visitante.SG.ILL \\
\hline $\mathbf{N}$ kŭŭès̀a & & (fin. vieras) \\
\hline
\end{tabular}

O ditongo UPA [uз] (IPA $\left.\left[\mathrm{u}^{\varepsilon}\right]\right)$, quando palatalizado, torna-se UPA [uə] (IPA $\left[\mathrm{u}^{\mathrm{e}}\right]$ ) (e equivale na ortografia oficial $\left.\mathrm{a}<\mathrm{uâ}\right\rangle \rightarrow\left\langle\mathrm{ue}^{\prime}>\right.$ ), como pode ser visto na forma nominativa:

\begin{tabular}{|c|c|c|}
\hline Itkonen & Korhonen & Glossa \\
\hline $\mathbf{P}$ kŭ $\breve{s ̦, S^{\mathrm{E}}}$ & / kŭŏ'ssĕ / & visitante.SG.NOM \\
\hline 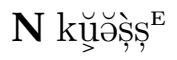 & [kự̆ & (fin. vieras) \\
\hline
\end{tabular}

Paatsjoki mostra uma variante não arredondada (elemento inicial do ditongo IPA $[u]$ ) e mais alta (segundo elemento $[\varepsilon]$, reduzido) em comparação a Nuortijärvi (com IPA $\left[\mathrm{u}^{\mathrm{a}}\right]$ ). A palatalização acompanha o sufixo -e e um alçamento do segundo elemento do ditongo na sílaba tônica.

\begin{tabular}{|c|c|c|}
\hline Itkonen & Korhonen & Glossa \\
\hline $\begin{array}{l}\mathbf{P} \text { miełł }^{\mathrm{a}} \\
\mathbf{N} \text { miелл } \\
\mathrm{a}\end{array}$ & - & $\begin{array}{l}\text { mente.SG.NOM } \\
\text { (fin. mieli) }\end{array}$ \\
\hline
\end{tabular}

A discussão a respeito desta variante será feita em 5.2.5.

\begin{tabular}{|l|l|l|}
\hline Itkonen & Korhonen & Glossa \\
\hline $\begin{array}{l}\text { P kuossi } \\
\text { A kuoss }\end{array}$ & / kuọssă / ] & abeto verme- \\
[kuos̆s $^{\mathrm{A}}$ & $\begin{array}{l}\text { lho.SG.NOM. } \\
\text { (fin. } \text { kuusi) }\end{array}$ \\
\hline
\end{tabular}

\begin{tabular}{|c|c|c|}
\hline Itkonen & Korhonen & Glossa \\
\hline $\begin{array}{l}\mathbf{P} \text { pöa } \bar{D} D Z^{\mathrm{a}} \\
\mathbf{N} \text { puaD̆Dza }\end{array}$ & - & $\begin{array}{l}\text { rena.SG.NOM } \\
\text { (fin. poro) }\end{array}$ \\
\hline
\end{tabular}


Observando o sistema vocálico da variante de Paatsjoki, nota-se, no núcleo da sílaba tônica, em pelo menos 30\% do corpus, uma variante com valor fonético mais anterior, em comparação aos outros dialetos. Um exemplo é <peä's's>.SG.NOM, <piẹ'ss>.sg.gen, <peä's'sa>.SG.ILL, "casca de vidoeiro":

\begin{tabular}{|c|c|c|}
\hline Itkonen & Korhonen & Glossa \\
\hline $\mathbf{P}$ piĕșs ${ }^{\dot{E}}$ & / pĕă'ssĕ / & casca de vido- \\
\hline 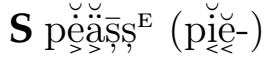 & [pe्人̄ășș $\left.{ }^{\mathrm{E}}\right]$ & eiro.SG.NOM \\
\hline 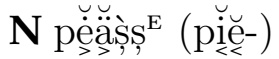 & & (fin. tuohi) \\
\hline
\end{tabular}

\begin{tabular}{|l|l|l|}
\hline Itkonen & Korhonen & Glossa \\
\hline $\mathbf{P}$ pieșș & easca de vido- \\
$\mathbf{N}$ pẹäs,̦, & - & eiro.SG.GEN \\
& & (fin. tuohi) \\
\hline
\end{tabular}

\begin{tabular}{|c|c|c|}
\hline Itkonen & Korhonen & Glossa \\
\hline 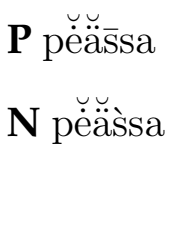 & - & $\begin{array}{l}\text { casca de vido- } \\
\text { eiro.SG.ILL } \\
\text { (fin. tuohi) }\end{array}$ \\
\hline
\end{tabular}

No SG.NOM, um grupo acentual palatalizado, enquanto Paatsjoki utilizava UPA [ie] (IPA [ie] ], Nourtijärvi e Suonikylä utilizavam UPA [ẹä] (IPA [eæx]-[iæ] ) (dada a marca de anteriorização no UPA, o valor fonético desta variante estava bem próximo da de Paatsjoki), havendo também a variante UPA [ię (quase análoga em valor fonético a UPA [ẹ̦ăa] $]$ ). Simplificando, pode-se entender que Paatsjoki a realizava de forma levemente mais anterior e elevada do que as outras variantes. Na transcrição feita por Korhonen, após as realocações, é indicada a transcrição UPA [e्रä] (IPA [ẹæ]), ainda que isso não exclua que pronúncias mais próximas a UPA [ie] ocorressem em menor grau e não tenham sido registradas.

No SG.ILL, com a adição do sufixo - $a$ e despalatalização do grupo acentual, o 
ditongo em Paatsjoki iguala-se à variante de Nourtijärvi, que, por sua vez, não é anteriorizada como no nominativo.

O exemplo seguinte apresenta duas variantes em Paatsjoki para $<$ sấvvel>.SG.NOM, ${ }^{9}$ "timalo", sendo uma delas associada aos falantes mais jovens:

\begin{tabular}{|c|c|c|}
\hline Itkonen & Korhonen & Glossa \\
\hline 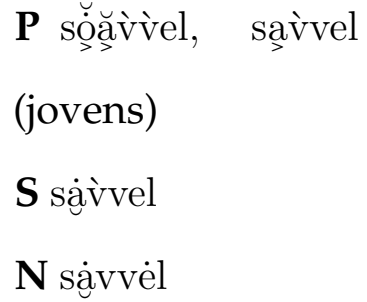 & $\begin{array}{l}\text { < sấvvel > } \\
\text { [săìvel] }\end{array}$ & $\begin{array}{l}\text { timalo.SG.NOM } \\
\text { (fin. harri) }\end{array}$ \\
\hline
\end{tabular}

A grafia sugerida por Korhonen (quando estabeleceu um sistema de escrita para a língua), como foi especificado pelo autor, leva em consideração o dialeto de Suonikylä - que, neste caso, tem a mesma variante que Nuortijärvi e os falantes

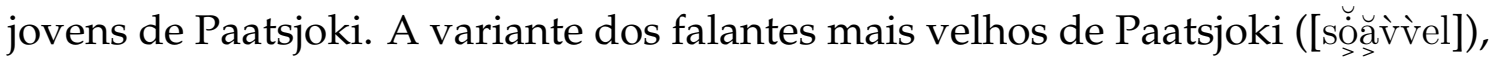
portanto, perdia espaço já antes das realocações, ainda que, possivelmente, não tenha desaparecido - as grafias alternativas (conforme expostas na nota de rodapé) a contemplam.

\subsubsection{Os dialetos do Sul - Nuortijärvi e Suonikylä}

Os dialetos de Nuortijärvi e Suonikylä não são tratados tão detalhadamente por Itkonen quanto Paatsjoki, a respeito do qual o autor afirma ter obtido a maior quantidade de informação linguística. No entanto, transcrições de palavras no dialeto de Nuortijärvi são quase tão numerosas quanto as no dialeto de Paatsjoki em Itkonen 2011 [1958]. Nuortijärvi é, atualmente, o único dialeto do saami skolt falado na Rússia.

\footnotetext{
$9 \mathrm{Na}$ plataforma Neahttadigisánit, sugere-se como grafias possíveis também <suâ'v'vel> e <suä́v'vel>), Fonte: http://saan.oahpa.no/detail/sms/fin/suä'vvel.html [Último acesso: 23/08/2017]
} 
Os dados a respeito da coleta de material e das condições das transcrições fonéticas também não são tão claros. O dialeto de Nuortijärvi foi observado por Itkonen a partir de 1914, primeiramente através de 4 informantes: 1) 70 anos, sexo feminino; 2) 50 anos, sexo masculino; 3) 40 anos, sexo feminino; 4) 19 anos, sexo masculino (Itkonen, 2011 [1958] : XII). Os experimentos linguísticos e a coleta de dados, porém, não tiveram o mesmo êxito de Paatsjoki. Em 1955, em Helsinki, o autor pôde coletar dados novamente a partir de duas informantes do sexo feminino de 45 e 55 anos. Não fica claro, porém, se eram falantes do dialeto de Nuortijärvi ou Suonikylä, ou de ambos. (Itkonen, 2011 [1958]: XVIII-XIX). Entre 1930 e 1943, a fala de informantes do dialeto de Suonikylä foi analisada em Helsinki, em especial, de um informante de por volta de 50 anos, sexo masculino (Itkonen, 2011 [1958]: XVIII-XIX).

Estes dois dialetos foram categorizados por Sammallahti (1998) como dialetos do Sul e a respeito deles foram levantadas pelo autor as seguintes diferenças fonológicas (conforme citado em 1.3): Nuortijärvi possui a oclusiva $d$ no lugar da fricativa não sibilante đ: Suonikylä vué[đđ]ed 'dormir' vs. Nuortijärvi vué[dd]ed, Hirvasjärvi vue’[dd]e (na ortografia oficial, <vue’đđed>. Nuortijärvi também possui, no lugar das sibilantes sonoras em final de palavra $z$ (IPA [z]) e $\check{z}$ (IPA [3]),

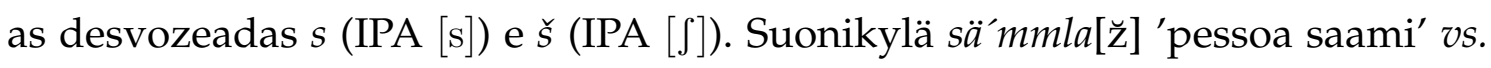
Nuortijärvi sämmla[š]. Este último exemplo encontra confirmação no corpus:

\begin{tabular}{|c|c|c|}
\hline Itkonen & Korhonen & Glossa \\
\hline 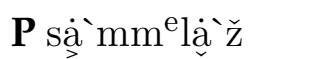 & - & pessoa \\
\hline 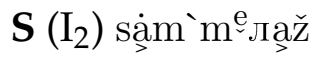 & & ami.SG.NOM \\
\hline 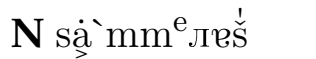 & & (fin. saamelainen) \\
\hline
\end{tabular}

UPA [⿳亠丷厂s] é uma fricativa palatalizada.

Quanto ao inventário de vogais e ditongos, as duas variantes não apresentam 
divergências significativas entre si. Entre elas e o dialeto do Norte, Paatsjoki, as diferenças centrais foram apresentadas na subseção anterior, e referem-se majoritariamente ao valor de F2 (anteriorização/posteriorização) em algumas vogais e ditongos. Outra diferença está na realização do fonema /ä/. Para exemplificá-lo, podemos apresentar o caso a seguir: Em <airru>.SG.ILL "remo" e <mannu>.SG.GEN "lua", a seguir, temos no núcleo da sílaba tônica o fonema /a / (UPA [a]; IPA [a]), o qual Nuortijärvi e Paatsjoki (Suonikylä não fornece dados o suficiente) não mostram diferenças. Na forma nominativa destas mesmas palavras, quando temos /ä/ <ä>, ${ }^{10}$ temos Paatsjoki UPA [ä] (IPA [ä]) e Nuortijärvi UPA [a] $]$ (IPA [ạ+ $]$ ]), como em <äirr>.SG.NOM "remo" e <mään>.SG.NOM "lua":

\begin{tabular}{|c|c|c|}
\hline Itkonen & Korhonen & Glossa \\
\hline 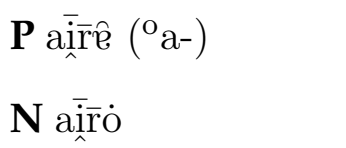 & - & $\begin{array}{l}\text { remo.SG.ILL } \\
\text { (fin. airo) }\end{array}$ \\
\hline Itkonen & Korhonen & Glossa \\
\hline $\begin{array}{l}\text { P S maǹne }\left(\mathrm{m}^{\mathrm{o}} \mathrm{a}-\right) \\
\mathbf{N} \text { mannó }\end{array}$ & $\begin{array}{l}\text { / manno / } \\
\text { [man̄no] }\end{array}$ & $\begin{array}{l}\text { lua.SG.GEN } \\
\text { (fin. kuu) }\end{array}$ \\
\hline Itkonen & Korhonen & Glossa \\
\hline 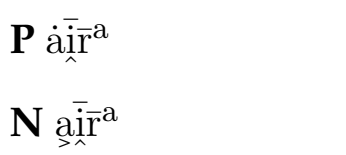 & 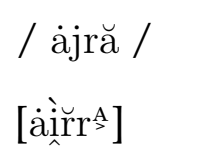 & $\begin{array}{l}\text { remo.SG.NOM } \\
\text { (fin. airo) }\end{array}$ \\
\hline Itkonen & Korhonen & Glossa \\
\hline $\begin{array}{l}\text { P S mān }{ }^{\mathrm{a}} \\
\mathbf{N} \text { mā̄n }{ }^{\mathrm{a}}\end{array}$ & - & $\begin{array}{l}\text { lua.SG.NOM } \\
\text { (fin. kuu) }\end{array}$ \\
\hline
\end{tabular}

\footnotetext{
${ }^{10}$ Feist (2015) escolhe representá-lo como IPA [æ].
} 


\subsubsection{O dialeto de Sevettijärvi (originalmente, de Suonikylä)}

Não há especificação a respeito do perfil dos informantes para as transcrições de Korhonen (1971) e Korhonen et al. (1973). Nesse momento da língua, após as realocações para a Finlândia, os falantes que tinham como L2 o russo estavam passando a ter o finlandês, em especial as novas gerações, uma mudança que influencia não apenas os futuros empréstimos a entrar na língua, como também possíveis trocas estruturais.

Nas décadas de 60 e 70, porém, não temos um intervalo de tempo suficiente com as transcrições de Itkonen para observar tais tendências. As transcrições de Korhonen são relevantes para enterdermos a forma da língua que foi usada no início da normativização do saami skolt, quando, pela primeira vez, uma forma foi escolhida como oficial. As razões para tal, apesar de não especificadas claramente pelo autor, podem ser relacionadas à quantidade de falantes dessa variante e facilidade de acesso a essa comunidade de fala.

Sendo Suonikylä um dialeto do Sul, as transcrições de Korhonen se assemelham principalmente às de Nuortijärvi em Itkonen. Este autor não forneceu muitas transcrições no dialeto de Suonikylä pré-realocações, mas, nos poucos exemplos disponíveis, nota-se que o que foi registrado por Korhonen nem sempre corresponde exatamente ao que foi registrado décadas antes por Itkonen quanto ao mesmo dialeto - isso, porém, longe de significar uma mudança linguística, muito mais provavelmente é um indício da variabilidade dentro do próprio dialeto de Suonikylä; variantes diferentes, ainda que igualmente plausíveis, foram transcritas por cada pesquisador, fornecidas por seus respectivos informantes.

Alguns exemplos, com eventuais comentários:

\begin{tabular}{|c|c|c|}
\hline Itkonen & Korhonen & Glossa \\
\hline $\mathbf{P}$ pĕăli $\bar{D}^{\mathrm{A}}$ & $<$ peäldd > & campo.SG.NOM \\
\hline $\mathbf{S}$ péăł̇ $\bar{D}^{A}$ & 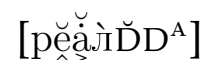 & (fin. pelto) \\
\hline
\end{tabular}


No exemplo acima, o ditongo núcleo de sílaba <eä> é UPA [ëä] (IPA [ęæ] ou [ræ]) em Itkonen, seguida pela aproximante [1] (em P) ou [1] (em S). O mesmo autor (cf.5.2.1) havia colocado [ $t]$ como uma aproximante típica de Paatsjoki; com esse exemplo, mostra-se que ela também ocorria em Suonikylä. Em Korhonen, temos UPA [èn] (IPA [ë̈]), seguida por $\pi\left[l_{n}^{\complement}\right]$. Possivelmente, essa pronúncia levemente posterior, em comparação com Suonikylä em Itkonen, é uma variante possível dentro do mesmo dialeto.

\begin{tabular}{|c|c|c|}
\hline Itkonen & Korhonen & Glossa \\
\hline $\begin{array}{l}\mathbf{P} \text { spașșeB } \\
\mathbf{S} \text { spàșșeB } \\
\mathbf{N}\left(\text { s)pașşe }{ }^{\mathrm{b}} \mathrm{p}\right.\end{array}$ & $\begin{array}{l}\text { / spasseb / } \\
\text { [spạșșeB] }\end{array}$ & $\begin{array}{l}\text { obrigado.INTERJ. } \\
\text { (fin. kiitos) }\end{array}$ \\
\hline Itkonen & Korhonen & Glossa \\
\hline $\begin{array}{l}\mathbf{P} \text { pięŭnì } \\
\mathbf{S}\left(\mathrm{I}_{2}\right) \text { pičňnči } \\
\mathbf{N} \text { piencnnei }\end{array}$ & $\begin{array}{l}\text { / picnnaj / } \\
\text { [piçn̆näị] }\end{array}$ & $\begin{array}{l}\text { cachorro.SG.NOM } \\
\text { (fin. koira) }\end{array}$ \\
\hline Itkonen & Korhonen & Glossa \\
\hline 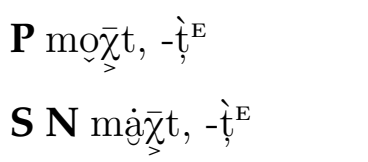 & $\begin{array}{l}\text { / máht / } \\
\text { [mààț }\end{array}$ & $\begin{array}{l}\text { como.ADV } \\
\text { (fin. kuinka) }\end{array}$ \\
\hline Itkonen & Korhonen & Glossa \\
\hline 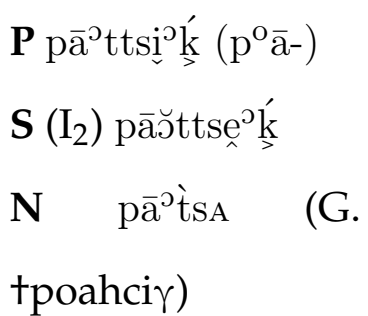 & 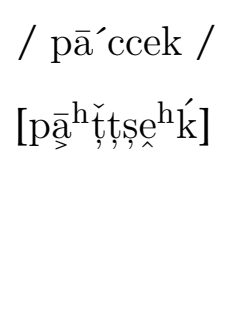 & $\begin{array}{l}\text { cone.SG.NOM } \\
\text { (fin. käpy) }\end{array}$ \\
\hline
\end{tabular}

Neste exemplo, os diacríticos de palatalização em Korhonen são um equívoco tipográfico, se de fato no SG.NOM. 


\begin{tabular}{|c|c|c|}
\hline Itkonen & Korhonen & Glossa \\
\hline P S kumppp $p^{E}$ & $\begin{array}{l}<\mathrm{ku}^{\prime} \mathrm{mpp}> \\
{\left[\mathrm{ku}_{>}^{\mathrm{i}} \grave{\mathrm{m}}^{\mathrm{h}} \mathrm{pp}^{\mathrm{E}}\right]}\end{array}$ & $\begin{array}{l}\text { lobo.SG.NOM. } \\
\text { (fin. susi) }\end{array}$ \\
\hline Itkonen & Korhonen & Glossa \\
\hline P S vạaştēD & $\begin{array}{l}\text { / västad / } \\
\text { [vàșțçD] }\end{array}$ & $\begin{array}{l}\text { responder.INF } \\
\text { (fin. vastata) }\end{array}$ \\
\hline Itkonen & Korhonen & Glossa \\
\hline 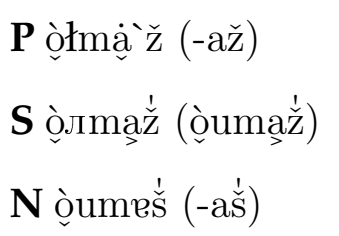 & $\begin{array}{l}<\text { ååumaž > } \\
\text { [åumă̌z] }\end{array}$ & $\begin{array}{l}\text { ser hu- } \\
\text { mano.SG.NOM } \\
\text { (fin. ihminen) }\end{array}$ \\
\hline
\end{tabular}

Nos dialetos do Sul, л pode ser realizada como [u] frente a [m] (cf. 5.2.1).

\begin{tabular}{|c|c|c|}
\hline Itkonen & Korhonen & Glossa \\
\hline 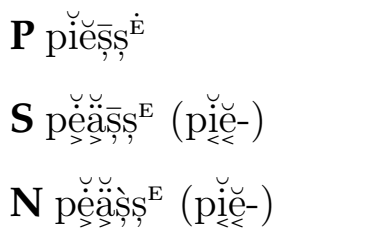 & 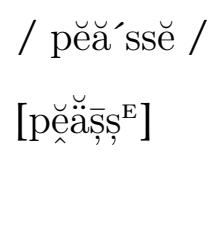 & $\begin{array}{l}\text { casca de vido- } \\
\text { eiro.SG.NOM } \\
\text { (fin. tuohi) }\end{array}$ \\
\hline Itkonen & Korhonen & Glossa \\
\hline 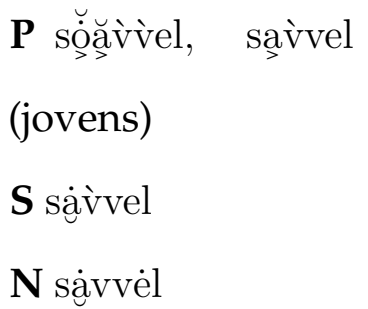 & $\begin{array}{l}<\text { sấvvel > }^{\text {[sàvivel] }}\end{array}$ & $\begin{array}{l}\text { timalo.SG.NOM } \\
\text { (fin. harri) }\end{array}$ \\
\hline
\end{tabular}

\subsubsection{Os ditongos [ie] e [ie] / [uo] e [uo]}

O ditongo /ie्र/, segundo Korhonen (1971), é realizado como [ie] frente a palatalização (como em mente.SG.ILL, miõ $7 l e),{ }^{11}$ e [ię $]$ sem palatalização, como em

11 “[...] rinnalla anal. / pie’sse /, uudessa systeemissä / pie'sse /” Korhonen 1971:75. 
mão.SG.NOM ǩiõtt.

\begin{tabular}{|c|c|c|}
\hline Itkonen & Korhonen & Glossa \\
\hline 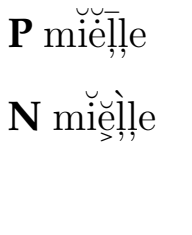 & 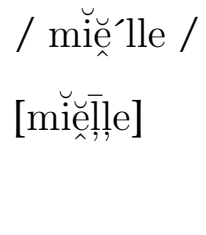 & $\begin{array}{l}\text { mente.SG.ILL } \\
\text { (fin. mieli) } \\
<\text { miõ'lle> }\end{array}$ \\
\hline Itkonen & Korhonen & Glossa \\
\hline $\begin{array}{l}\mathbf{P} \text { kie }^{\mathrm{O}} \mathrm{tt}^{\mathrm{A}} \\
\mathbf{N} \text { ḱiestt }^{\mathrm{A}}\end{array}$ & 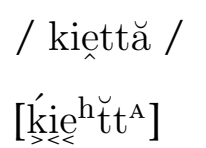 & 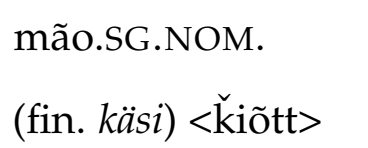 \\
\hline
\end{tabular}

As transcrições de Itkonen (2011 [1958]) para as palavras, acima, seguem a mesma lógica: num grupo acentual palatalizado, o ditongo e realizado de forma mais anterior do que quando não palatalizado. A seguir, mente.SG.NOM, < miõll>, sem palatalização. É neste contexto fonológico que vemos [e], e somente no dialeto de Paatsjoki. Isso nos leva a concluir que [e] é menos anterior (e mais central, próxima de um IPA [ə] ou [ẹT]) que [iè] ([ie] $])$, visto que a última está presente em Paatsjoki na raiz palatalizada (que acompanha uma anteriorização maior do núcleo vocálico).

\begin{tabular}{|l|l|l|}
\hline Itkonen & Korhonen & Glossa \\
\hline $\mathbf{P}$ miełł $^{\mathrm{a}}$ & - & mente.SG.NOM \\
$\mathbf{N}$ піелл $^{\mathrm{a}}$ & & (fin. mieli) $<$ miõll $>$ \\
\hline
\end{tabular}

Segundo o autor, havia outro ditongo fonêmico, /ie/, que ocorreria somente em contexto fonológico palatalizado, como em falésia de areia.SG.NOM <miéll>. Ou seja, um fonema que não existe na forma não palatalizada. Conforme as transcrições fonéticas a seguir, vê-se que falésia de areia.SG.NOM <mie'll> quase forma um par mínimo com mente.SG.ILL <miõ`lle>, se não fosse pelo grau de anteriorização do ditongo, e pelo /e/ final reduzido (mente.SG.ILL < miõ ’lle $>$ tem 
Tabela 5.3: Fonemas x Realização fonética, em Korhonen (1971)

\begin{tabular}{|c|c|c|c|}
\hline Ortografia & Fonema & UPA & IPA \\
\hline iõ iõ' & /ie / & [iec & [ie],[ie] ]/_ñ pal.; [ie] ]/_pal. \\
\hline$i e^{\prime}$ & /ie/ & [ie]/_pal. & [iẹ]/_pal. \\
\hline iâ ié & /ic/ & [ick]/_ñ pal.; [ic]/_pal. & 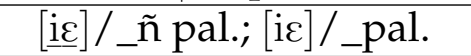 \\
\hline
\end{tabular}

no núcleo de sílaba tônica um ditongo de valor fonético mais anterior do que falésia de areia.SG.NOM <mié'll>).

\begin{tabular}{|c|c|c|}
\hline Itkonen & Korhonen & Glossa \\
\hline 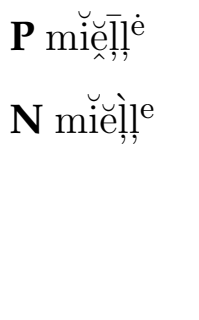 & 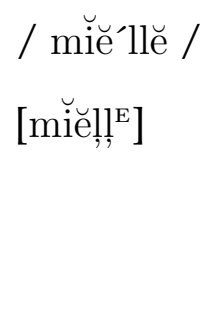 & $\begin{array}{l}\text { falésia de } \\
\text { areia.SG.NOM } \\
\text { (fin. hiek- } \\
\text { katörmä)<mie'll> }\end{array}$ \\
\hline Itkonen & Korhonen & Glossa \\
\hline $\begin{array}{l}\mathbf{P} \text { mię̌łła } \\
\mathbf{N} \text { miе̌̆лла }\end{array}$ & - & $\begin{array}{l}\text { falésia de } \\
\text { areia.SG.ILL } \\
\text { (fin. hiekkatörmä) } \\
<\text { meâlla> }\end{array}$ \\
\hline
\end{tabular}

Korhonen (1971) identificou uma diferença fonêmica, que representou como /ie्र/ e /ie/, e afirmou que o saami skolt estaria passando por uma redução no quadro de fonemas: /ie/ e /ie/ se tornariam ambos /ie/. Segue uma esquematização:

No entanto, não é provável que o quadro fonêmico estivesse em processo de redução e que ambas tenham se tornado uma, mas sim a questão encontra-se na forma de interpretar quais são as formas subjacentes. Considerando que as vogais e ditongos palatalizados são alofones em distribuição complementar das versões plenas, não seria possível haver um quadro fonêmico no qual um fonema não possui uma versão plena, somente a palatalizada. O ditongo /ie्र/ equivale ao ditongo fonêmico que a ortografia oficial representa como $<$ iõ $>$ (palatalizado, $<$ iõ $>$ ), 
ao passo que /ie/, por sua vez, é equivalente $\mathrm{a}<\mathrm{ie}^{\prime}>$, a versão palatalizada $\mathrm{de}<\mathrm{iâ}>$.

Algo semelhante ocorre com /uo/: segundo Korhonen (1971), este seria realizado como [uo] em um grupo acentual não palatalizado; e como[u!̣] num palatalizado. Seria diferente de /uo/, que ocorre somente em contexto fonológico palatalizado, realizado como [uə]. No entanto, a mesma palavra transcrita por Korhonen tendo [uI] no núcleo palatalizado, em Itkonen, possui [uə] $(<$ kuõ`sse >.SG.ILL "abeto vermelho"):

\begin{tabular}{|c|c|c|}
\hline Itkonen & Korhonen & Glossa \\
\hline P kŭŏșșe & / kŭợ’sse / & abeto verme- \\
\hline N kŭə̆ș̦s,e & [kưuỊ,s̄s, & $\begin{array}{l}\text { lho.SG.ILL. } \\
\text { (fin. kuusi) }\end{array}$ \\
\hline
\end{tabular}

Diante disso, vê-se que /uo / e /uo/ são, na realidade, um mesmo fonema (na ortografia oficial atual, <uõ >. Outros exemplos são:

\begin{tabular}{|l|l|l|}
\hline Itkonen & Korhonen & Glossa \\
\hline $\mathbf{P}$ kuoss $^{\mathrm{A}}$ & $/$ kuossă $_{\wedge}$ & abeto verme- \\
$\mathbf{N}$ kuoss $^{\mathrm{A}}$ & [kuos̆s$\left.^{\mathrm{A}}\right]$ & $\begin{array}{l}\text { lho.SG.NOM. } \\
\text { (fin. } k u u s i)\end{array}$ \\
\hline
\end{tabular}

Ortograficamente $<$ kuõss $>$.

\begin{tabular}{|l|l|l|}
\hline Itkonen & Korhonen & Glossa \\
\hline $\mathbf{P}$ muorr $\left.{ }^{\mathrm{a}}\right)$ & $<$ muõrr $>$ & árvore.SG.NOM \\
$\mathbf{N}$ muorr & {$[$ fin. $p u u)$} \\
& {$\left[\mathrm{muor̆}^{\mathrm{A}}\right]$} & \\
\hline $\left.\mathrm{mu}^{\ominus} \mathrm{rr}^{\mathrm{A}}\right]$ & \\
\hline
\end{tabular}

Ortograficamente <muõrr $>$. 


\begin{tabular}{|c|c|c|}
\hline Itkonen & Korhonen & Glossa \\
\hline $\mathbf{P}$ mŭŏŗŗe & $<$ mui'rre $>$ & árvore.SG.ILL \\
\hline $\mathbf{N}$ mŭə̆̀̆re & [mụ̦̆rre] & (fin. puu) \\
\hline
\end{tabular}

Ortograficamente <muõ'rre $>$. 


\section{Considerações finais}

Para compreender o percurso da língua saami skolt no século XX, é necessário considerar uma série de aspectos interligados. A presente pesquisa teve como foco o pequeno recorte que compete aos registros da língua pré- e pós-realocações; porém, deve-se ressaltar que a língua não era homogênea antes delas, ou tornou-se depois. A situação geopolítica do povo saami skolt tampouco resume-se a esse único período de turbulência com impacto na comunidade de fala, apesar ter sido o qual detalhamos aqui.

Conforme demonstrado ao longo deste trabalho, o saami skolt não pode ser entendido se observado isoladamente - a compreensão da filogenética, e das relações de contato cujos efeitos permeiam todos os campos da língua, são partes igualmente essenciais.

O nível individual de bilinguismo com o russo por parte dos falantes de saami skolt era, ao que os as informações coletadas indicam, bastante heterogêneo; no entanto, o bilinguismo social com o russo perdurou por, provavelmente, centenas de anos. Conforme ressaltado em 4.2.2, essa coexistência prolongada resulta em modificações desde o nível semântico até o fonético, ainda que, na estrutura de superfície, as línguas permaneçam distintas. Além do russo, o saami skolt manteve relações de contato também com outras línguas saami, como o saami kildin, a partir do qual possivelmente desenvolveu o alofone $\left[{ }^{\mathrm{a}} \mathrm{a}\right]$ para /a/, no dialeto de Paatsjoki, conforme descrito em 5.2.2.

O bilinguismo com o russo, porém, não é mais uma realidade para a maioria dos falantes de saami skolt (com exceção do dialeto de Nuortijärvi): atualmente, a dinâmica do bilinguismo estabelece-se com o finlandês, num contexto social e 
sob parâmetros bastante distintos, que resultam em efeitos em curso igualmente diferentes da situação anterior. Conforme descrito em 1.5, os falantes mais velhos, em especial os nascidos nas siidas originais, possuem o saami skolt como L1, ao mesmo tempo que têm menor domínio da escrita; na situação oposta estão as gerações mais jovens, que têm acesso à língua através da educação formal, mas proficiência baixa, contando, majoritariamente, com o finlandês como L1.

O percurso do povo e língua saami skolt ao longo do século $\mathrm{XX}$, conforme exposto em 1.2, é marcado por acontecimentos geopolíticos que resultaram em rupturas territoriais, e, por consequência, culturais e linguísticas. Não apenas as realocações, mas também, e talvez principalmente, a política assimilatória promovida após a fixação do povo saami skolt na Finlândia, representaram danos profundos para a manutenção da língua (cf. 1.4), de modo que a situação atual do saami skolt quanto ao número, distribuição e proficiência dos falantes e o risco real de extinção da língua têm ligações nítidas com tais eventos.

Esta pesquisa procurou reunir dados e registros da fonética e fonologia do saami skolt em dois períodos nos quais a língua estava inserida em contextos bastante distintos. Os dados e transcrições de Itkonen são muito valiosos ao registrar os dialetos originais antes das realocações (em parte, durante) - realocações estas que mudaram completamente a dinâmica das comunidades de fala e foram seguidas de um período de muitas perdas para a língua. A partir desses dados, procurei traçar, no que compete ao inventário de vogais e ditongos, as particularidades de cada variante.

As transcrições fonéticas feitas por Korhonen, disponíveis de maneira fragmentada ao longo de duas publicações (Itkonen 2011 [1958], Itkonen 1916), representam a língua após a fixação e reorganização das comunidades de fala na Finlândia, e o início da gramaticalização. Através delas, é possível observar a variante da língua que foi estabelecida como oficial, e o grau de semelhança e possíveis divergências 
com o que foi registrado por Itkonen a respeito do mesmo dialeto.

Dado o breve intervalo de tempo, não eram esperadas diferenças significativas entre o inventário de vogais e ditongos do dialeto de Suonikylä e as transcrições de Itkonen e Korhonen. Não necessitavam ser - e não são - idênticos, mas os pontos de divergência são resultado mais provável da heterogeneidade dentro do dialeto de Suonikylä. O estabelecimento dessa variante como base para a gramaticalização trará efeitos mensuráveis somente com o tempo - como, por exemplo, se será um fator de condicionamento do comportamento de fala dos falantes mais jovens.

Os dialetos de Paatsjoki, Suonikylä e Nuortijärvi têm, foneticamente, uma identidade relativamente clara, seja através de características no inventário de consoantes ou de vogais e ditongos. Cabe, porém, especificar que tais características não são necessariamente particulares de um dialeto ou outro, mas podem ser mais ou menos comuns em cada um deles. O dialeto de Paatsjoki, conforme descrito em 5.2.2, destaca-se por uma realização mais anteriorizada das vogais e ditongos em sílaba tônica em comparação a Suonikylä e Nuortijärvi; mesmo em grupos acentuais palatalizados, que em todos os dialetos acarretam algum grau de anteriorização. Além disso, há as preferências de cada variante para a realização das aproximantes laterais (5.2.1).

Com a reorganização das comunidades de fala na Finlândia, uma questão relevante é como ocorre - e se ocorre - a dinâmica entre essas variantes dentro desse relativamente novo contexto social. Visto que, entre os falantes mais jovens, o grau de proficiência é mais baixo, e o contato com a língua é garantido através do ensino formal, é possível que a heterogeneidade da língua esteja num processo contínuo de redução.

Porém, com o desenvolvimento de iniciativas de preservação linguística, que promovem o contato dos falantes mais jovens com os mais velhos, o saami skolt pode estar trilhando o caminho para a manutenção de suas comunidades de fala. 


\section{Referências Bibliográficas}

AIKIO, A., "Etymological nativization of loanwords: A case study of saami and finnish", in: TOIVONEN, IDA \& Nelson, DiAne (Eds.), "Saami Linguistics", Current Issues in Linguistic Theory 288, 17-52, Amsterdam/Philadelphia: John Benjamins B.V, 2007.

AIKIO, A., "An essay on saami ethnolinguistic prehistory", in: GRÜNTHAL, RIHO \& Kallio, Petri (Eds.), "A Linguistic Map of Prehistoric Northern Europe”, Mémoires de la Société Finno-Ougrienne 266, 63-117, Helsinki: SuomalaisUgrilainen Seura, 2012.

AntTILA, RAimo, Historical and Comparative Linguistics, Amsterdam/Philadelphia: John Benjamins B.V., 1989.

Ashby, PATRICIA, Understanding Phonetics, Understanding Language, London, Hodder Education, 2011.

Auroux, S., A revolução tecnológica da informação, Campinas: EdUnicamp, 1992.

CARPELAN, C., "A look at the sámi and their cultural eras in the light of archaeological research", in: PENNANEN, JUKKA \& NÄKKÄLÄJÄRVI, KLEMETTI (Eds.), "Siidastallan: From Lapp Communities to Modern Sámi Life”, Siida Sámi Museum Inari. Jyväskylä: Gummerus Kirjapaino Oy, 2003.

FEIST, T., A Grammar of Skolt Saami, Tese de Doutoramento, School of Languages, Linguistics and Cultures, Faculty of Humanities, University of Manchester, https: / / www.escholar.manchester.ac.uk/api/datastream?publicationPid=ukac-man-scw:123128\&datastreamId=FULL-TEXT.PDF, 2010. 
FEIST, T., A Grammar of Skolt Saami, Helsinki: Suomalais-Ugrilainen Seura, 2015.

FLEMMING, E., “Contrast and perceptual distinctiveness (pre-publication version)", in: Hayes, B., Kirchner, R. \& Steriade, D. (Eds.), "PhoneticallyBased Phonology", http:/ / web.mit.edu/flemming/www/paper/CandP13.pdf [Último acesso: 29/01/2016]: Cambridge: Cambridge University Press, 2004.

GENETZ, ARVID, Kuollan lapin murteiden sanakirja ynnä kielennäytteitä - Wörterbuch der Kola-lappischen Dialekte nebst Sprachproben, Helsinki, 1891.

Gordon, M. J., Labov: A Guide for the Perplexed, London, New York: Bloomsbury Academic, 2013.

GUY, G., "Variationist approaches to phonological change", in: JOSEPH, B. \& R., JANDA (Eds.), "Handbook of Historical Linguistics", 369-400, Oxford: Blackwell, 2003.

ITKONEN, T., Venäjänlapin konsonanttien astevaihtelu Koltan, Kildinin ja Turjan murteiden mukaan, MSFOu XXXIX, 1916.

ITKOnEN, T., Koltan-ja Kuolanlapin sanakirja, Helsinki: Suomalais-Ugrilainen Seura, 2011 [1958].

JANHUnEN, J., "Proto-uralic - what, where, and when?", in: “The Quasquicentennial of the Finno-Ugrian Society", volume Suomalais-Ugrilaisen Seuran Toimituksia 258, 57-78, Helsinki: Finno-Ugric Society, 2009.

KIPARSKY, P., "The phonological basis of sound change”, in: JOSEPH, B. \& R., JANDA (Eds.), "Handbook of Historical Linguistics", 313-342, Oxford: Blackwell, 2003.

Korhonen, M., Mosnikoff, J. \& SAmmallahti, P., Koltansaamen opas, Castrenianumin toimitteita 4, Helsinki: Suomalais-Ugrilainen Seura, 1973. 
KORHONEN, MIKKO, “Ehdotus koltanlapin suonikylän (nyk. sevettijärven) murteen fonemaattiseksi transkriptioksi", in: ITKONEN, E., ITKONEN, T. \& KORHONEN, P., M. \& SAMmALlahti (Eds.), “Lapin murteiden fonologiaa", 69-86, Helsinki: Suomalais-ugrilainen Seura, 1971.

LAAKSO, J., "Being finno-ugrian, being in the minority - reflections on linguistic and other criteria", in: GRÜNTHAL, RiHO \& KOVÁCS, MAGDOLNA (Eds.), "Ethnic and Linguistic Context of Identity: Finno-Ugric Minorities", Uralica Helsingiensia 5, 13-36, Helsinki: Vammalan Kirjapaino Oy, 2011.

Ladenfoged, K., P.; Johnson, A Course in Phonetics, 6 ed., Boston: Wadsworth Cengage Learning, 2011.

LinKola, A., "The skolt sámi today", in: PenNANEN, JUKKA \& NÄKKÄLÄJÄrVI, KLEMETTI (Eds.), "Siiddastallan: From Lapp communities to modern Sámi life", 204-205, Inari Sámi Museum. Jyväskylä: Gummerus Kirjapaino Oy, 2003.

LiNKOLA, M., A.;LINKOLA, "The skolt sámi - a minority within a minority", in: Pennanen, JukKa \& NÄKKÄläJÄrvi, Klemetti (Eds.), “Siiddastallan: From Lapp communities to modern Sámi life", 129-137, Inari Sámi Museum. Jyväskylä: Gummerus Kirjapaino Oy, 2003.

MCRobbie-UtAsi, Zita, Quantity in the Skolt (Lappish) Saami language: An acoustic analysis., Uralic and Altaic Series 165, Bloomington, IN: Indiana University, 1999.

Moshnikoff, S., Moshnikoff, J. \& KopOnen, E., Koltansaamen Koulukielioppi, Inari: Samediggi, 2009.

Nelson, D. \& Toivonen, I., Saami Linguistics, Amsterdam/Philadelphia: John Benjamins Publishing Company, 2007.

PARPOLA, A., "Formation of the indo-european and uralic (finno-ugric) language families in the light of archaeology", in: GRÜNTHAL, R. \& KALLIO, P. (Eds.), 
"A Linguistic Map of Prehistoric Northern Europe", Mémoires de la Société Finno-Ougrienne 266, Helsinki: Suomalais-Ugrilainen Seura, 2012.

PAtrick, P. L., “The speech community”, in: Chambers, J. K., Trudgill, P. \& SCHILlingestes, N. (Eds.), "Handbook of variation and change", 573-597, Oxford: Blackwell, 2004.

RIESSLER, M., "Loanwords in kildin saami, a uralic language of northern europe", in: Haspelmath, M. \& TADMOR, U. (Eds.), “Loanwords in the World's Languages - A Comparative Handbook", 384-413, Berlin: De Gruyter Mouton, 2009.

RobERGE, P. T., "The teleology of change: Functional and non-functional explanations for language variation and change", in: HERNÁNDEZ-CAMPOY, J. M. \& CONDE-Silvestre, J. C. (Eds.), "The Handbook of Historical Sociolinguistics", 369-386, Chichester, West Sussex, UK; Malden, MA: Wiley-Blackwell, 2012.

Sammallahti, PeKKa, The Saami Languages: An introduction, Karasjok: Davvi Girji OS, 1998.

SEURUJÄRVI-KARI, I., "'we took our language back' - the formation of a sámi identity within the sámi movement and the role of the sámi language from the 1960s until 2008", in: GrÜNTHAL, RiHo \& KovÁcs, Magdolna (Eds.), "Ethnic and Linguistic Context of Identity: Finno-Ugric Minorities", Uralica Helsingiensia 5, 37-78, Helsinki: Vammalan Kirjapaino Oy, 2011.

SovijÄrvi, A. \& Peltola, R., Suomalais-ugrilainen tarkekirjoitus. Helsingin yliopiston fonetiikan laitoksen julkaisuja, Helsinki: University of Helsinki, https://helda.helsinki.fi/bitstream/handle/10224/4089/sovijarvi1-24.pdf [Último acesso: 30 Mai 2016], 1970. 
VAn COETSEM, F., "Defining the two transfer types", in: "Loan phonology and the two transfer types in language contact", 7-24, Dordrecht: Foris Publications, 1988.

VAN DER Hulst, H., "Word accent systems in the languages of europe", in: VAn Der Hulst, H., Goedemans, R. \& VAn Zanten, E. (Eds.), “A Survey of Word Accentual Patterns in the Languages of the World", 429-508, Berlin, New York: De Gruyter Mouton, 2010.

VANIN, A. A., "Considerações relevantes sobre definições de 'comunidade de fala"', 2009.

URL http://eduem.uem.br/ojs/index.php/ActaSciLangCult/article/ viewFile/6367/6367 [Últimoacesso:26/07/2017]

WeInREICH, U., LABOV, W. \& HERZOG, M., "Empirical foundations for a theory of language change", in: LEHMANN, W. \& MALKIEL, Y. (Eds.), “Directions for Historical Linguistics", 95-198, Austin: University of Texas Press, 1968.

Weinreich, U., LAbOV, W. \& HerzoG, M., “Fundamentos empíricos para uma teoria da mudança linguística", São Paulo: Parábola, trad.: Marcos Bagno; revisão técnica: Carlos Alberto Faraco., [1968] 2006.

Wilbur, J., A Grammar of Pite Saami, Berlin: Language Science Press, 2014.

WinforD, D., An introduction to Contact Linguistics, Oxford: Blackwell, 2003.

WINFORD, D., "Contact-induced changes - classification and processes", Diachronica, volume 22, Issue 2:373-427, 2005. 


\section{Corpus}

As palavras que compõem este corpus foram retiradas deItkonen (2011 [1958]), Korhonen (1971) e Korhonen et al. (1973).

Na primeira coluna, apresento a palavra conforme transcrita foneticamente por Korhonen, nos dialetos de Paatsjoki (P), Suonikylä (S) e Nuortijärvi (N), entre as décadas de 10 e 30 . As palavras foram registradas majoritariamente nos dialetos de Paatsjoki e Nuortijärvi.

Na segunda coluna, a transcrição feita por Korhonen (década de 60-70), pósrealocação para a Finlândia. Quando entre barras (/ /), trata-se da transcrição fonêmica, retirada de Korhonen 1971; quando entre chaves $(<>)$, indica-se a forma ortográfica da palavra, característica de Korhonen et al. 1973 (publicação que estabeleceu a ortografia oficial do saami skolt). Entre colchetes ([ ]), temos a transcrição fonética.

$\mathrm{Na}$ terceira coluna, referente à etimologia, tratam-se de suposições. Algumas palavras que constam como etimologia germânica ou báltica não necessariamente entraram diretamente no saami skolt a partir dessas línguas, mas frequentemente foram empréstimos que chegaram via finlandês.

No campo referente à glossa, além desta, há também a palavra em finlandês, para que possa ser feita a consulta cruzada em dicionários finlandês-saami skolt, e a grafia oficial da palavra em saami skolt, retirada da plataforma Neahttadigisánit (http://saan.oahpa.no).

As palavras estão dispostas com base no primeiro som da transcrição em Itkonen na seguinte ordem: $\mathrm{a}-\mathrm{e}-\mathrm{h}-\mathrm{j}-\mathrm{k}-1-\mathrm{m}-\mathrm{n}-\mathrm{o}-\mathrm{p}-\mathrm{s}-\mathrm{t}-\mathrm{v}$. 
1.

\begin{tabular}{|c|c|c|c|}
\hline Itkonen & Korhonen & Etimologia & Glossa \\
\hline $\mathbf{P}$ a $\overline{\mathrm{in}}^{\mathrm{a}}$ & / àjră / & Escandinava & remo.SG.NOM \\
\hline $\mathbf{N} \underset{>\wedge}{\operatorname{ai} \bar{r}^{\mathrm{a}}}$ & [äĭr̆r $\left.{ }^{A}{ }^{A}\right]$ & & (fin. airo) <äirr > \\
\hline
\end{tabular}

2.

\begin{tabular}{|c|c|c|c|}
\hline Itkonen & Korhonen & Etimologia & Glossa \\
\hline 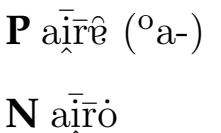 & - & Escandinava & $\begin{array}{l}\text { remo.SG.ILL } \\
\text { (fin. airo) < airru> }\end{array}$ \\
\hline
\end{tabular}

3.

\begin{tabular}{|c|c|c|c|}
\hline Itkonen & Korhonen & Etimologia & Glossa \\
\hline $\mathbf{P} \dot{a}_{\bar{l}} \overline{\bar{G}_{\bar{\lambda}}}{ }^{\mathrm{E}}\left(-\overline{\mathrm{D}}^{\mathrm{E}}\right)$ & $<\hat{a}^{\prime} l \underline{g} \check{g}$ > & Não identifi- & menino.SG.NOM \\
\hline 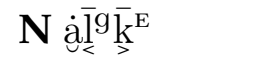 & 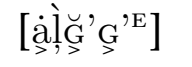 & cada & (fin. poika) <â'lğğ $>$ \\
\hline
\end{tabular}

\begin{tabular}{|c|c|c|c|}
\hline Itkonen & Korhonen & Etimologia & Glossa \\
\hline 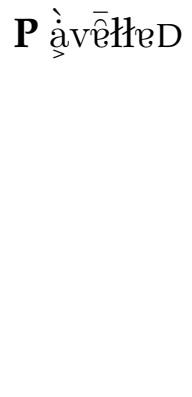 & 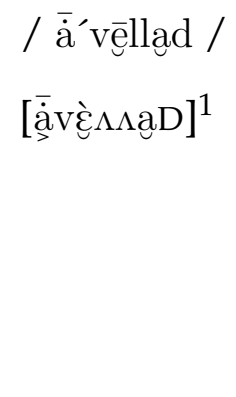 & Fino-úgrica & $\begin{array}{l}\text { abrir (repetida- } \\
\text { mente ou gradual- } \\
\text { mente).INF. } \\
\text { (fin. availla)<ää- } \\
\text { võõllâd }>\end{array}$ \\
\hline
\end{tabular}

\begin{tabular}{|c|c|c|c|}
\hline Itkonen & Korhonen & Etimologia & Glossa \\
\hline $\mathbf{P}$ à̀vểłam & 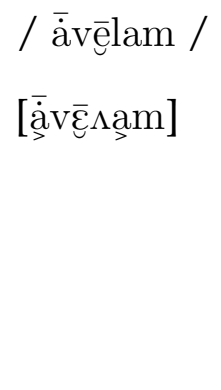 & Fino-úgrica & $\begin{array}{l}\text { abrir (repetida- } \\
\text { mente ou gradual- } \\
\text { mente).PST.1.SG. } \\
\text { (fin. availla) <ää- } \\
\text { võõlam> }\end{array}$ \\
\hline
\end{tabular}


6.

\begin{tabular}{|c|c|c|c|}
\hline Itkonen & Korhonen & Etimologia & Glossa \\
\hline 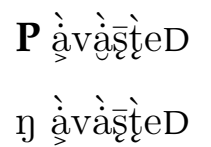 & 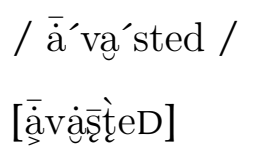 & Fino-úgrica & $\begin{array}{l}\text { abrir.INF. } \\
\text { (fin. avata) }\end{array}$ \\
\hline
\end{tabular}

\begin{tabular}{|c|c|c|c|}
\hline Itkonen & Korhonen & Etimologia & Glossa \\
\hline $\mathbf{P} e^{\mathrm{j}} \overline{\mathrm{t}} \mathrm{t} \check{\mathrm{s} a}$ & / ečča / & Fino-úgrica & pai.SG.ILL \\
\hline $\mathbf{N}$ ęśtttš̀ & 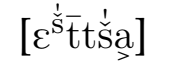 & & (fin. isä) $<\mathrm{e}^{\prime} \breve{c ̌ c ̌}>$ \\
\hline
\end{tabular}

\begin{tabular}{|c|c|c|c|}
\hline Itkonen & Korhonen & Etimologia & Glossa \\
\hline P S hả & 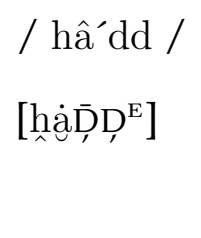 & $\begin{array}{l}\text { Não identifi- } \\
\text { cada }\end{array}$ & $\begin{array}{l}\text { preço.SG.NOM } \\
\text { (fin. hinta) } \\
<\text { hâ'dd> }\end{array}$ \\
\hline
\end{tabular}

9.

\begin{tabular}{|c|c|c|c|}
\hline Itkonen & Korhonen & Etimologia & Glossa \\
\hline $\mathbf{P}$ jieng ${ }^{\mathrm{a}}$ & $<$ jieyy $>$ & Fino-úgrica & gelo.SG.NOM \\
\hline $\mathbf{N}$ jiey $y^{\mathrm{a}}$ & {$\left[\operatorname{jieg}_{<}{ }^{a} y^{a}\right]$} & & (fin. jä̈) <jiõ̃y > \\
\hline
\end{tabular}

10.

\begin{tabular}{|l|l|l|l|}
\hline Itkonen & Korhonen & Etimologia & Glossa \\
\hline $\mathbf{P}$ jo ${ }^{\circ} \mathrm{kk}^{\mathrm{A}}$ (jo-) & $/$ jokkă & Fino-úgrica & rio.SG.NOM \\
$\mathbf{N}$ jookk & & & (fin. joki) $<$ jokk $>$ \\
\hline
\end{tabular}

\begin{tabular}{|c|}
\hline Glossa \\
\hline $\begin{array}{l}\text { rio.SG.ILL } \\
(\text { fin. joki) <jo ‘̌k̆e> }\end{array}$ \\
\hline
\end{tabular}

\begin{tabular}{|c|c|c|c|}
\hline Itkonen & Korhonen & Etimologia & Glossa \\
\hline $\mathbf{P} \mathrm{j} \overline{\mathrm{o}}^{\mathrm{D}} \mathrm{kk}^{\mathrm{A}}$ & $\begin{array}{l}\text { / jōkkka / } \\
{\left[\mathrm{j} \overline{\mathrm{h}}^{\mathrm{h}} \breve{\mathrm{k}} \mathrm{k}^{\mathrm{A}}\right]}\end{array}$ & Fino-úgrica & $\begin{array}{l}\text { beber.PRS.3.SG } \\
\text { (fin. juoda) <jookk> }\end{array}$ \\
\hline
\end{tabular}




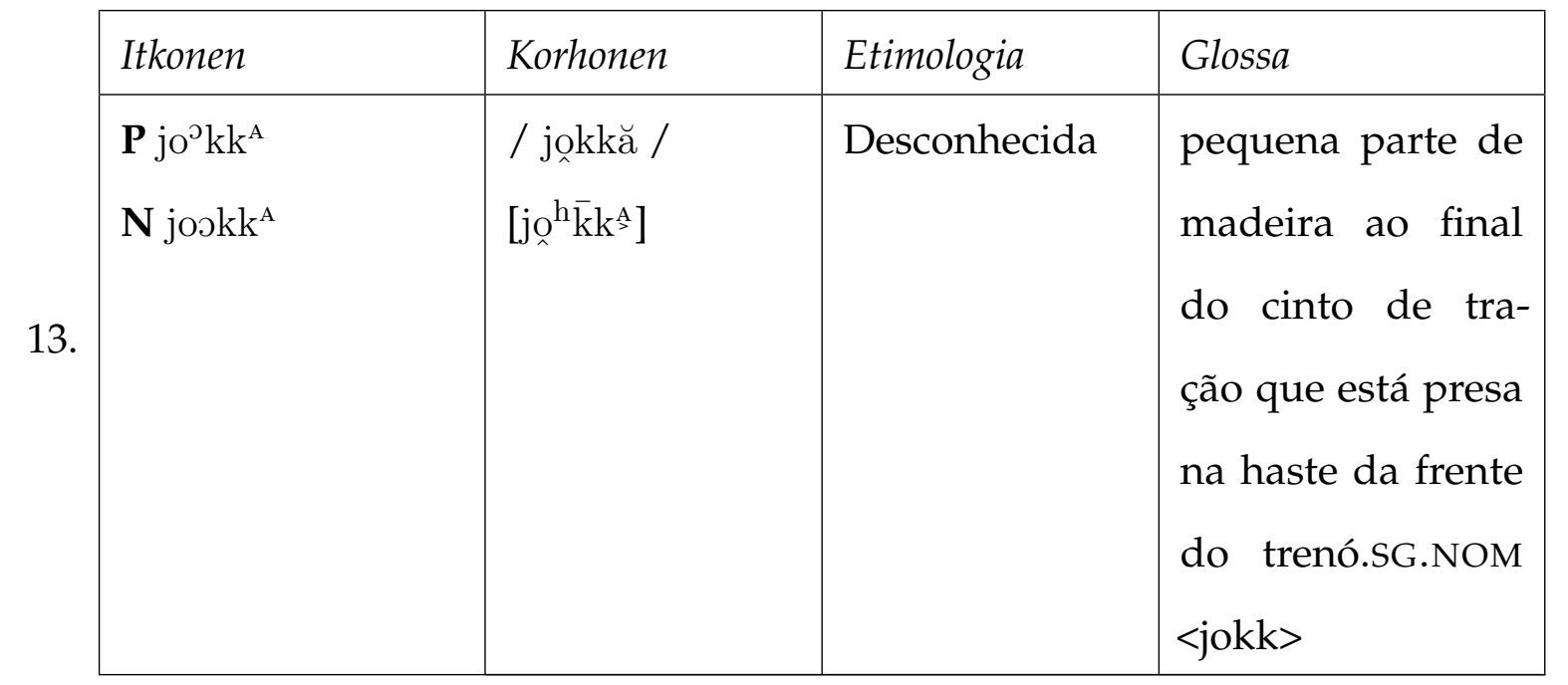

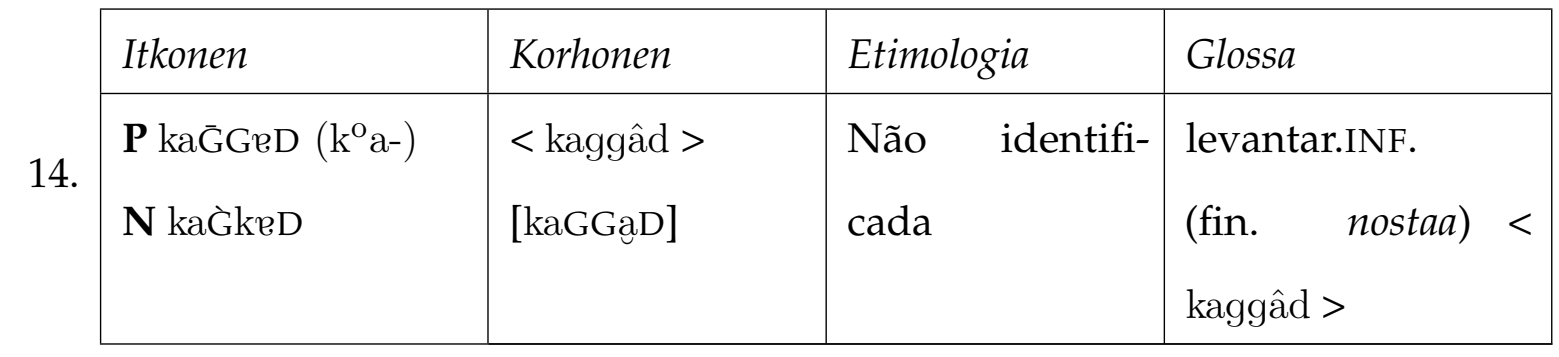

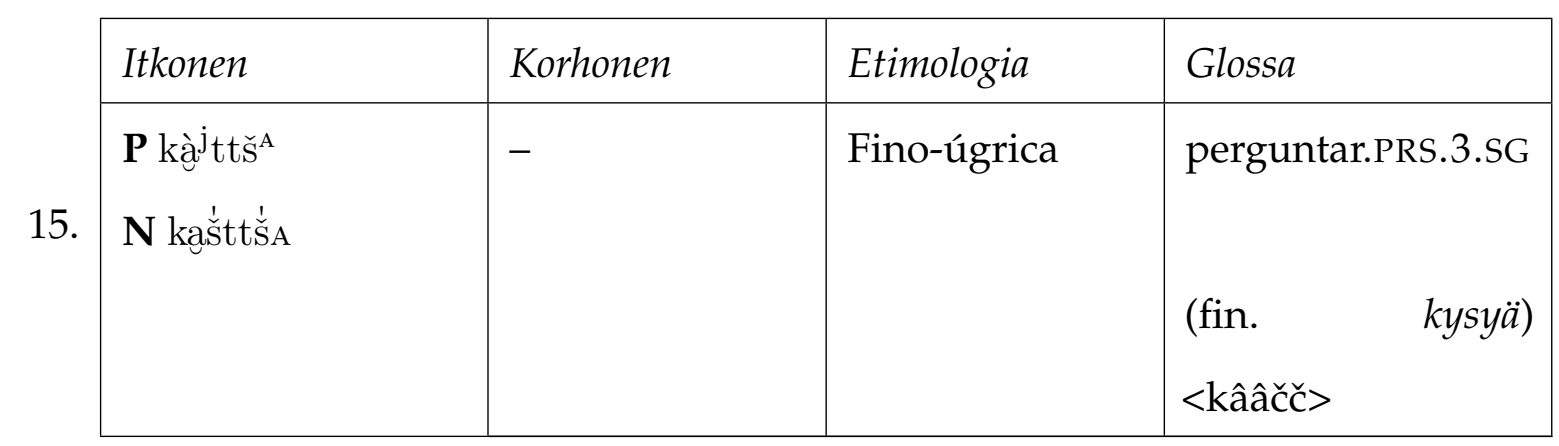

\begin{tabular}{|c|c|c|c|}
\hline Itkonen & Korhonen & Etimologia & Glossa \\
\hline 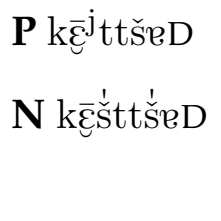 & 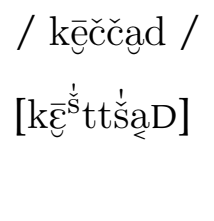 & Fino-úgrica & $\begin{array}{l}\text { perguntar.INF } \\
\text { (fin. kysyä) } \\
<\text { kõõččâd> }\end{array}$ \\
\hline
\end{tabular}




\begin{tabular}{|c|c|c|c|}
\hline Itkonen & Korhonen & Etimologia & Glossa \\
\hline $\mathbf{P}$ ḱełła jeD & $\begin{array}{l}\text { / kellǐjed / } \\
{\left[{ }_{>}^{\prime} \varepsilon \lambda_{\Lambda} \Lambda^{\mathrm{i}} \mathrm{jeD}\right]}\end{array}$ & $\begin{array}{l}\text { Não identifi- } \\
\text { cada }\end{array}$ & 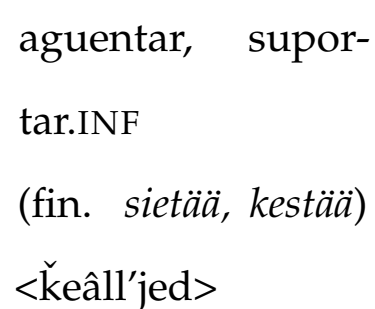 \\
\hline
\end{tabular}

\begin{tabular}{|c|c|c|c|}
\hline Itkonen & Korhonen & Etimologia & Glossa \\
\hline P N ḱëäzzam & 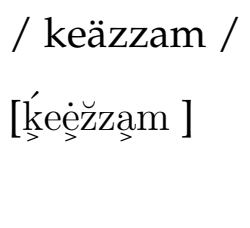 & $\begin{array}{l}\text { Não identifi- } \\
\text { cada }\end{array}$ & $\begin{array}{l}\text { puxar.PRS.1.SG. } \\
\text { (fin. vetää) } \\
<\check{\text { keäzzam> }}\end{array}$ \\
\hline
\end{tabular}

\begin{tabular}{|l|l|l|l|}
\hline Itkonen & Korhonen & Etimologia & Glossa \\
\hline P N ḱieșșeD & - & Não identifi- & $\begin{array}{l}\text { puxar.INF. } \\
\text { (fin. } \\
\text { cada vetää) }\end{array}$ \\
\hline
\end{tabular}

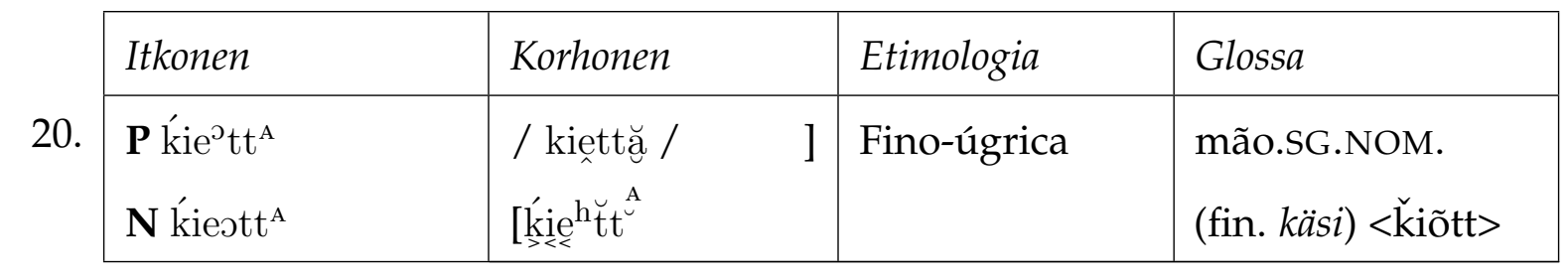

\begin{tabular}{|c|c|c|c|}
\hline Itkonen & Korhonen & Etimologia & Glossa \\
\hline $\begin{array}{l}\mathbf{P} \text { kọ̣le } \\
\mathbf{N} \text { kọ, }]_{1}^{\mathrm{e}}\end{array}$ & 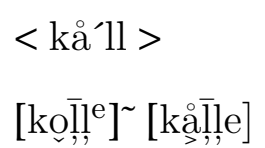 & Germânica & $\begin{array}{l}\text { ouro.SG.NOM } \\
\text { (fin. kulta) <kå } 11>\end{array}$ \\
\hline
\end{tabular}

\begin{tabular}{|c|c|c|c|}
\hline Itkonen & Korhonen & Etimologia & Glossa \\
\hline $\begin{array}{l}\mathbf{P} \text { kōłla } \\
\mathbf{N} \text { kơ }{ }^{\mathrm{a}} \text { ліла }\end{array}$ & - & Germânica & $\begin{array}{l}\text { ouro.SG.ILL } \\
\text { (fin. } k \text { ulta) }<\text { kålla }>\end{array}$ \\
\hline
\end{tabular}




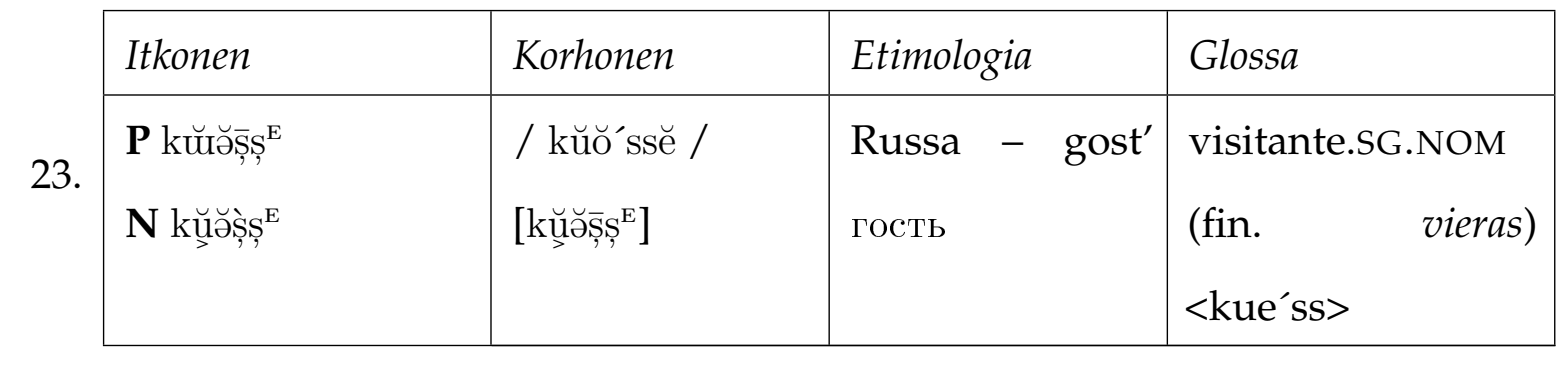

\begin{tabular}{|c|c|c|c|}
\hline Itkonen & Korhonen & Etimologia & Glossa \\
\hline 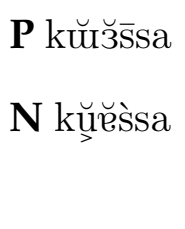 & - & $\begin{array}{l}\text { Russa }- \text { gost }^{\prime} \\
\text { гость }\end{array}$ & $\begin{array}{l}\text { visitante.SG.ILL } \\
\text { (fin. vieras) } \\
<\text { kuâssa> }\end{array}$ \\
\hline
\end{tabular}

\begin{tabular}{|c|c|c|c|}
\hline Itkonen & Korhonen & Etimologia & Glossa \\
\hline $\begin{array}{l}\mathbf{P} \text { kuo }^{\circ} \text { ttsed } \\
\mathbf{N} \text { kŭeottseD } \\
\text { +koahce- })\end{array}$ & $\begin{array}{l}\text { / kuåccad / } \\
\text { [kuåh }{ }_{\text {ttsaD] }}\end{array}$ & $\begin{array}{l}\text { Não identifi- } \\
\text { cada }\end{array}$ & $\begin{array}{l}\text { chegar por úl- } \\
\text { timo.INF } \\
\text { (fin. pitää perää) } \\
<\text { kuåccâd> }\end{array}$ \\
\hline
\end{tabular}

\begin{tabular}{|c|c|c|c|}
\hline Itkonen & Korhonen & Etimologia & Glossa \\
\hline $\begin{array}{l}\text { P kuoDDZam } \\
\mathbf{N} \text { kuaD̆DZam }\end{array}$ & - & $\begin{array}{l}\text { Não identifi- } \\
\text { cada }\end{array}$ & $\begin{array}{l}\text { chegar por úl- } \\
\text { timo.PRS.1.sG } \\
\text { (fin. pitää perää) } \\
<\text { kuåzzam> }\end{array}$ \\
\hline
\end{tabular}

\begin{tabular}{|l|l|l|l|}
\hline Itkonen & Korhonen & Etimologia & Glossa \\
\hline $\mathbf{P}$ kóa ${ }^{\circ}$ tts $^{\mathrm{A}}$ & - & Não identifi- & chegar por úl- \\
$\mathbf{N}$ kŭajttsa & & cada & $\begin{array}{l}\text { timo.PRS.3.SG } \\
\text { (fin. pitää perää) } \\
\end{array}$ \\
& & & $<$ kuäcc> \\
\hline
\end{tabular}




\begin{tabular}{|c|c|c|c|}
\hline Itkonen & Korhonen & Etimologia & Glossa \\
\hline 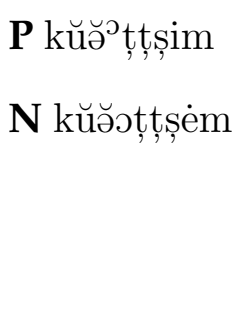 & - & $\begin{array}{l}\text { Não identifi- } \\
\text { cada }\end{array}$ & $\begin{array}{l}\text { chegar por úl- } \\
\text { timo.PST.1.PL } \\
\text { (fin. pitää perää) } \\
<\text { kuåzzim> }\end{array}$ \\
\hline
\end{tabular}

\begin{tabular}{|l|l|l|l|}
\hline Itkonen & Korhonen & Etimologia & Glossa \\
\hline $\mathbf{P}$ kŭəș̦̦țeD & - & Não identifi- & ver.INF \\
$\mathbf{N}$ kŭŏșted & & cada & näkyä) \\
& & & <kue'stted> \\
\hline
\end{tabular}

\begin{tabular}{|c|c|c|c|}
\hline Itkonen & Korhonen & Etimologia & Glossa \\
\hline 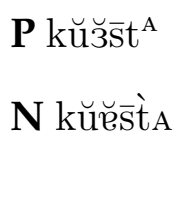 & - & $\begin{array}{l}\text { Não identifi- } \\
\text { cada }\end{array}$ & $\begin{array}{l}\text { ver.PRS.3.SG. } \\
\text { (fin. nükyä) } \\
<\text { kuâstt> }\end{array}$ \\
\hline
\end{tabular}

\begin{tabular}{|c|c|c|c|}
\hline Itkonen & Korhonen & Etimologia & Glossa \\
\hline $\begin{array}{l}\mathbf{P} \text { kuoșt }^{\mathrm{I}} \\
\mathbf{N} \text { kuossti }\end{array}$ & - & $\begin{array}{l}\text { Não identifi- } \\
\text { cada }\end{array}$ & $\begin{array}{l}\text { ver.PST.3.SG } \\
\text { (fin. näkyä) } \\
<\text { kuõ'sti> } \\
\text { <kue'sti> }\end{array}$ \\
\hline
\end{tabular}

\begin{tabular}{|l|l|l|l|}
\hline Itkonen & Korhonen & Etimologia & Glossa \\
\hline P kŭōsted & - & Fino-úgrica & molhar.INF \\
N kŭŏs̄teD (kŭă-) & & & (fin. kostua) <kuåst- \\
& & & tâd> \\
\hline
\end{tabular}


33.

\begin{tabular}{|c|c|c|c|}
\hline Itkonen & Korhonen & Etimologia & Glossa \\
\hline $\begin{array}{l}\mathbf{P} \text { kọ̆ăs̆̀ta } \\
\mathbf{N} \text { kŭăs̆ta }\end{array}$ & - & Fino-úgrica & $\begin{array}{l}\text { molhar.PRS.3.SG } \\
\text { (fin. kostua) } \\
<\text { kuästt> }\end{array}$ \\
\hline
\end{tabular}

34.

\begin{tabular}{|c|c|c|c|}
\hline Itkonen & Korhonen & Etimologia & Glossa \\
\hline $\begin{array}{l}\mathbf{P} \text { kŭŏș̦tim } \\
\mathbf{N} \text { kŭŏșstèm }\end{array}$ & - & Fino-úgrica & $\begin{array}{l}\text { molhar.PST.1.SP } \\
\text { (fin. kostua) } \\
\text { <kuå'sttem> }\end{array}$ \\
\hline
\end{tabular}

35.

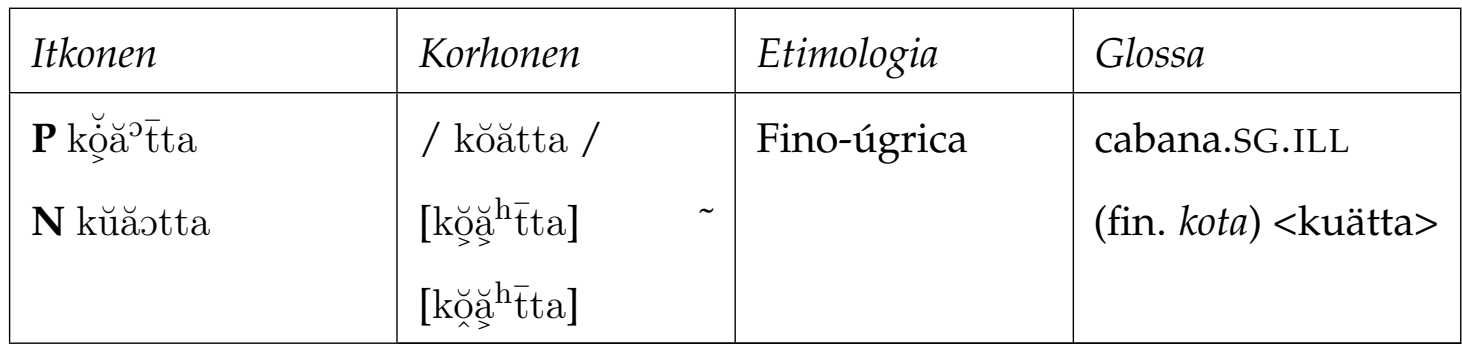

36.

\begin{tabular}{|c|c|c|c|}
\hline Itkonen & Korhonen & Etimologia & Glossa \\
\hline $\begin{array}{l}\mathbf{P} \text { kọ̆a } a^{a} t t^{\dot{E}} \\
\mathbf{N} \text { kŭestțț }\end{array}$ & - & Fino-úgrica & $\begin{array}{l}\text { cabana.SG.NOM } \\
(\text { fin. } k o t a)<\text { kue }^{\prime} \mathrm{tt}>\end{array}$ \\
\hline
\end{tabular}

37.

\begin{tabular}{|c|c|c|c|}
\hline Itkonen & Korhonen & Etimologia & Glossa \\
\hline $\begin{array}{l}\mathbf{P} \operatorname{kuo}_{>} \delta \hat{i} \\
\eta \operatorname{ku} \overline{\mathrm{i}}\end{array}$ & - & Fino-úgrica & $\begin{array}{l}\text { cabana.PL.G } \\
\text { (fin. kota) <kue'di }> \\
<\text { kuä'di }>^{\prime}\end{array}$ \\
\hline
\end{tabular}

38.

\begin{tabular}{|c|c|c|c|}
\hline Itkonen & Korhonen & Etimologia & Glossa \\
\hline P kŭ3ssțed & / kucss'ted / & Fino-úgrica & entreter.INF \\
\hline $\mathbf{N}$ kŭess $\left({ }^{\mathrm{A} J}\right) \grave{t t} t \in \mathrm{D}$ & [kuăs̆steD] & & $\begin{array}{l}\text { (fin. kestitä) <kuâs- } \\
\text { sted }>\end{array}$ \\
\hline
\end{tabular}




\begin{tabular}{|c|c|c|c|}
\hline Itkonen & Korhonen & Etimologia & Glossa \\
\hline $\begin{array}{l}\mathbf{P} \text { kŭussăa }{ }^{\mathrm{t} t} \\
\mathbf{N} \operatorname{kuassa}_{>} \mathrm{t}\end{array}$ & - & Fino-úgrica & $\begin{array}{l}\text { entreter.PRS.3.SG } \\
\text { (fin. kestitä) <kuâs- } \\
\text { sat> }\end{array}$ \\
\hline
\end{tabular}

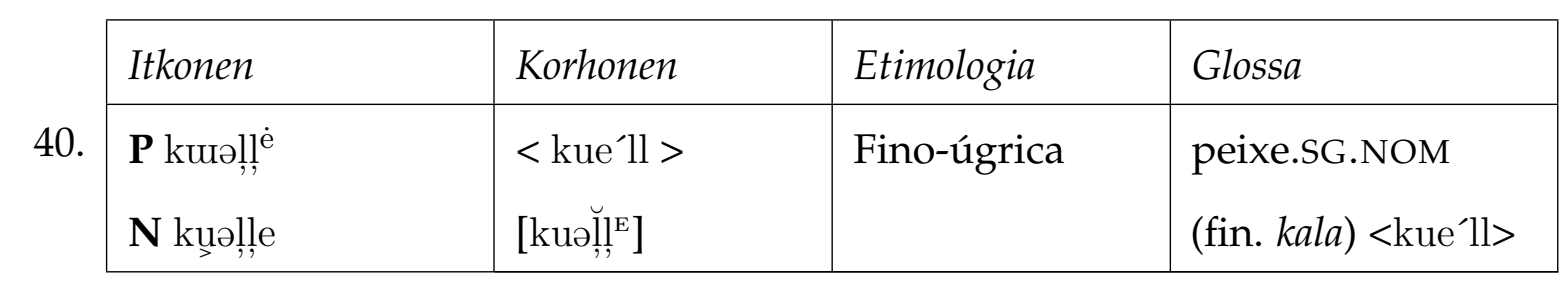

\begin{tabular}{|c|c|c|c|}
\hline Itkonen & Korhonen & Etimologia & Glossa \\
\hline 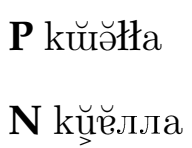 & - & Fino-úgrica & $\begin{array}{l}\text { peixe.SG.ILL } \\
\text { (fin. kala) }<\text { kuâlla> }\end{array}$ \\
\hline
\end{tabular}

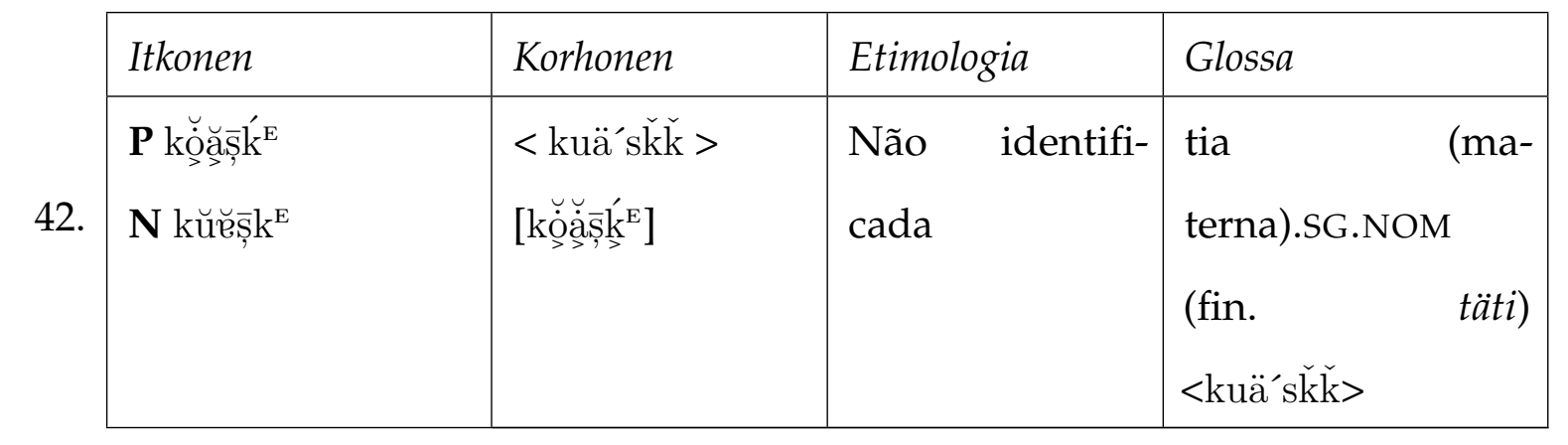

43.

\begin{tabular}{|l|l|l|ll|}
\hline Itkonen & Korhonen & Etimologia & Glossa & \\
\hline $\mathbf{P}$ kọ̆̆ăs̀̀a & - & Não identifi- & tia & (ma- \\
$\mathbf{N}$ kŭăs̀ska & & cada & $\begin{array}{l}\text { terna).sG.ILL } \\
\text { (fin. täti) }\end{array}$ & \\
\hline
\end{tabular}




\begin{tabular}{|c|c|c|c|c|}
\hline \multirow[b]{2}{*}{44.} & Itkonen & Korhonen & Etimologia & Glossa \\
\hline & 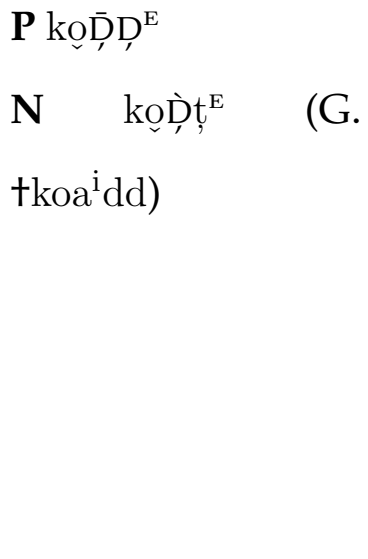 & 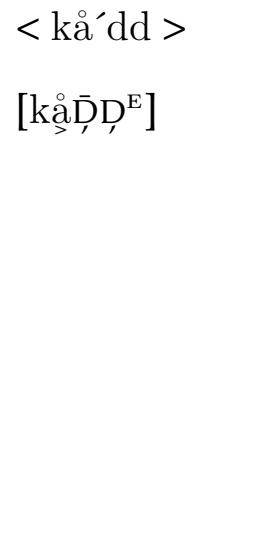 & $\begin{array}{l}\text { Não identifi- } \\
\text { cada }\end{array}$ & $\begin{array}{l}\text { rena.SG.NOM } \\
\text { (possivelmente, } \\
\text { a subespécie de } \\
\text { floresta, Rangifer } \\
\text { tarandus fennicus). } \\
\text { (fin. peura) } \\
<\text { kå }^{\mathrm{d} d \mathrm{~d}>}\end{array}$ \\
\hline \multirow[b]{2}{*}{45.} & Itkonen & Korhonen & Etimologia & Glossa \\
\hline & 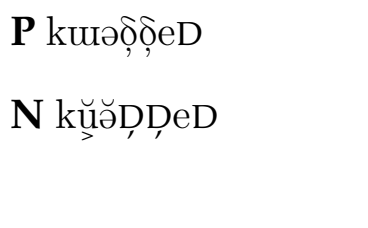 & 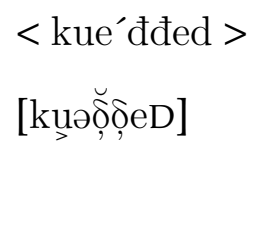 & $\begin{array}{l}\text { Não identifi- } \\
\text { cada }\end{array}$ & $\begin{array}{l}\text { deixar.INF. } \\
\text { (fin. jättää) } \\
\text { <kue'dđed> }\end{array}$ \\
\hline
\end{tabular}

\begin{tabular}{|c|c|c|c|}
\hline Itkonen & Korhonen & Etimologia & Glossa \\
\hline $\begin{array}{l}\mathbf{P} \text { kŭзбăàm } \\
\mathbf{N} \text { kụeDam }\end{array}$ & - & $\begin{array}{l}\text { Não identifi- } \\
\text { cada }\end{array}$ & $\begin{array}{l}\text { deixar.PRS.1.SG. } \\
\text { (fin. jättää) } \\
<\text { kuâđam> }\end{array}$ \\
\hline
\end{tabular}

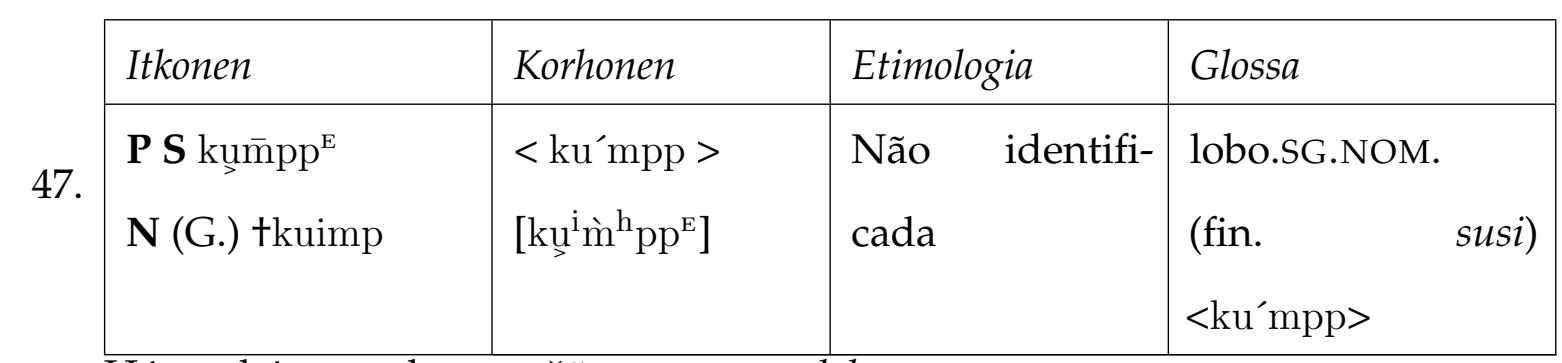

Há também a palavra < čõrmm > para lobo.

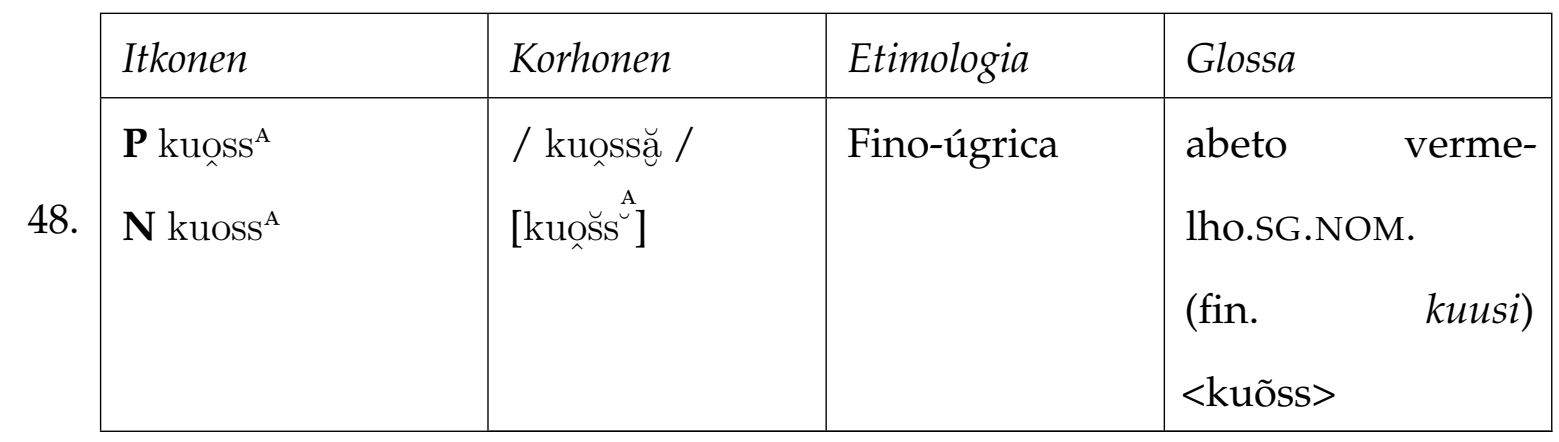




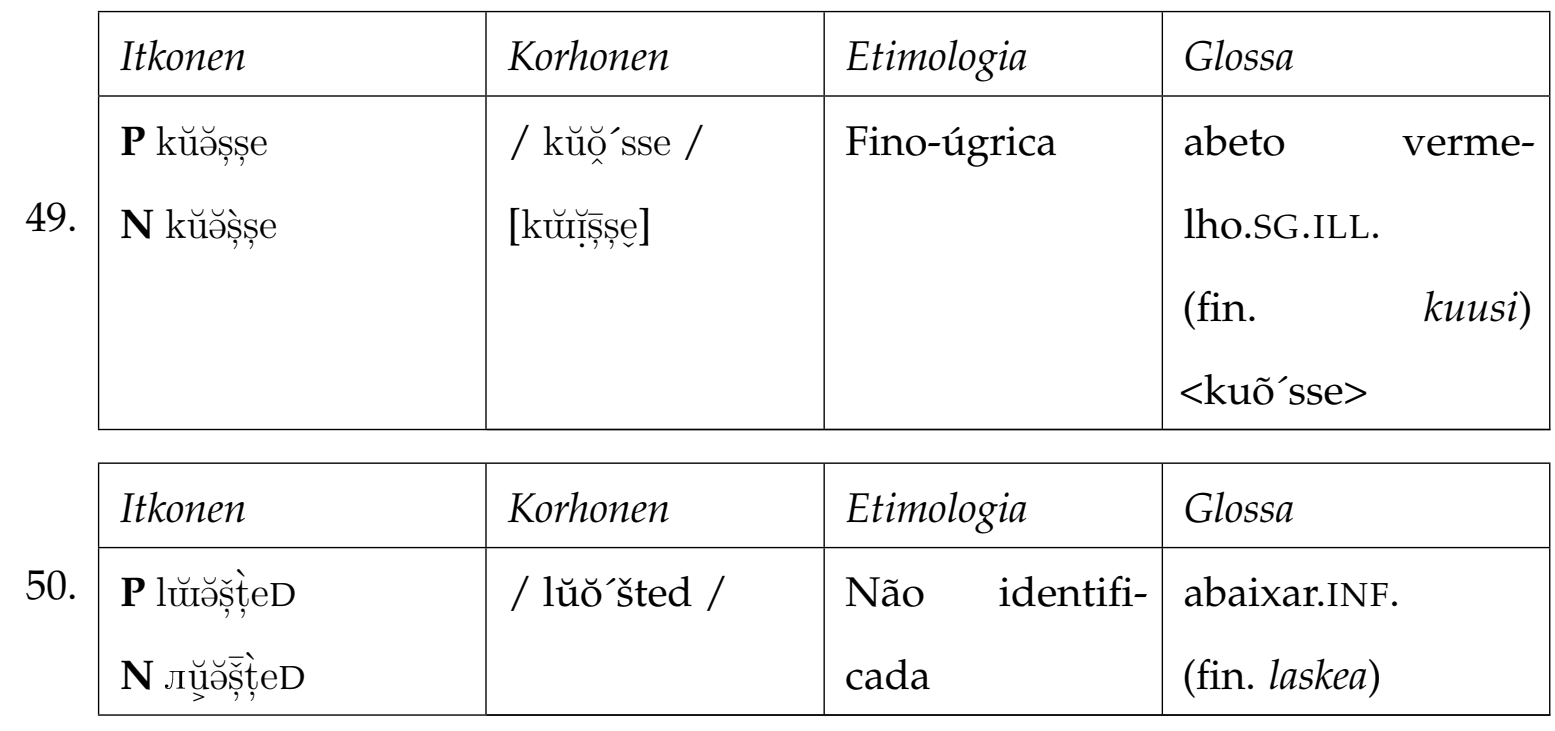

\begin{tabular}{|c|c|c|c|c|}
\hline \multirow[b]{2}{*}{51.} & Itkonen & Korhonen & Etimologia & Glossa \\
\hline & $\begin{array}{l}\mathbf{P} \text { luзštăm } \\
\mathbf{N} \text { ле̧šstam }\end{array}$ & - & $\begin{array}{l}\text { Não identifi- } \\
\text { cada }\end{array}$ & $\begin{array}{l}\text { abaixar.PRS.1.SG. } \\
\text { (fin. laskea) }\end{array}$ \\
\hline \multirow[b]{2}{*}{52.} & Itkonen & Korhonen & Etimologia & Glossa \\
\hline & $\begin{array}{l}\mathbf{P} \text { luoșțí } \\
\mathbf{N} \text { лuәșॅți }\end{array}$ & - & $\begin{array}{l}\text { Não identifi- } \\
\text { cada }\end{array}$ & $\begin{array}{l}\text { abaixar.PST.3.SG. } \\
\text { (fin. laskea) }\end{array}$ \\
\hline
\end{tabular}

\begin{tabular}{|l|l|l|l|}
\hline Itkonen & Korhonen & Etimologia & Glossa \\
\hline $\mathbf{P}$ liemm $^{\mathrm{a}}$ & - & Fino-úgrica & caldo.SG.NOM. \\
$\mathbf{N}$ liemm $^{\mathrm{a}}$ & & & (fin. liemi) \\
& & & $<$ liõmm> \\
\hline
\end{tabular}

\begin{tabular}{|c|c|c|c|}
\hline Itkonen & Korhonen & Etimologia & Glossa \\
\hline $\begin{array}{l}\text { P liẹmmme } \\
\mathbf{N} \text { liẹ̆mme }\end{array}$ & $\begin{array}{l}\text { / liemmă / } \\
{\left[\operatorname{lie}_{<} \breve{m m}^{\mathrm{A}}\right]}\end{array}$ & Fino-úgrica & $\begin{array}{l}\text { caldo.SG.ILL. } \\
\text { (fin. liemi) } \\
\text { <liõ'mme> }\end{array}$ \\
\hline
\end{tabular}

\begin{tabular}{|c|c|c|c|}
\hline Itkonen & Korhonen & Etimologia & Glossa \\
\hline $\begin{array}{l}\mathbf{P} \operatorname{luoss}^{\mathrm{A}} \\
\mathbf{N} \operatorname{ruoss}^{\mathrm{A}}\end{array}$ & $\begin{array}{l}\text { / luossăă / } \\
{\left[\operatorname{uos̆s}^{A}{ }^{A}\right]}\end{array}$ & Fino-úgrica & $\begin{array}{l}\text { salmão.SG.NOM. } \\
\text { (fin. lohi) <luõss> }\end{array}$ \\
\hline
\end{tabular}




\begin{tabular}{|c|c|c|c|}
\hline Itkonen & Korhonen & Etimologia & Glossa \\
\hline 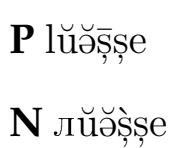 & - & Fino-úgrica & $\begin{array}{l}\text { salmão.SG.ILL. } \\
\text { (fin. lohi) <luõ'sse> }\end{array}$ \\
\hline
\end{tabular}

\begin{tabular}{|c|c|c|c|}
\hline Itkonen & Korhonen & Etimologia & Glossa \\
\hline 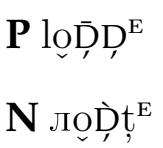 & $\begin{array}{l}<\text { lå }^{\prime} \mathrm{dd}> \\
{\left[\operatorname{lă\supset }_{\supset}{ }^{\mathrm{E}}{ }^{\mathrm{E}}\right]}\end{array}$ & Fino-úgrica & $\begin{array}{l}\text { pássaro.SG.NOM. } \\
(\text { fin. lintu) <lå’dd> }\end{array}$ \\
\hline
\end{tabular}

\begin{tabular}{|c|c|c|c|}
\hline Itkonen & Korhonen & Etimologia & Glossa \\
\hline $\begin{array}{l}\mathbf{P} \text { lō̄̄Da } \\
\mathbf{N} \text { ло̆ằ̀ta }\end{array}$ & - & Fino-úgrica & $\begin{array}{l}\text { pássaro.SG.ILL. } \\
\text { (fin. lintu) <lådda> }\end{array}$ \\
\hline
\end{tabular}

\begin{tabular}{|c|c|c|c|}
\hline Itkonen & Korhonen & Etimologia & Glossa \\
\hline $\begin{array}{l}\mathbf{P} \text { laụ̀ }{ }^{\circ} k^{\mathrm{A}}\left(\mathrm{l}^{\mathrm{O}} \mathrm{a}-\right) \\
\mathbf{N} \text { лай̀ } k^{\mathrm{A}}\end{array}$ & $\begin{array}{l}<\text { laukk > } \\
{\left[\text { лай }{ }_{\wedge}^{\mathrm{h}} \mathrm{kk}^{\mathrm{A}} \text { ] }\right.}\end{array}$ & Fino-úgrica & $\begin{array}{l}\text { bolsa.SG.NOM. } \\
\text { (fin. laukku) } \\
\text { <laukk> }\end{array}$ \\
\hline
\end{tabular}

\begin{tabular}{|c|c|c|c|}
\hline Itkonen & Korhonen & Etimologia & Glossa \\
\hline 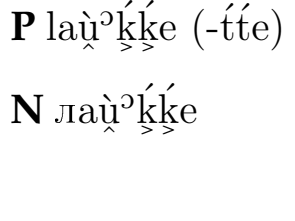 & - & Fino-úgrica & $\begin{array}{l}\text { bolsa.SG.ILL. } \\
\text { (fin. laukku) } \\
\text { <lau’̌̌ǩke }\end{array}$ \\
\hline
\end{tabular}

\begin{tabular}{|c|c|c|c|}
\hline Itkonen & Korhonen & Etimologia & Glossa \\
\hline $\begin{array}{l}\mathbf{P} \operatorname{măhn,~}^{\mathrm{e}} \\
\mathbf{N} \text { măn, } n^{\mathrm{e}}\end{array}$ & 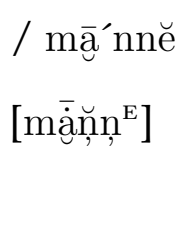 & Fino-úgrica & $\begin{array}{l}\text { ovo.SG.NOM. } \\
\text { (fin. muna) } \\
<\text { mââ'm> }\end{array}$ \\
\hline
\end{tabular}

\begin{tabular}{|l|l|l|l|}
\hline 62. & Korhonen & Etimologia & Glossa \\
\hline $\mathbf{P}$ man̄na & - & Fino-úgrica & ovo.SG.ILL. \\
$\mathbf{N}$ màñna & & (fin. muna) \\
& & & $<$ mânna $>$ \\
\hline
\end{tabular}


63.

\begin{tabular}{|c|c|c|c|}
\hline Itkonen & Korhonen & Etimologia & Glossa \\
\hline $\begin{array}{l}\mathbf{P} \text { męn,ni } \\
\mathbf{N} \text { mẹn, } \bar{i}\end{array}$ & - & Fino-úgrica & $\begin{array}{l}\text { ovo.PL.G.. } \\
\text { (fin. } \quad \text { muna) } \\
\text { <mõõ'ni> }\end{array}$ \\
\hline
\end{tabular}

64.

\begin{tabular}{|c|c|c|c|}
\hline Itkonen & Korhonen & Etimologia & Glossa \\
\hline $\begin{array}{l}\mathbf{P} \operatorname{màin}\left({ }^{e}\right) \text { șted } \\
\left(\mathrm{m}^{\mathrm{O}} \text { à- }\right) \\
\mathbf{N} \text { màin }\left(^{\mathrm{a}}\right) \text { șted }\end{array}$ & $\begin{array}{l}\text { / mājnăsted / } \\
\text { [màinșteD] }\end{array}$ & Báltica & $\begin{array}{l}\text { contar.INF } \\
(\text { fin. kertoa (satuja)) } \\
<\text { mainsted }>\end{array}$ \\
\hline
\end{tabular}

65.

\begin{tabular}{|c|c|c|c|}
\hline Itkonen & Korhonen & Etimologia & Glossa \\
\hline $\begin{array}{l}\mathbf{P} \text { mięrr }{ }^{\mathrm{a}} \\
\mathbf{N} \text { mierr }{ }^{\mathrm{a}}\end{array}$ & $\begin{array}{l}\text { / micrrăă / } \\
{\left[\operatorname{mi\varepsilon } \breve{r} \breve{a}^{A}\right]}\end{array}$ & Indo-europeia & $\begin{array}{l}\text { mar.SG.NOM } \\
\text { (fin. meri) <miârr }>\end{array}$ \\
\hline
\end{tabular}

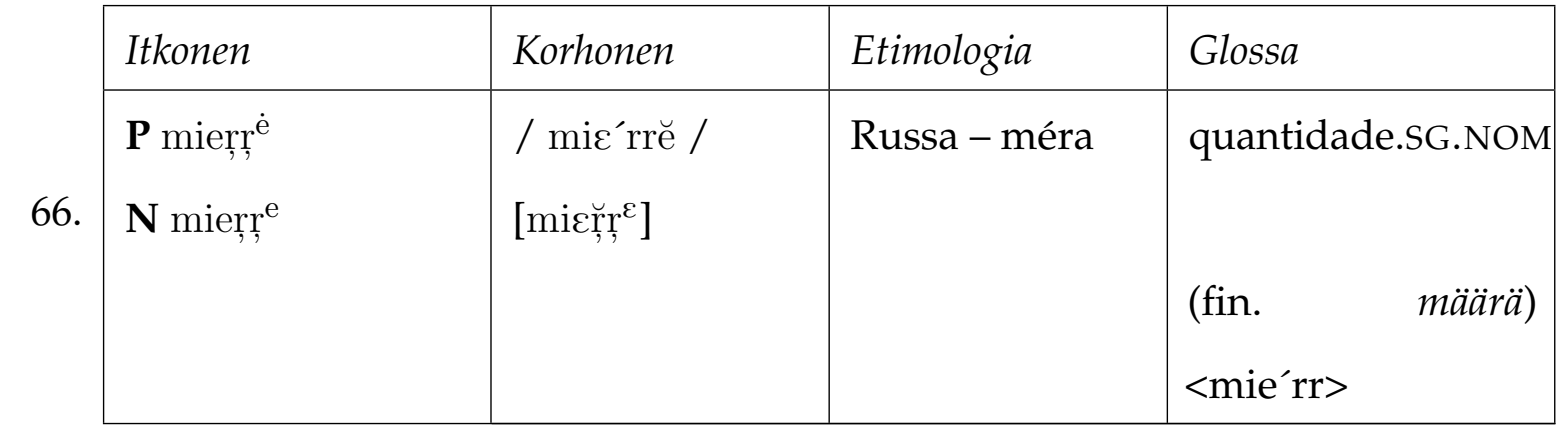

\begin{tabular}{|l|l|l|l|}
\hline Itkonen & Korhonen & Etimologia & Glossa \\
\hline $\begin{array}{l}\text { P mĕărīra } \\
\text { N mẹằ̀ra }\end{array}$ & - & Russa méra & quantidade.SG.ILL \\
& & & (fin. määrä) \\
& & & $<$ meärra $>$ \\
\hline
\end{tabular}

68.

\begin{tabular}{|l|l|l|ll|}
\hline Itkonen & Korhonen & Etimologia & Glossa & \\
\hline P S maǹne $\left(\mathrm{m}^{\mathrm{o}} \mathrm{a}-\right)$ & $/$ manno $/$ & Fino-úgrica & lua.SG.GEN & \\
N mannó & [man̄no] & & (fin. & kuu $)$ \\
& & & $<$ mannu> & \\
\hline
\end{tabular}




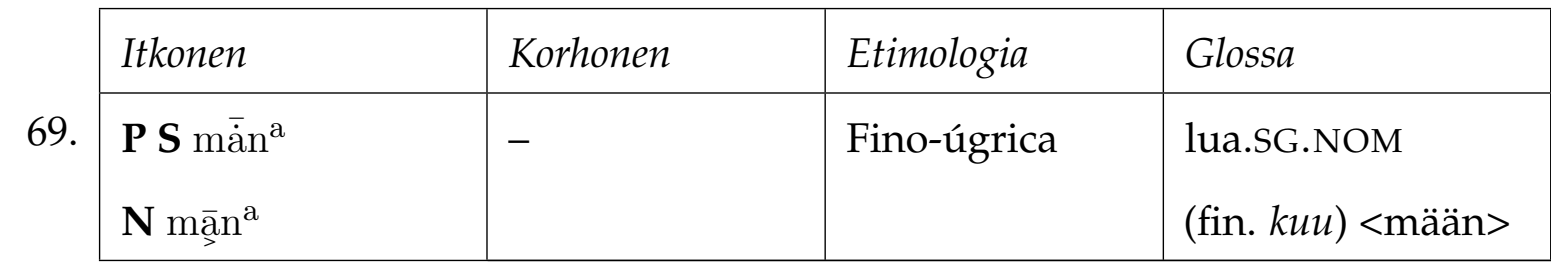

\begin{tabular}{|c|c|c|c|}
\hline Itkonen & Korhonen & Etimologia & Glossa \\
\hline 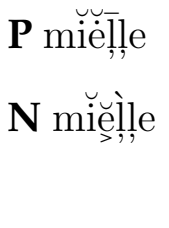 & 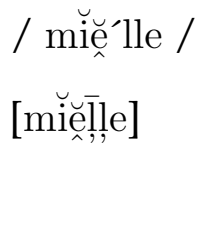 & $\begin{array}{l}\text { Não identifi- } \\
\text { cada }\end{array}$ & $\begin{array}{l}\text { mente.SG.ILL } \\
\text { (fin. mieli) } \\
<\text { miõ'lle }>\end{array}$ \\
\hline
\end{tabular}

\begin{tabular}{|l|l|l|l|}
\hline 71.konen & Korhonen & Etimologia & Glossa \\
\hline $\begin{array}{l}\mathbf{P} \text { miełł } \\
\mathbf{N} \text { miелл }^{\mathrm{a}}\end{array}$ & - & $\begin{array}{l}\text { Não identifi- } \\
\text { cada }\end{array}$ & $\begin{array}{l}\text { mente.SG.NOM } \\
\text { (fin. mieli) }<\text { miõll }>\end{array}$ \\
\hline
\end{tabular}

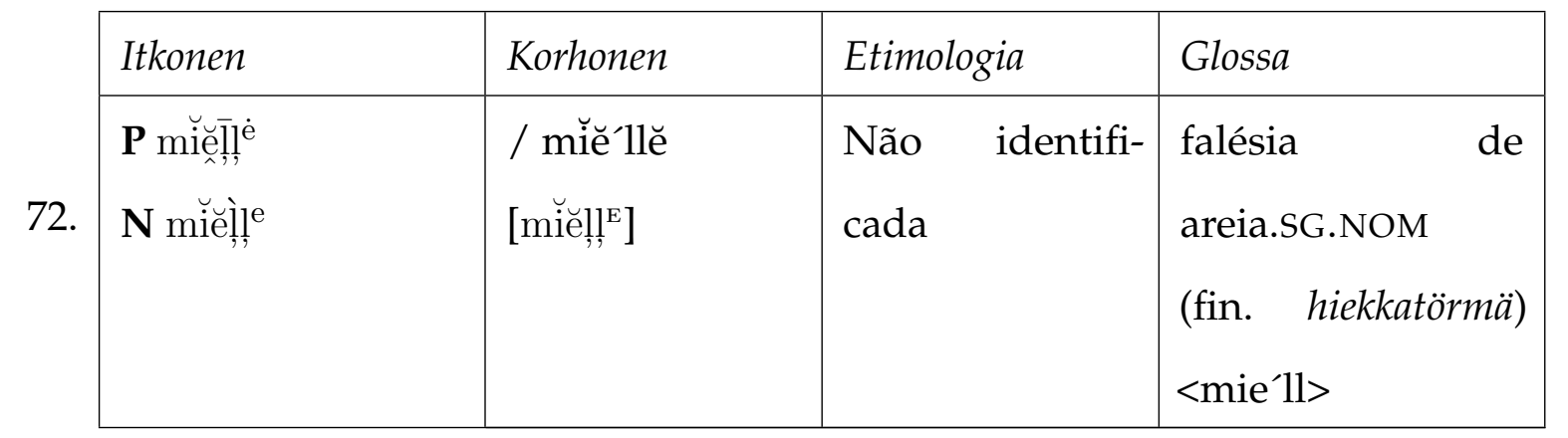

\begin{tabular}{|c|c|c|c|}
\hline Itkonen & Korhonen & Etimologia & Glossa \\
\hline $\begin{array}{l}\mathbf{P} \text { mię̆łła } \\
\mathbf{N} \text { miӗ̨лла }\end{array}$ & - & $\begin{array}{l}\text { Não identifi- } \\
\text { cada }\end{array}$ & $\begin{array}{l}\text { falésia de } \\
\text { areia.SG.ILL } \\
\text { (fin. hiekkatörmä) } \\
<\text { meâlla> }\end{array}$ \\
\hline
\end{tabular}

\begin{tabular}{|c|c|c|c|}
\hline Itkonen & Korhonen & Etimologia & Glossa \\
\hline 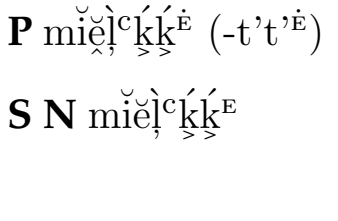 & $\begin{array}{l}<\operatorname{mie}^{\prime} l \check{k} \breve{k}> \\
{\left[\operatorname{miĕ}^{\mathrm{h}}{\underset{>}{k} k^{\prime}}^{\mathrm{E}}\right]}\end{array}$ & Germânica & 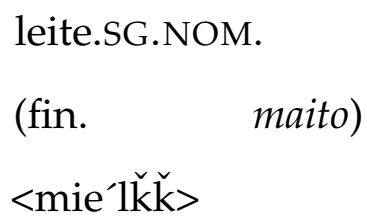 \\
\hline
\end{tabular}


Aqui, usa-se ${ }^{c}$ no lugar de ${ }^{\supset}$ para representar a aspiração (tal qual em leite.SG.ILL). Foi mantido conforme o original.

\begin{tabular}{|c|c|c|c|}
\hline Itkonen & Korhonen & Etimologia & Glossa \\
\hline 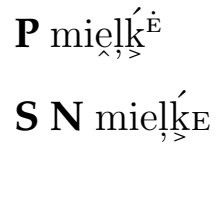 & - & Germânica & $\begin{array}{l}\text { leite.SG.GEN. } \\
\text { (fin. maito) } \\
\text { <mie'ľ }>\end{array}$ \\
\hline
\end{tabular}

\begin{tabular}{|c|c|c|c|}
\hline Itkonen & Korhonen & Etimologia & Glossa \\
\hline 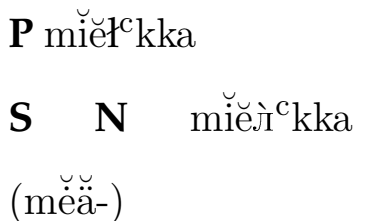 & - & Germânica & $\begin{array}{l}\text { leite.SG.ILL. } \\
\text { (fin. maito) } \\
<\text { meâlkka> }\end{array}$ \\
\hline
\end{tabular}

\begin{tabular}{|c|c|c|c|}
\hline Itkonen & Korhonen & Etimologia & Glossa \\
\hline 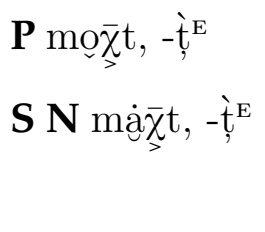 & 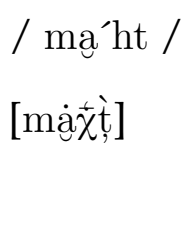 & $\begin{array}{l}\text { Não identifi- } \\
\text { cada }\end{array}$ & $\begin{array}{l}\text { como.ADV } \\
\text { (fin. kuinka) } \\
<\text { mä'htt> }\end{array}$ \\
\hline
\end{tabular}

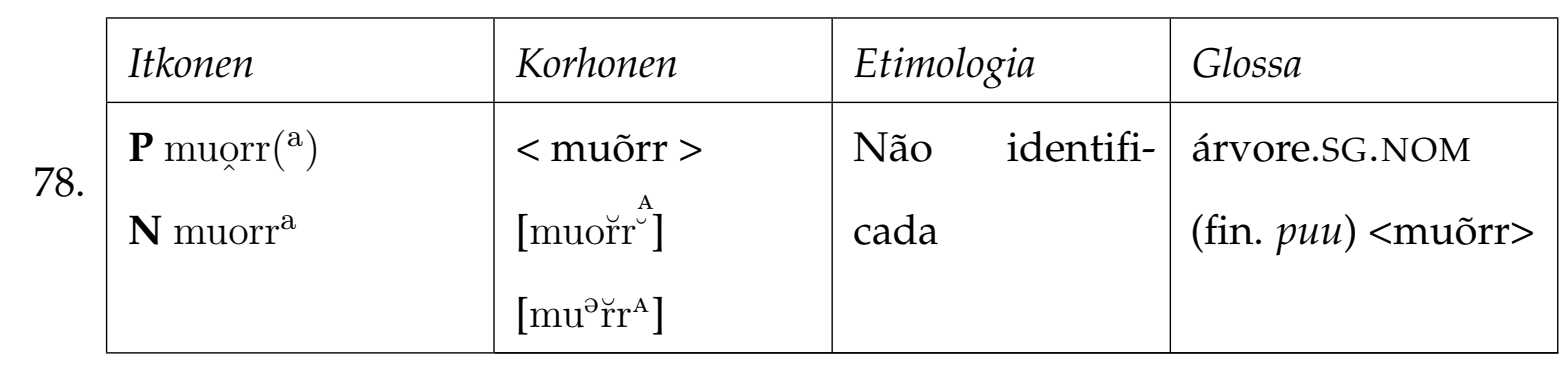

\begin{tabular}{|c|c|c|c|}
\hline Itkonen & Korhonen & Etimologia & Glossa \\
\hline 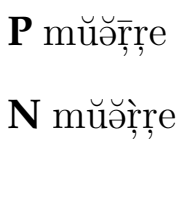 & $\begin{array}{l}\text { < mui'rre > } \\
\text { [mụ̣̆,rre] }\end{array}$ & $\begin{array}{l}\text { Não identifi- } \\
\text { cada }\end{array}$ & $\begin{array}{l}\text { árvore.SG.ILL } \\
\text { (fin. } \quad \text { puu) } \\
<\text { mui'rre> }\end{array}$ \\
\hline
\end{tabular}


80.

\begin{tabular}{|c|c|c|c|}
\hline Itkonen & Korhonen & Etimologia & Glossa \\
\hline $\mathbf{P} n \bar{i}_{v^{\prime}} \bar{B}^{\mathrm{E}}$ & $<$ ne'ibb $>$ & Não identifi- & faca.SG.NOM \\
\hline $\mathbf{N}$ nei $i^{\mathrm{b}} \overline{\mathrm{p}}^{\mathrm{E}}$ & [nei` ${ }^{\circ} \mathrm{B}^{\mathrm{E}}$ ] & cada & $\begin{array}{l}\text { (fin. veitsi) } \\
<\text { ne'ibb }>\end{array}$ \\
\hline
\end{tabular}

81.

\begin{tabular}{|c|c|c|c|}
\hline Itkonen & Korhonen & Etimologia & Glossa \\
\hline $\mathbf{P}$ òłmăă $(-a z ̌)$ & < ååumaž > & Não identifi- & hu- \\
\hline $\mathbf{S}$ òлmąż̀ (òumąz̆) & [āumăž] & cada & mano.SG.NOM \\
\hline N òumes̆̀ (-as̆́) & & & (fin. ihminen) \\
\hline
\end{tabular}

82.

\begin{tabular}{|c|c|c|c|}
\hline Itkonen & Korhonen & Etimologia & Glossa \\
\hline $\begin{array}{l}\mathbf{P} \text { pŭŏ}{ }^{\top} \text { ttse }\left(\mathrm{p}^{\mathrm{u}} \mathrm{O}^{-}\right) \\
\mathbf{N} \text { pŭŏottsó }\end{array}$ & 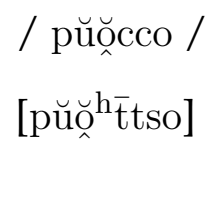 & Indo-europeia & $\begin{array}{l}\text { rena.SG.GEN } \\
\text { (fin. poro) } \\
<\text { puõccu> }\end{array}$ \\
\hline
\end{tabular}

83.

\begin{tabular}{|c|c|c|c|}
\hline Itkonen & Korhonen & Etimologia & Glossa \\
\hline $\begin{array}{l}\mathbf{P} \text { pọa } \bar{D} D Z^{\mathrm{a}} \\
\mathbf{N} \text { puaD̆DZ }\end{array}$ & - & Indo-europeia & $\begin{array}{l}\text { rena.SG.NOM } \\
\text { (fin. poro) }<\text { puä33> }\end{array}$ \\
\hline
\end{tabular}

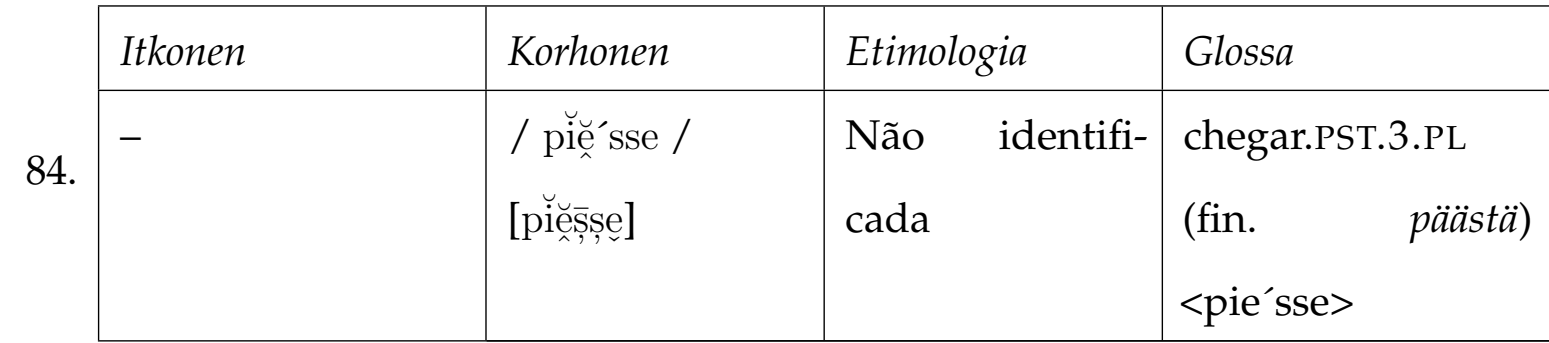

\begin{tabular}{|c|c|c|c|}
\hline Itkonen & Korhonen & Etimologia & Glossa \\
\hline $\begin{array}{l}\mathbf{P} \text { pięzzam } \\
\mathbf{N} \text { pięzzam }\end{array}$ & $\begin{array}{l}\text { / piczzam / } \\
\text { [piçžzam] }\end{array}$ & $\begin{array}{l}\text { Não identifi- } \\
\text { cada }\end{array}$ & $\begin{array}{l}\text { chegar.PRS.1.SG } \\
\text { (fin. päästä) <piâz- } \\
\text { zam> }\end{array}$ \\
\hline
\end{tabular}


86.

\begin{tabular}{|l|l|l|l|}
\hline Itkonen & Korhonen & Etimologia & Glossa \\
\hline $\mathbf{P}$ pëäss ${ }^{\mathrm{A}}$ & - & Não identifi- & chegar.PRS.3.SG \\
$\mathbf{N}$ pëässa & & cada & (fin. päästä) \\
& & & $<$ peäss $>$ \\
\hline
\end{tabular}

87.

\begin{tabular}{|l|l|l|l|}
\hline Itkonen & Korhonen & Etimologia & Glossa \\
\hline $\mathbf{P}$ pieșșim & - & Não identifi- & chegar.PST.1.SG \\
$\mathbf{N}$ piěșșèm & & cada & (fin. päästä) \\
& & & $<$ pie'ssem> \\
\hline
\end{tabular}

88.

\begin{tabular}{|l|l|l|l|}
\hline Itkonen & Korhonen & Etimologia & Glossa \\
\hline $\mathbf{P}$ piessseD & - & Não identifi- & chegar.INF \\
$\mathbf{N}$ piessed & & cada & (fin. päästä) <piâs- \\
& & & sâd> \\
\hline
\end{tabular}

89.

\begin{tabular}{|c|c|c|c|}
\hline Itkonen & Korhonen & Etimologia & Glossa \\
\hline $\mathbf{P} \mathbf{N} p \bar{\varepsilon} r t^{A}(\mathbf{N}-\mathrm{A})$ & $\begin{array}{l}/ \mathrm{p} \bar{\varepsilon} \mathrm{rtăa} / \\
{\left[\mathrm{p} \bar{\varepsilon} \mathrm{r}^{\mathrm{h}} \mathrm{t}^{\mathrm{A}}\right]\left[\mathrm{p} \bar{\varepsilon} \mathrm{r}^{\mathrm{h}} \dot{\mathrm{t}}^{\mathrm{A}}\right]}\end{array}$ & Fino-úgrica & $\begin{array}{l}\text { cabana.SG.GEN } \\
\text { (fin. pirtti) < põõrt> }\end{array}$ \\
\hline
\end{tabular}

90.

\begin{tabular}{|l|l|l|l|}
\hline Itkonen & Korhonen & Etimologia & Glossa \\
\hline P N pes̀rc tt & - & Fino-úgrica & $\begin{array}{l}\text { cabana.SG.NOM } \\
\text { (fin. pirtti) }<\text { põrtt }>\end{array}$ \\
\hline
\end{tabular}

91.

\begin{tabular}{|c|c|c|c|}
\hline Itkonen & Korhonen & Etimologia & Glossa \\
\hline $\mathbf{P} \mathbf{N}$ perr ${ }^{\mathrm{c}}$ țte & $\begin{array}{l}\text { / pérte / } \\
\left.\text { [perr̆ }{ }^{\mathrm{t} t t e]}\right]\end{array}$ & Fino-úgrica & $\begin{array}{l}\text { cabana.SG.ILL } \\
\text { (fin. pirtti) } \\
<\text { põ'rtte> }\end{array}$ \\
\hline
\end{tabular}


92.

\begin{tabular}{|l|l|l|l|}
\hline Itkonen & Korhonen & Etimologia & Glossa \\
\hline $\mathbf{P}$ pāštam & / pāštam / & Fino-úgrica & fritar.PRS.1.sG \\
$\mathbf{N}$ pāăštam & & & (fin. paistaa) $<$ pääš- \\
& & & tam> \\
\hline
\end{tabular}

93.

\begin{tabular}{|c|c|c|c|}
\hline Itkonen & Korhonen & Etimologia & Glossa \\
\hline $\begin{array}{l}\mathbf{P} \text { päșisted } \\
\mathbf{N} \text { päș̆teD }\end{array}$ & - & Fino-úgrica & $\begin{array}{l}\text { fritar.INF } \\
\text { (fin. paistaa) } \\
<\text { pä'̌štted }>\end{array}$ \\
\hline
\end{tabular}

94.

\begin{tabular}{|l|l|l|l|}
\hline Itkonen & Korhonen & Etimologia & Glossa \\
\hline $\mathbf{P}$ pāšț & - & Fino-úgrica & fritar.PST.1.SG \\
$\mathbf{N}$ pāș̆tì & & (fin. paistaa) \\
& & & <paa'šti> \\
\hline
\end{tabular}

95.

\begin{tabular}{|c|c|c|c|}
\hline Itkonen & Korhonen & Etimologia & Glossa \\
\hline P pąَ̧̄̄az & / paldaz & Não identifi- & lobo.SG.GEN \\
\hline 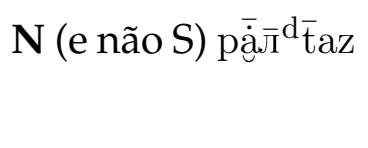 & [pasī̌ną̧Z]/ & cada & $\begin{array}{l}\text { (fin. susi) <pâld- } \\
\text { daz> }\end{array}$ \\
\hline
\end{tabular}

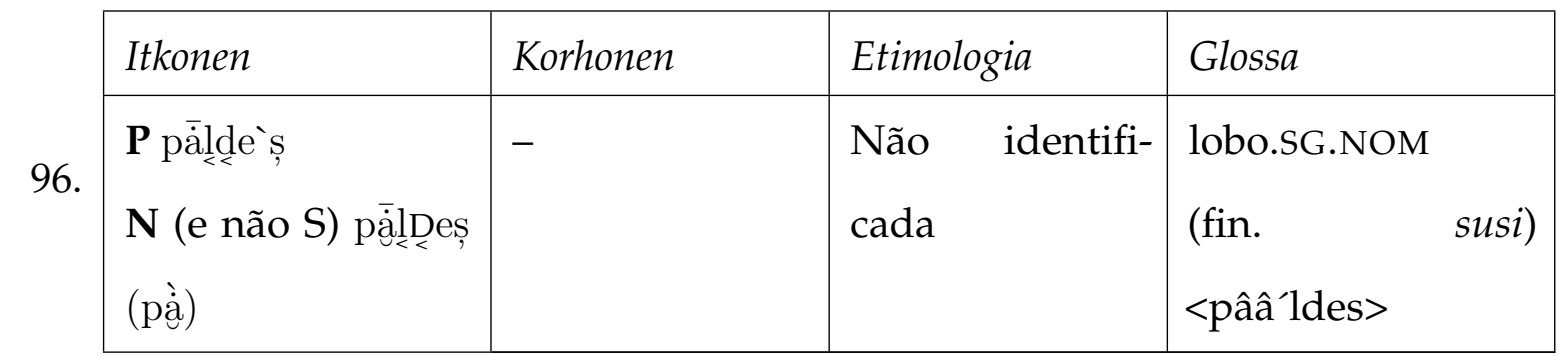

\begin{tabular}{|c|c|c|c|}
\hline Itkonen & Korhonen & Etimologia & Glossa \\
\hline $\begin{array}{l}\mathbf{P} \text { pieșș } \\
\mathbf{N} \text { pieșș } \\
\text { E }\end{array}$ & $\begin{array}{l}\text { / piéssĕ / } \\
{[\text { pieș̆ș }}\end{array}$ & Fino-úgrica & $\begin{array}{l}\text { ninho.SG.NOM (fin. } \\
\text { pesä) <pie'ss> }\end{array}$ \\
\hline
\end{tabular}




\begin{tabular}{|c|c|c|c|}
\hline Itkonen & Korhonen & Etimologia & Glossa \\
\hline $\begin{array}{l}\mathbf{P} \text { piezzże } \\
\mathbf{N} \text { piezzzĕ }\end{array}$ & - & Fino-úgrica & $\begin{array}{l}\text { ninho.SG.GEN } \\
\text { (fin. pesä) <pie'zz> }\end{array}$ \\
\hline
\end{tabular}

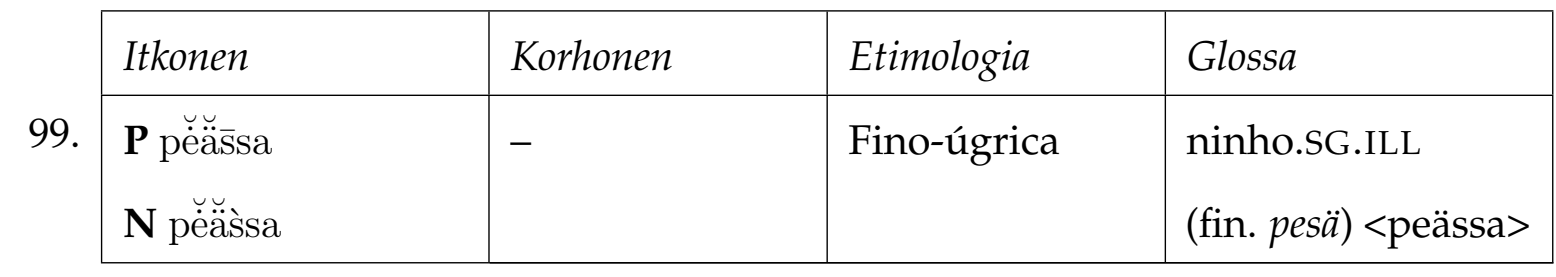

\begin{tabular}{|c|c|c|c|}
\hline Itkonen & Korhonen & Etimologia & Glossa \\
\hline 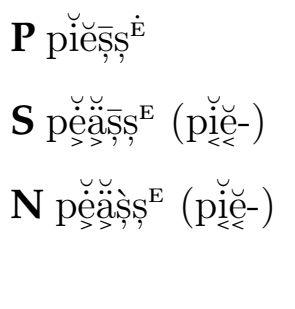 & 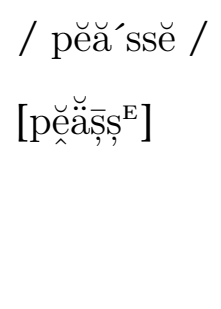 & Fino-úgrica & $\begin{array}{l}\text { casca de vido- } \\
\text { eiro.SG.NOM } \\
\text { (fin. tuohi) } \\
\text { <peä'ss> }\end{array}$ \\
\hline
\end{tabular}

\begin{tabular}{|l|l|l|l|}
\hline Itkonen & Korhonen & Etimologia & Glossa \\
\hline $\mathbf{P}$ pieșșie & - & Fino-úgrica & casca de vido- \\
$\mathbf{N}$ pẹäșȘE & & & $\begin{array}{l}\text { eiro.SG.GEN } \\
\text { (fin. tuohi })<\text { pie'ss> }\end{array}$ \\
\hline
\end{tabular}

\begin{tabular}{|l|l|l|l|}
\hline Itkonen & Korhonen & Etimologia & \multicolumn{2}{|l|}{ Glossa } \\
\hline P pĕă̄issa & - & Fino-úgrica & casca de vido- \\
N pĕăs̀sa & & eiro.SG.ILL \\
& & & (fin. \\
& & & $<$ tuohi) \\
\hline
\end{tabular}

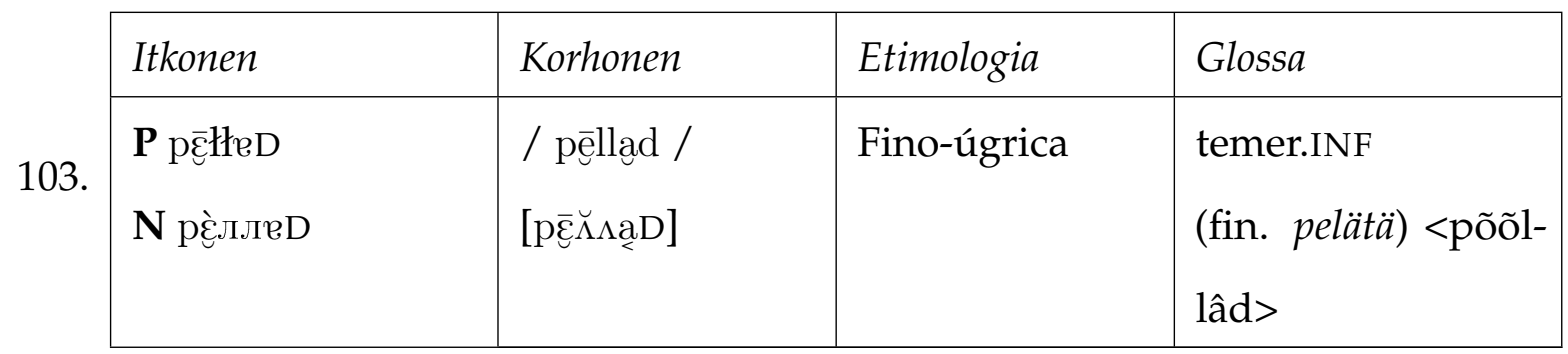




\begin{tabular}{|c|c|c|c|}
\hline Itkonen & Korhonen & Etimologia & Glossa \\
\hline $\begin{array}{l}\mathbf{P} \text { p } \bar{z} ł a m \\
\mathbf{N} \text { ревлаm }\end{array}$ & $\begin{array}{l}\text { / pēlam / } \\
\text { [p } \bar{\varepsilon} \Lambda_{\supset} \text { am] }\end{array}$ & Fino-úgrica & $\begin{array}{l}\text { temer.PRS.1.SG } \\
\text { (fin. pelätä)<põõ- } \\
\text { lam> }\end{array}$ \\
\hline
\end{tabular}

\begin{tabular}{|c|c|c|c|}
\hline Itkonen & Korhonen & Etimologia & Glossa \\
\hline $\begin{array}{l}\mathbf{P} \text { ра̄̆łł } \\
\mathbf{N} \text { рауллӑ }\end{array}$ & - & Fino-úgrica & $\begin{array}{l}\text { temer.PRS.3.SG } \\
\text { (fin. pelätä) <pââll> }\end{array}$ \\
\hline
\end{tabular}

\begin{tabular}{|c|c|c|c|}
\hline Itkonen & Korhonen & Etimologia & Glossa \\
\hline 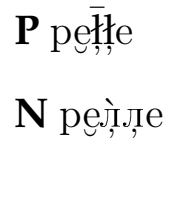 & - & Fino-úgrica & $\begin{array}{l}\text { temer.PST.3.PL } \\
\text { (fin. pelätä) } \\
<\text { põ'lle }>\end{array}$ \\
\hline
\end{tabular}

\begin{tabular}{|c|c|c|c|}
\hline Itkonen & Korhonen & Etimologia & Glossa \\
\hline $\begin{array}{l}\mathbf{P} \text { pięn̆nì } \\
\mathbf{S}\left(\mathrm{I}_{2}\right) \text { pičňnči } \\
\mathbf{N} \text { piennnei }\end{array}$ & $\begin{array}{l}\text { / picnnaj / } \\
\text { [pįçn̆näi] }\end{array}$ & Fino-úgrica & $\begin{array}{l}\text { cachorro.SG.NOM } \\
\text { (fin. koira) <piân- } \\
\text { nai> }\end{array}$ \\
\hline
\end{tabular}

\begin{tabular}{|c|c|c|c|}
\hline Itkonen & Korhonen & Etimologia & Glossa \\
\hline $\begin{array}{l}\mathbf{P} \text { piẹ̆ṇ̆ṇe } \\
\mathbf{N} \text { piẹ̆ṇne }\end{array}$ & - & Fino-úgrica & $\begin{array}{l}\text { cachorro.SG.GEN } \\
\text { (fin. koira) } \\
\text { <pie'nne> }\end{array}$ \\
\hline
\end{tabular}

\begin{tabular}{|c|c|c|c|}
\hline Itkonen & Korhonen & Etimologia & Glossa \\
\hline 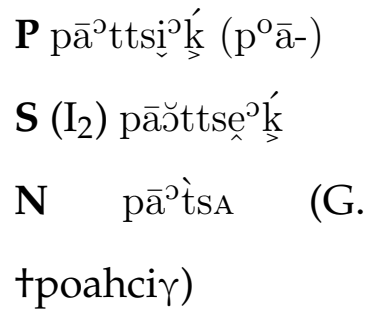 & 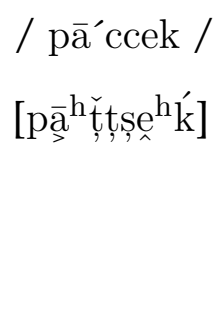 & $\begin{array}{l}\text { Não identifi- } \\
\text { cada }\end{array}$ & $\begin{array}{l}\text { cone.SG.NOM } \\
\text { (fin. käpy) <pa- } \\
\text { accǐ̌ }>\end{array}$ \\
\hline
\end{tabular}




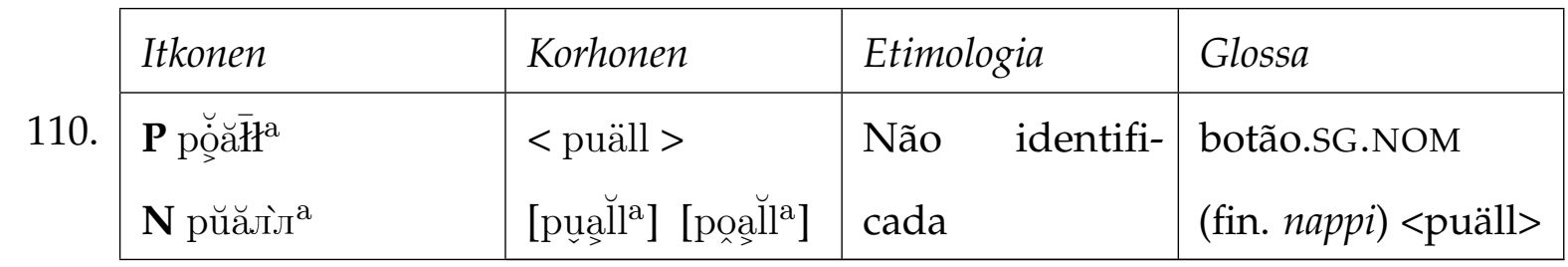

111.

\begin{tabular}{|l|l|l|l|}
\hline Itkonen & Korhonen & Etimologia & Glossa \\
\hline $\mathbf{P}$ pọałłă & - & Não identifi- & botão.SG.GEN \\
$\mathbf{N}$ puаллӑ & cada & (fin. \\
& & & $<$ nappiäl(l)> \\
\hline
\end{tabular}

112.

\begin{tabular}{|c|c|c|c|}
\hline Itkonen & Korhonen & Etimologia & Glossa \\
\hline 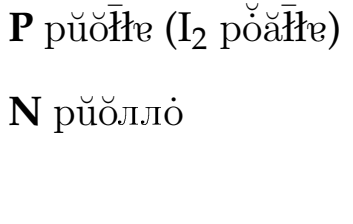 & - & $\begin{array}{l}\text { Não identifi- } \\
\text { cada }\end{array}$ & $\begin{array}{l}\text { botão.SG.ILL } \\
\text { (fin. nappi) } \\
<\text { puållu> }\end{array}$ \\
\hline
\end{tabular}

\begin{tabular}{|c|c|c|c|}
\hline Itkonen & Korhonen & Etimologia & Glossa \\
\hline $\mathbf{P}$ pẹäli $\bar{D}^{\mathrm{A}}$ & $<$ peäldd > & Germânica & campo.sG.NOM \\
\hline 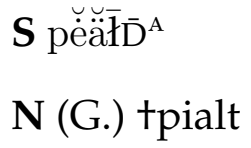 & 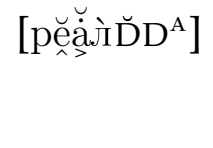 & & $\begin{array}{l}\text { (fin. pelto) } \\
<\text { peäldd }>\end{array}$ \\
\hline
\end{tabular}

\begin{tabular}{|c|c|c|c|}
\hline Itkonen & Korhonen & Etimologia & Glossa \\
\hline $\begin{array}{l}\mathbf{P} \text { pëäld }{ }^{\mathrm{a}}\left(-\mathrm{D}^{\mathrm{A}}\right) \\
\mathbf{S} \text { pëäł } \bar{D}^{\mathrm{A}}\end{array}$ & - & Germânica & $\begin{array}{l}\text { campo.SG.GEN } \\
\text { (fin. pelto) < peäld> }\end{array}$ \\
\hline
\end{tabular}

\begin{tabular}{|c|c|c|c|}
\hline Itkonen & Korhonen & Etimologia & Glossa \\
\hline 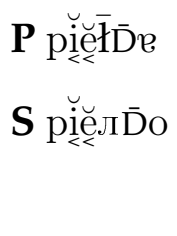 & - & Germânica & $\begin{array}{l}\text { campo.SG.ILL } \\
\text { (fin. pelto) <pi- } \\
\text { âlddu> }\end{array}$ \\
\hline
\end{tabular}


116.

\begin{tabular}{|c|c|c|c|}
\hline Itkonen & Korhonen & Etimologia & Glossa \\
\hline 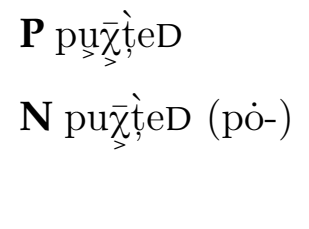 & $\begin{array}{l}<\mathrm{pu}^{\prime} \text { htted }> \\
{[\mathrm{pus} \underset{>}{\mathrm{t}}, \mathrm{eD}]}\end{array}$ & $\begin{array}{l}\text { Não identifi- } \\
\text { cada }\end{array}$ & $\begin{array}{l}\text { trazer.INF } \\
\text { (fin. tuoda) } \\
\text { <pu'htted }>\end{array}$ \\
\hline
\end{tabular}

A transcrição fonética de Korhonen no original encontra-se parcialmente ilegível, sendo o uso de $\chi$ uma suposição.

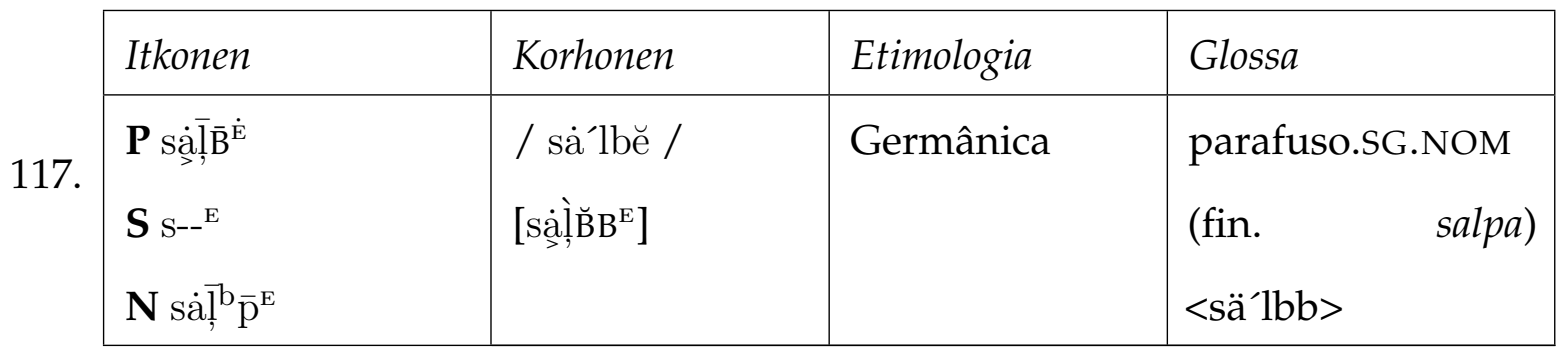

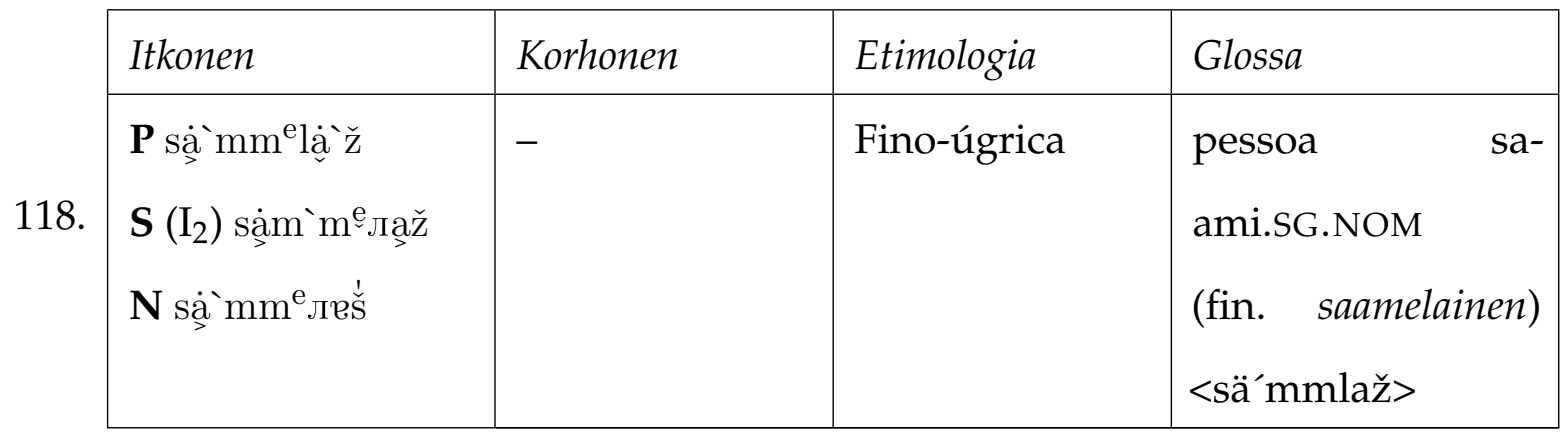

\begin{tabular}{|c|c|c|c|}
\hline Itkonen & Korhonen & Etimologia & Glossa \\
\hline- & 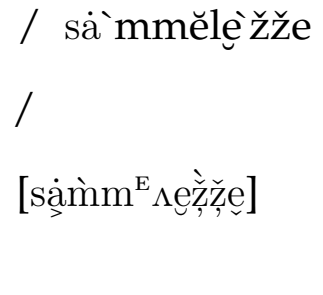 & Fino-úgrica & $\begin{array}{l}\text { pessoa sa- } \\
\text { ami.sG.ILL } \\
\text { (fin. saamelainen) } \\
\text { <sä'mmlõ'žže> }\end{array}$ \\
\hline
\end{tabular}

\begin{tabular}{|c|c|c|c|}
\hline Itkonen & Korhonen & Etimologia & Glossa \\
\hline 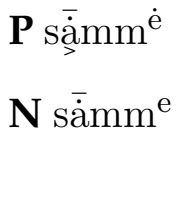 & - & Fino-úgrica & $\begin{array}{l}\text { saami.SG.NOM } \\
\text { (fin. saami) } \\
\text { <sää'mm> }\end{array}$ \\
\hline
\end{tabular}




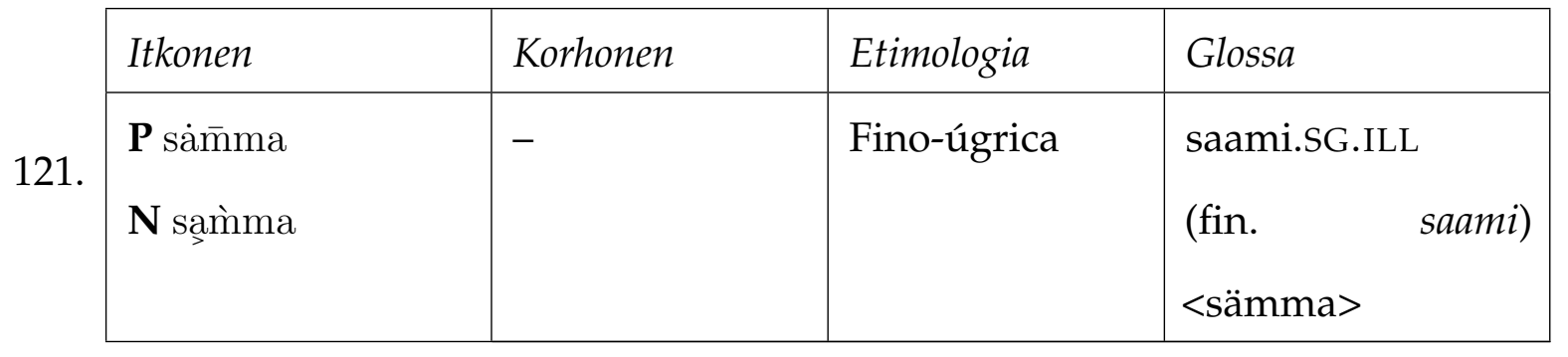

\begin{tabular}{|l|l|l|l|}
\hline Itkonen & Korhonen & Etimologia & Glossa \\
\hline $\mathbf{P}$ sāmì & - & Fino-úgrica & saami.PL.GEN \\
N sāmì & & & (fin. saami) \\
& & & $<$ saa'mi> \\
\hline
\end{tabular}

\begin{tabular}{|c|c|c|c|}
\hline Itkonen & Korhonen & Etimologia & Glossa \\
\hline P S N sëäm ${ }^{\mathrm{a}}$ & $\begin{array}{l}<\text { seäm > } \\
{\left[\text { seảa }{ }^{\mathrm{a}}\right]}\end{array}$ & $\begin{array}{l}\text { Não identifi- } \\
\text { cada }\end{array}$ & $\begin{array}{l}\text { barba.SG.NOM } \\
\text { (fin. parta) <seäm> }\end{array}$ \\
\hline
\end{tabular}

\begin{tabular}{|c|c|c|c|}
\hline Itkonen & Korhonen & Etimologia & Glossa \\
\hline $\begin{array}{l}\text { P sợăàvìel, sạvivel } \\
\text { (jovens) } \\
\text { S sạiv̀vel } \\
\text { N sạivvèl }\end{array}$ & $\begin{array}{l}<\text { sấvvel > } \\
\text { [säv̀vel] }\end{array}$ & $\begin{array}{l}\text { Não identifi- } \\
\text { cada }\end{array}$ & $\begin{array}{l}\text { timalo.SG.NOM } \\
\text { (fin. harri) } \\
\text { <suä'vvel> } \\
\text { <suâ'vvel> } \\
\text { <sâ'vvel> }\end{array}$ \\
\hline
\end{tabular}

\begin{tabular}{|l|l|l|l|}
\hline Itkonen & Korhonen & Etimologia & Glossa \\
\hline $\mathbf{P}$ spașșeB & / spasseb / & Russa & obrigado.INTERJ. \\
$\mathbf{S}$ spàșșeB & [spașș̦eB] & & (fin. kiitos) \\
$\mathbf{N}($ s)pașșe & & <spä́sseb> \\
\hline
\end{tabular}

\begin{tabular}{|c|c|c|c|}
\hline Itkonen & Korhonen & Etimologia & Glossa \\
\hline $\begin{array}{l}\mathbf{P} \operatorname{su}^{\circ} k k e D \\
\mathbf{N} \text { sùokkeD }\end{array}$ & $\begin{array}{l}\text { / sūkkąD / } \\
{\left[\mathrm{su}^{\mathrm{h}} \mathrm{k}_{\mathrm{k}} \underset{<}{ }\right]}\end{array}$ & Fino-úgrica & $\begin{array}{l}\text { remar.INF } \\
\text { (fin. soutaa) <suuk- } \\
\text { kâd }>\end{array}$ \\
\hline
\end{tabular}




\begin{tabular}{|c|c|c|c|}
\hline Itkonen & Korhonen & Etimologia & Glossa \\
\hline 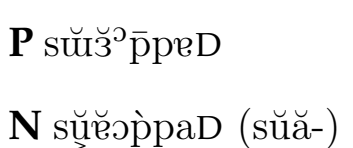 & - & $\begin{array}{l}\text { Não identifi- } \\
\text { cada }\end{array}$ & $\begin{array}{l}\text { lançar.INF } \\
\text { (fin. heittää) }\end{array}$ \\
\hline
\end{tabular}

\begin{tabular}{|c|c|c|c|}
\hline Itkonen & Korhonen & Etimologia & Glossa \\
\hline $\begin{array}{l}\mathbf{P} \text { sŭŏ}{ }^{\circ} \bar{p} p \gtrless m \\
\mathbf{N} \text { sŭŏ’̀̀póm }\end{array}$ & - & $\begin{array}{l}\text { Não identifi- } \\
\text { cada }\end{array}$ & $\begin{array}{l}\text { lançar.PST.1.SG } \\
\text { (fin. heittää) }\end{array}$ \\
\hline
\end{tabular}

\begin{tabular}{|c|c|c|c|}
\hline Itkonen & Korhonen & Etimologia & Glossa \\
\hline $\begin{array}{l}\mathbf{P} \text { tiè } e^{\mathrm{t} t t ̦ i ̀ ~} \\
\mathbf{N} \text { tięotțèi }\end{array}$ & - & Fino-úgrica & $\begin{array}{l}\text { sábio.SG.NOM } \\
\text { (fin. tietäjä) } \\
\text { <tie'tti> }\end{array}$ \\
\hline
\end{tabular}

\begin{tabular}{|c|c|c|c|}
\hline Itkonen & Korhonen & Etimologia & Glossa \\
\hline 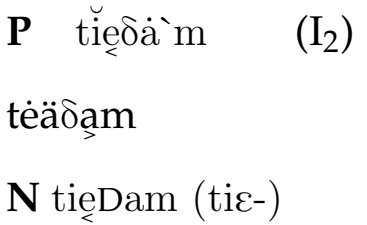 & 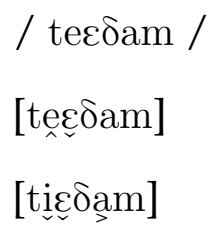 & Fino-úgrica & $\begin{array}{l}\text { saber.PRS.1.SG } \\
\text { (fin. tietää) } \\
\text { <teâđam> }\end{array}$ \\
\hline
\end{tabular}

\begin{tabular}{|c|c|c|c|}
\hline Itkonen & Korhonen & Etimologia & Glossa \\
\hline $\begin{array}{l}\mathbf{P} \text { tie }{ }^{\mathrm{o} t t, t e D} \\
\mathbf{N} \text { tiesțteD }\end{array}$ & - & Fino-úgrica & $\begin{array}{l}\text { saber.INF } \\
\text { (fin. } \quad \text { tietää) } \\
<\text { tie'tted }>^{\prime}\end{array}$ \\
\hline
\end{tabular}

\begin{tabular}{|l|l|l|l|}
\hline Itkonen & Korhonen & Etimologia & Glossa \\
\hline P tuopDer & - & Fino-úgrica & montanha.SG.NOM \\
$\mathbf{N}$ tuoDDar & & & (fin. tunturi) $<$ tuõd- \\
& & & dâr $>$ \\
\hline
\end{tabular}




\begin{tabular}{|c|c|c|c|}
\hline Itkonen & Korhonen & Etimologia & Glossa \\
\hline- & 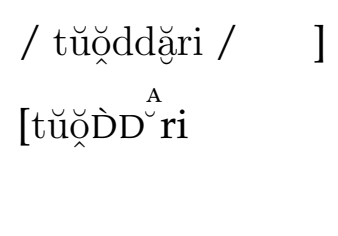 & Fino-úgrica & $\begin{array}{l}\text { montanha.PL.GEN } \\
\text { (fin. tunturi) <tuõd- } \\
\text { dri> }\end{array}$ \\
\hline
\end{tabular}

\begin{tabular}{|c|c|c|c|}
\hline Itkonen & Korhonen & Etimologia & Glossa \\
\hline 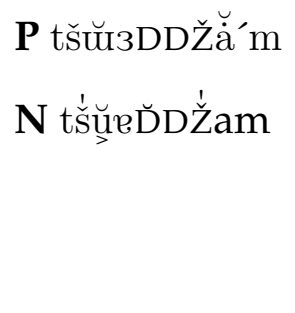 & 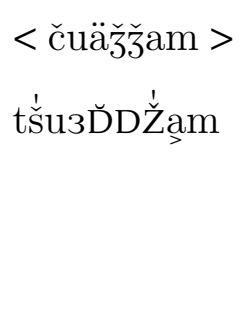 & Fino-úgrica & $\begin{array}{l}\text { estar } \\
\text { pé.PRS.1.sG } \\
\text { (fin. seisoa) } \\
\text { <čuâžžam> }\end{array}$ \\
\hline
\end{tabular}

\begin{tabular}{|c|c|c|c|}
\hline Itkonen & Korhonen & Etimologia & Glossa \\
\hline P S vàiștēē & $\begin{array}{l}\text { / västad / } \\
\text { [väșț,çD] }\end{array}$ & Fino-úgrica & $\begin{array}{l}\text { responder.INF } \\
\text { (fin. vastata) } \\
<\text { vä'stteed> }\end{array}$ \\
\hline
\end{tabular}

\begin{tabular}{|l|l|l|l|}
\hline 136. & Korhonen & Etimologia & Glossa \\
\hline $\mathbf{P}$ vuussk $^{\mathrm{A}}$ & / vueskă / & Não identifi- & perca.SG.NOM \\
$\mathbf{N}$ vụesk $^{\mathrm{A}}$ (vua-) & [vuăsk ${ }^{\mathrm{A}}$ ] & cada & (fin. ahven) \\
& & & $<$ vuâsk> \\
\hline
\end{tabular}

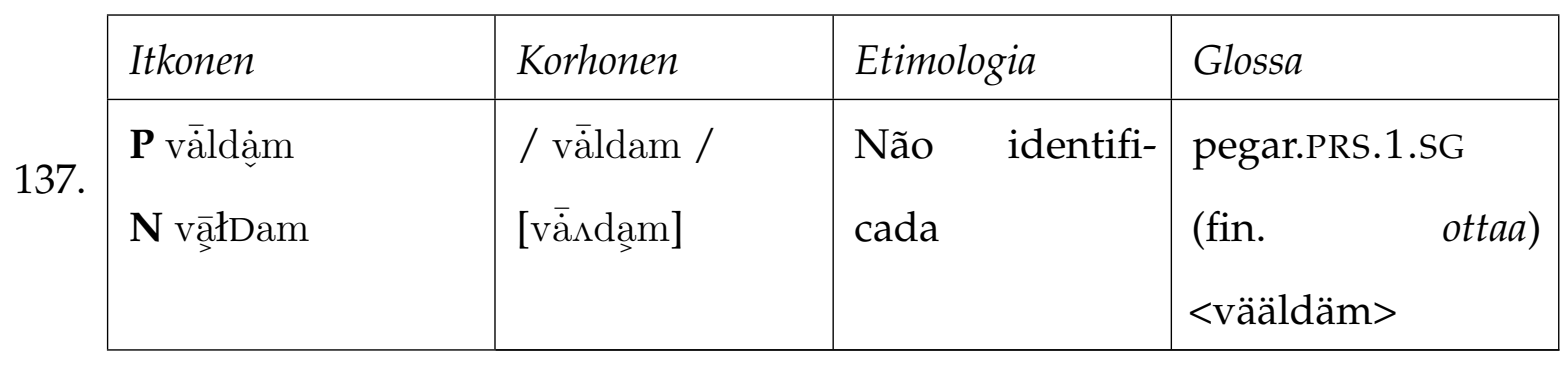

\begin{tabular}{|c|c|c|c|}
\hline Itkonen & Korhonen & Etimologia & Glossa \\
\hline 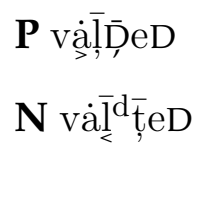 & - & $\begin{array}{l}\text { Não identifi- } \\
\text { cada }\end{array}$ & $\begin{array}{l}\text { pegar.INF } \\
\text { (fin. ottaa) } \\
<\text { vä'ldded }>\end{array}$ \\
\hline
\end{tabular}




\begin{tabular}{|c|c|c|c|}
\hline Itkonen & Korhonen & Etimologia & Glossa \\
\hline $\begin{array}{l}\mathbf{P} \text { vìzyam } \\
\mathbf{N} \text { vìjyam }\end{array}$ & 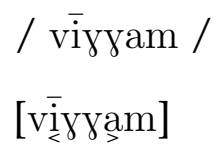 & $\begin{array}{l}\text { Não identifi- } \\
\text { cada }\end{array}$ & $\begin{array}{l}\text { levar.PRS.1.SG } \\
\text { (fin. viedä) }\end{array}$ \\
\hline
\end{tabular}

\begin{tabular}{|c|c|c|c|}
\hline Itkonen & Korhonen & Etimologia & Glossa \\
\hline $\begin{array}{l}\mathbf{P} \text { vēं } \mathrm{kk}^{\mathrm{A}} \\
\mathbf{N} \text { vè̀ } \mathrm{kk}^{\mathrm{A}}\end{array}$ & $\begin{array}{l}\text { / vēkkă / } \\
{\left[\mathrm{v}^{\mathrm{\varepsilon}} \mathrm{h} \mathrm{kk}^{\mathrm{A}}\right]}\end{array}$ & $\begin{array}{l}\text { Não identifi- } \\
\text { cada }\end{array}$ & $\begin{array}{l}\text { levar.PRS.3.SG } \\
\text { (fin. viedä) <ve- } \\
\text { ekk> }\end{array}$ \\
\hline
\end{tabular}

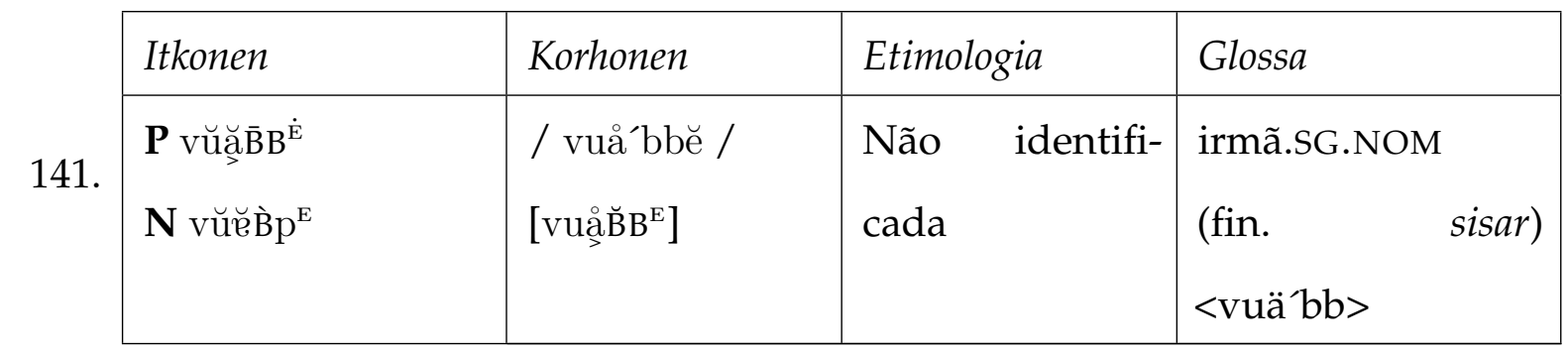

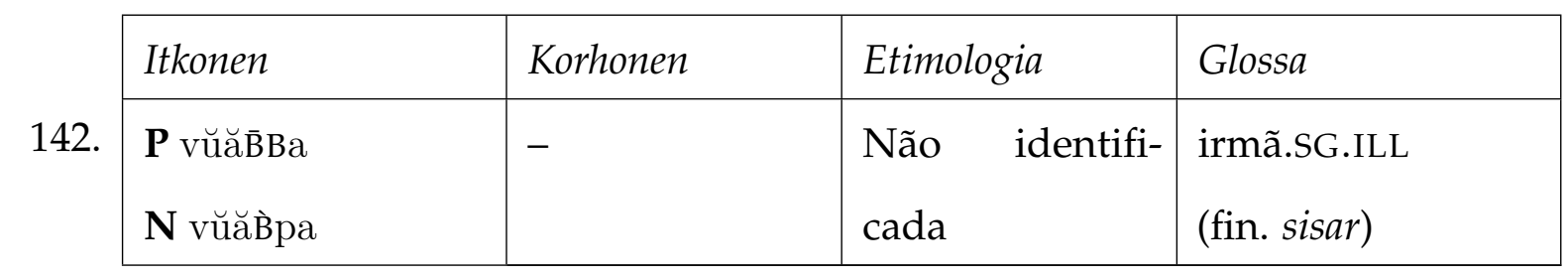

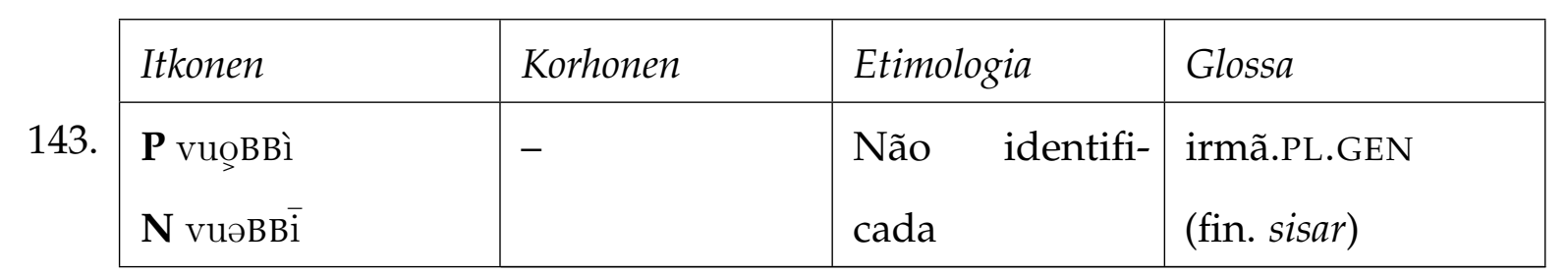

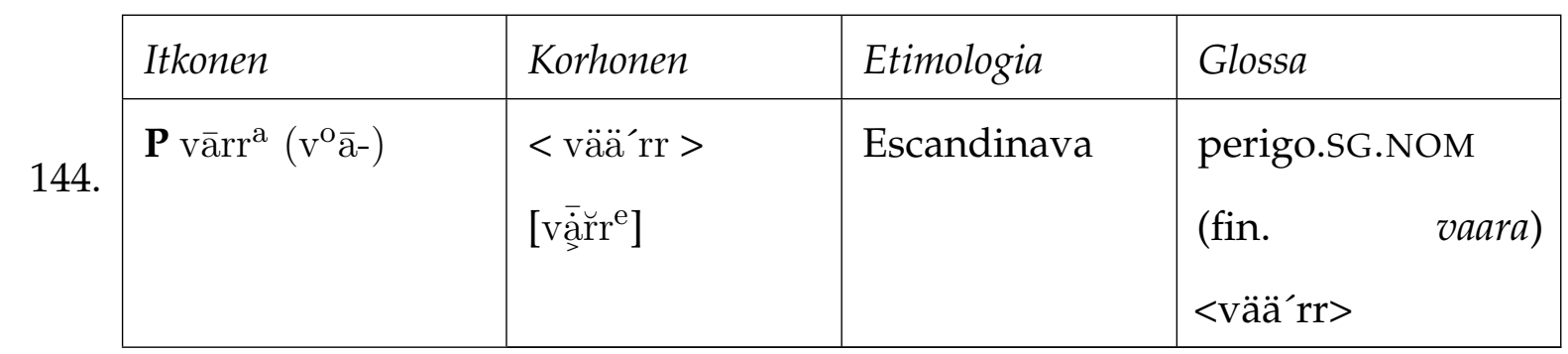

\begin{tabular}{|c|c|c|c|}
\hline Itkonen & Korhonen & Etimologia & Glossa \\
\hline $\begin{array}{l}\mathbf{P} \text { vŭŏvit }{ }^{\mathrm{A}}\left(-\mathrm{rt}^{\mathrm{A}}\right) \\
\mathbf{N} \text { vŭŏ} \breve{p}^{\mathrm{p}} \grave{\mathrm{t}}^{\mathrm{A}}\end{array}$ & 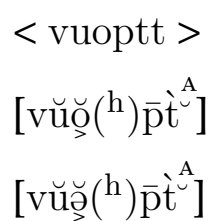 & $\begin{array}{l}\text { Não identifi- } \\
\text { cada }\end{array}$ & $\begin{array}{l}\text { fio de ca- } \\
\text { belo.SG.NOM } \\
\text { (fin. hius) <vuõptt> }\end{array}$ \\
\hline
\end{tabular}




\begin{tabular}{|c|c|c|c|c|}
\hline Itkonen & Korhonen & Etimologia & Glossa & \\
\hline 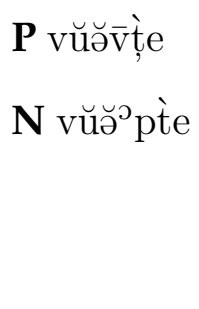 & - & $\begin{array}{l}\text { Não identifi- } \\
\text { cada }\end{array}$ & $\begin{array}{l}\text { fio de } \\
\text { belo.SG.ILL } \\
\text { (fin. } \\
\text { <vuõ'ptte> }\end{array}$ & $\begin{array}{r}\text { ca- } \\
\text { hius) }\end{array}$ \\
\hline
\end{tabular}

\begin{tabular}{|c|c|c|c|}
\hline Itkonen & Korhonen & Etimologia & Glossa \\
\hline 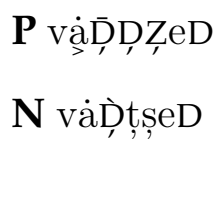 & 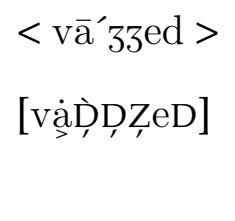 & $\begin{array}{l}\text { Não identifi- } \\
\text { cada }\end{array}$ & $\begin{array}{l}\text { caminhar.INF } \\
\text { (fin. kävellä) } \\
<\text { vä'3zed> }\end{array}$ \\
\hline
\end{tabular}

\begin{tabular}{|l|l|l|l|}
\hline Itkonen & Korhonen & Etimologia & Glossa \\
\hline P vāDDZẳm & - & Não identifi- & caminhar.PRS.1.SG \\
N vạ̄D̆DZam & & cada & (fin. kävellä) \\
& & & $<$ <ää3zam> \\
\hline
\end{tabular}

\begin{tabular}{|c|c|c|c|}
\hline Itkonen & Korhonen & Etimologia & Glossa \\
\hline $\begin{array}{l}\mathbf{P} \text { vil'l'e } \\
\mathbf{N} \text { vil'l'a }\end{array}$ & $\begin{array}{l}<\text { villj }> \\
{\left[\operatorname{vili}^{\stackrel{a}{a}}\right]}\end{array}$ & Fino-úgrica & $\begin{array}{l}\text { irmão.SG.NOM } \\
\text { (fin. veli) }\end{array}$ \\
\hline
\end{tabular}

